\title{
Élysée 2.0 im Lichte des Europarechts - Der Vertrag von Aachen und die ,immer engere Union“
}

\author{
Jörg Ukrow"
}

Inhalt

A. Einleitung 4

B. Aufbau, Integrationsziel, Organisationsgefüge und Verhältnis des Vertrages von Aachen zum Élysée-Vertrag

I. Aufbau

6

II. Das Verhältnis des Vertrages von Aachen zum Élysée-Vertrag 8

III. Das Integrationsziel des Vertrags von Aachen 8

IV. Organisations- und Verfahrensrecht als Integrationsrecht 9

V. Der Vertrag von Aachen und die parlamentarische Ausgestaltung und Kontrolle von Integrationsverdichtungen

C. Die Präambel des Vertrags von Aachen 15

I. Zur rechtlichen Bedeutung der Präambel 15

II. Die politische Programmatik der Präambel im Lichte der PräambelRechtskultur der europäischen Verträge - eine Auswahl

D. Die wirtschafts-, sozial- und steuerpolitische Kohärenz-Konzeption des Vertrages von Aachen

E. Die deutsch-französische Zusammenarbeit und die immer engere Union 27

I. Einführung 27

II. Verstärkte Zusammenarbeit als Chance und Risiko für das Gelingen einer immer engeren Union

II. Der Vertrag von Aachen, die Rechtsetzung in der EU und die Umsetzung von EU-Recht

IV. Der Vertrag von Aachen und das Europa der Bürger 33

1. Fehlende Direktwirkung und Staatshaftungsrelevanz 33

2. Grundrechtliche Kontrollmöglichkeit über Rechtsprechung des BVerfG zu Integrationsverdichtungen 33

3. Regionale und grenzüberschreitende Zusammenarbeit 34

F. Gemeinsame Außen- und Sicherheitspolitik nach dem Vertrag von Aachen 36

I. Militärische Kooperation 36

II. Insbesondere: Die Beistandsklausel des Vertrags von Aachen 38

* Dr. Jörg Ukrow ist stellvertretender Direktor der Landesmedienanstalt Saarland (LMS) und geschäftsführendes Vorstandsmitglied des Instituts für Europäisches Medienrecht (EMR). 
III. Rüstungsindustrie- und -exportpolitik nach dem Vertrag von Aachen 42

IV. Ansätze zu einem umfassenden Sicherheitsbegriff im Vertrag von Aachen 44

V. UN

G. Der Beitrag des Vertrages von Aachen zur Verankerung der Nachhaltigkeit als Grundsatz des Völkerrechts

H. Auf dem Weg zur deutsch-französischen Kultur-, Bildungs- und Forschungsgemeinschaft

I. Ausblick

\section{A. Einleitung}

Am 22. Januar 1963 unterzeichneten der Präsident der Französischen Republik, Charles de Gaulle, und der Bundeskanzler der Bundesrepublik Deutschland, Konrad Adenauer, zusammen mit dem französischen Premierminister Georges Pompidou sowie den beiden Außenministern Maurice Couve de Murville und Gerhard Schröder den "Vertrag über die deutsch-französische Zusammenarbeit", ${ }^{1}$ den sog. Élysée-Vertrag. Mit ihm sollte nach Jahrzehnten der Konfrontation und Jahrhunderten angeblicher Erbfeindschaft die deutsch-französische Freundschaft besiegelt werden. Bereits zum 50-jährigen Jubiläum dieses Vertrags 2013 kam die Idee eines neuen deutschfranzösischen Grundlagenvertrags auf, wurde aber wegen der unterschiedlichen Vorstellungen von Bundeskanzlerin Angela Merkel und dem 2012 gewählten Staatspräsidenten Francois Hollande nicht weiter verfolgt. ${ }^{2}$ Am 26. September 2017 kündigte der französische Präsident Emmanuel Macron anlässlich einer europapolitischen Grundsatzrede in der Sorbonne u.a. an, dass er einen neuen deutsch-französischen Vertrag abzuschließen plane. ${ }^{3}$ Im Ergebnis dieses Impulses und nach mehreren Monaten intensiver Verhandlungen unterzeichneten Präsident Macron und Bundeskanzlerin Merkel am 22. Januar 2019, auf den Tag 56 Jahre nach dem Elysée-Abkommen, in Aachen den neuen Vertrag, der "Vertrag über die deutsch-französische Zusammenarbeit und Integration" betitelt wurde. ${ }^{4}$

Weder völker- noch europarechtlich hat der Élysée-Vertrag bislang besondere Aufmerksamkeit erfahren. Auf den Vertrag bezogene Studien sind im Schwerpunkt ge-

1 BGB1. 1963, II, S. 705.

2 Vgl. Thorel, Der Aachener Vertrag vom 22.01.2019. Nur ein symbolischer Akt oder auch politisch bedeutend?, cepAdhoc 22.01.2019, S. 2 .

3 Initiative pour l'Europe - Discours d'Emmanuel Macron pour une Europe souveraine, unie, démocratique, abrufbar unter : https://www.elysee.fr/emmanuel-macron/2017/09/26/initia tive-pour-l-europe-discours-d-emmanuel-macron-pour-une-europe-souveraine-unie-dem ocratique (05.03.2019).

4 Der Vertragstext ist in deutscher Sprache abrufbar unter : https://www.auswaertiges-amt.d e/blob/2178596/7b304525053dde3440395ecef44548d3/190118-download-Aachenervertragdata.pdf (05.03.2019), in französischer Sprache ist der „Traité entre la République française et la République fédérale d'Allemagne sur la coopération et l'intégration franco-allemandes" abrufbar unter : https://www.elysee.fr/emmanuel-macron/2019/01/22/signature-du-traitefranco-allemand-d-aix-la-chapelle (05.03.2019). 
schichts- und politikwissenschaftlicher Natur; ${ }^{5}$ auch rechtswissenschaftliche Betrachtungen ${ }^{6}$ sind stark völkerrechtsgeschichtlich geprägt und verzichten weithin auf rechtsdogmatische Einordnungen.

Dies muss zwar einerseits mit Blick auf die anerkannt hohe Bedeutung des Vertrages im Prozess nicht nur der deutsch-französischen Aussöhnung, sondern auch der Entwicklung der beiden Staaten zu Motoren der Integrationsvertiefung überraschen. Es bewegt sich aber auf der Linie der völkerrechtlichen Zurückhaltung gegenüber einer eigenständigen gattungsmäßigen Analyse von bilateralen hochpolitischen Verträgen über Zusammenarbeit zwischen Staaten. ${ }^{7}$

Eine vertiefte Analyse des Vertragswerks lohnt sich indessen nicht nur mit Blick auf dessen Verortung an der Schnittstelle von Europa- und Völkerrecht mit ihren rechtsvergleichenden Bezügen und staatsrechtlichen Ein- und Auswirkungen. Für sie spricht auch das Ziel der Vermeidung bzw. Bekämpfung von Desinformationskampagnen, ${ }^{8}$ wie sie in Bezug auf völkerrechtlich relevante Vereinbarungen jüngst z.B. aus Anlass des UN-Migrationspakts wie des Klimapaktes ${ }^{9}$ feststellbar waren. Auch

5 Vgl. z.B. Baumann, Begegnung der Völker? Der Élysée-Vertrag und die Bundesrepublik Deutschland, 2003; Defrance/Pfeil (Hrsg.), Der Élysée-Vertrag und die deutsch-französischen Beziehungen 1945-1963-2003, 2005; dies. (Hrsg.), La France, l’Allemagne et le traité de l'Élysée, 1963-2013, 2012; Fischer, Der diplomatische Prozess der Entstehung des deutschfranzösischen Vertrages von 1963, Vierteljahreshefte für Zeitgeschichte 41 (1993), S. $101 \mathrm{ff}$.; Jansen, Das Entstehen des deutsch-französischen Vertrages vom 22. Januar 1963, in: Blumenwitz (Hrsg.), Konrad Adenauer und seine Zeit, 1976, S. 249 ff.; Lappenküper, Die deutsch-französischen Beziehungen 1949-1963. Von der „Erbfeindschaft“ zur „Entente élémentaire", 2001; ders., Entente élémentaire. Die Geschichte des deutsch-französischen Freundschaftsvertrages vom 22. Januar 1963, 2003.

6 Vgl. Klein, Der Élysée-Vertrag vom 22. Januar 1963, in: Bezzenberger u.a. (Hrsg.), Die deutsch-französischen Rechtsbeziehungen, Europa und die Welt, in: Liber amicorum Otmar Seul, 2014, S. $248 \mathrm{ff}$.

$7 \mathrm{Zu}$ Ansätzen einer Dogmatik hochpolitischer Verträge im Verfassungsrecht vgl. BVerfGE 90, 286 (361 f.) sowie z.B. Bröhmer, Transparenz als Verfassungsprinzip, 2004, S. 316; zur völkerrechtlichen Einordnung von multilateralen Kooperationsformen vgl. z.B. Walter, Regional Arrangements and the United Nations Charter, in: Wolfrum (ed.), The Max Planck Encyclopedia of Public International Law, 2012/8, S. $746 \mathrm{f}$.

$8 \mathrm{Zu}$ Fake News und Desinformation vgl. Ukrow/Etteldorf, Fake News als Rechtsproblem, 2017.

Die ersten konkreten operativen Maßnahmen der EU zur Bekämpfung von Desinformation sind auf die Abwehr entsprechender Kampagnen aus Nicht-EU-Staaten außengerichtet und lassen Desinformationskampagnen, die ihre Ursprung in Mitgliedstaten der EU selbst haben, bislang unberücksichtigt; vgl. European Commission, Action Plan against Disinformation, 5. Dezember 2018, abrufbar unter https://ec.europa.eu/commission/sites/beta-political/file s/eu-communication-disinformation-euco-05122018_en.pdf (05.03.2019).

9 Vgl. „Die Kraft der Verratslegenden“, https://www.sueddeutsche.de/kultur/un-migrations pakt-fischer-lescano-1.4230745 (05.03.2019). 
der Vertrag von Aachen ist bereits Gegenstand solcher Desinformation. ${ }^{10}$ Der nachfolgende Beitrag soll auch mit den Mitteln der rechtswissenschaftlichen Analyse zur Abwehr solcher Desinformationskampagnen beitragen.

\section{B. Aufbau, Integrationsziel, Organisationsgefüge und Verhältnis des Vertrages von Aachen zum Élysée-Vertrag}

\section{Aufbau}

Der Vertrag besteht aus einer Präambel und sieben Kapiteln. Die primär inhaltlich ausgerichteten ersten fünf Kapitel befassen sich mit den Themen „Europäische Angelegenheiten“,11 „Frieden, Sicherheit und Entwicklung“,12 „Kultur, Bildung, Forschung und Mobilität“,13 „Regionale und grenzüberschreitende Zusammenarbeit“14 sowie „Nachhaltige Entwicklung, Klima, Umwelt und Wirtschaft“. ${ }^{15}$ Das anschließende, "Organisation" gewidmete Kapite ${ }^{16}$ stellt nicht den alleinigen Fundus organisationsrechtlicher Verpflichtungen des Vertrages dar, sondern wird durch einzelne Bestimmungen in den ersten fünf Kapiteln ergänzt. Das abschließende Kapitel ${ }^{17}$ regelt das Verhältnis dieses Vertrages zum Vertrag aus 1963 sowie im Wesentlichen aus völkerrechtlichen Verträgen vertraute Bestimmungen zum Inkrafttreten des Vertrages.

Der Vertrag ist deutlich umfangreicher als der Élysée-Vertrag. Dies entspricht der Entwicklungstendenz auch bei dem auf die Integration der EU gerichteten Primärrecht - von EWGV über EGV bis hin zu EUV und AEUV. Zwar hat die parallele Tendenz zur Erweiterung von Regelungen im Bereich des nationalen Verfassungsrechts kritische Nachfragen zur Beständigkeit des Verfassungsrechts ausgelöst. ${ }^{18}$ Diese Bedenken können allerdings mit Blick auf den Vertrag von Aachen schon deshalb nicht entsprechend geltend gemacht werden, weil dessen Bestimmungen im Wesentlichen hinreichend „in die Zeit hinein offen“"19 sind.

10 So behauptete z.B. der Abgeordnete der französischen Nationalversammlung Bernard Monot, ein Mitglied des Debout la France, am 11. Januar 2019 in einem später zurückgezogenen, auf Facebook und Youtube verbreiteten Video, dass dieser Vertrag "Elsass und Lothringen an eine fremde Macht liefern würde" und dass in diesen Regionen die Verwaltungssprache Deutsch werde, vgl. https://www.francebleu.fr/infos/politique/quand-bernard-monot-lan ce-une-fake-news-sur-le-traite-d-aix-la-chapelle-1548089803 (05.03.2019). Eine Woche später, am 18. Januar 2019, behauptete Marine Le Pen, die Präsidentin des Rassemblement national, gegenüber CNews, dass Frankreich seinen ständigen Sitz im Sicherheitsrat der Vereinten Nationen mit Deutschland teilen würde, vgl. https://www.lemonde.fr/les-deco deurs/article/2019/01/18/l-intox-de-marine-le-pen-sur-le-traite-d-aix-la-chapelle-qui-affa iblit-la-france_5411073_4355770.html (05.03.2019).

11 Kapitel 1, Artikel 1 und 2.

12 Kapitel 2, Artikel 3 bis 8.

13 Kapitel 3, Artikel 9 bis 12.

14 Kapitel 4, Artikel 13 bis 17.

15 Kapitel 5, Artikel 18 bis 22.

16 Kapitel 6, Artikel 23 bis 26.

17 Kapitel 7, Artikel 27 und 28

18 Vgl. z.B. Dreier, Grenzen demokratischer Freiheit im Verfassungsstaat, JZ 1994, S. 741, 748

19 Bäumlin, Staat, Recht und Geschichte, 1961, S. 15. 
Bereits im Aufbau des Vertrages wird die besondere Bedeutung deutlich, die die beiden Vertragsparteien der europäischen Ausrichtung ihrer sämtlichen bilateralen Beziehungen zumessen. Die „europäischen Angelegenheiten“ stehen an der Spitze des Korpus der Vertragsbestimmungen. Aus diesen Regelungen wie der herausgehobenen Stellung europäischer Fragestellungen in der Präambel des Vertrages werden zahlreiche Schwerpunkte in den nachfolgenden Kapiteln abgeleitet. ${ }^{20}$

Ein Vergleich des Aufbaus des Vertrags von Aachen mit den europäischen Verträgen, dem EUV wie dem AEUV, zeigt im Übrigen bemerkenswerte Aufbauunterschiede im Detail:

- Den Bestimmungen zum auswärtigen Handeln wird im Aachener Vertragswerk eine deutlich prominentere Rolle beigemessen als in EUV ${ }^{21}$ und AEUV. ${ }^{22}$ Gleiches gilt im Ansatz auch für die Fragen der Bildung, ${ }^{23}$ Kultur ${ }^{24}$ und Forschung. ${ }^{25}$

- Es überrascht nicht zuletzt vor dem Hintergrund der herausgehobenen Bedeutung, die der sozialen Dimension der Zusammenarbeit beigemessen wird, dass sich in den eigentlichen Vertragsbestimmungen keine Regelung ausdrücklich dem Thema "Soziales" widmet. Fragen des Sports, ${ }^{26}$ des Gesundheitswesens, ${ }^{27}$ des Verbraucherschutzes, ${ }^{28}$ des Tourismus ${ }^{29}$ und des Katastrophenschutzes, ${ }^{30}$ die im AEUV angesprochen werden, finden im Vertrag von Aachen zumindest keine ausdrückliche Erwähnung. Insbesondere in Bezug auf die ökonomische Bedeutung des Tourismus in beiden Vertragsstaaten und die besondere Rolle, die Touristen aus dem einen Vertragsstaat im jeweils anderen Vertragsstaat zukommt, ${ }^{31}$ überrascht die touristische Leerstelle des Vertrages von Aachen.

- Die Bestimmungen zur regionalen und grenzüberschreitenden Zusammenarbeit weisen demgegenüber deutlich über die nur rudimentäre Befassung mit dieser $\mathrm{Fa}$ cette eines subsidiär agierenden Europas der Bürger in den europäischen Verträgen hinaus.

20 Vgl. auch Thorel, Der Aachener Vertrag vom 22.01.2019. Nur ein symbolischer Akt oder auch politisch bedeutend?, cepAdhoc 22.01.2019, S. 2 .

21 Art. $21 \mathrm{ff}$. EUV.

22 Art. $205 \mathrm{ff}$. AEUV.

23 Art. 165 f. AEUV.

24 Art. 167 AEUV.

25 Art. $179 \mathrm{ff}$. AEUV.

26 Vgl. Art. 165 Abs. 2, 7. Spiegelstrich, AEUV.

27 Vgl. Art. 168 AEUV.

28 Vgl. Art. 169 AEUV.

29 Vgl. Art. 195 AEUV.

30 Vgl. Art. 196 AEUV.

31 Touristen aus Deutschland sind die größte touristische Einzelgruppe nach nationaler Herkunft in Frankreich, Touristen aus Frankreich die drittgrößte touristische Einzelgruppe nach nationaler Herkunft in Deutschland; vgl. http://www.quotidiendutourisme.com/des tination/tourisme-la-cooperation-entre-la-france-et-lallemagne-reconduite/152654 (05.03.2019). 


\section{Das Verhältnis des Vertrages von Aachen zum Élysée-Vertrag}

Nach Art. 27 des Vertrages von Aachen „ergänzt“ dieser Vertrag den Élysée Vertrag vom 22. Januar $1963 \mathrm{im}$ Sinne des Absatzes 4 der Schlussbestimmungen jenes Vertrags. Dieser Absatz regelt, dass „die beiden Regierungen die Anpassungen vornehmen (können), die sich zur Ausführung dieses Vertrages als wünschenswert erweisen.“

Vor diesem Hintergrund erscheint die Bezugnahme auf den Absatz 4 der Schlussbestimmungen des Vertrags aus 1963 zumindest rechtsdogmatisch fragwürdig. Denn bei dem Vertrag von Aachen handelt es sich weder um ein bloßes Regierungsabkommen noch lediglich um eine Anpassung zur Ausführung des Élysée-Vertrages.

Die „Ergänzungs“-Funktion des Vertrags von Aachen ist allerdings insoweit bedeutsam, als sie das Vorrangverhältnis bei ggf. inkonsistenten Vertragsbestimmungen prägt: Sind alle Vertragsparteien eines früheren Vertrags zugleich Vertragsparteien eines späteren, ohne dass der frühere Vertrag beendet oder suspendiert wird, was bei dem Élysée-Vertrag und dem Vertrag von Aachen der Fall ist, so findet nach dem völkergewohnheitsrechtlichen lex posterior-Grundsatz, der auch in Art. 30 Abs. 3 WVRK verankert ist, der frühere Vertrag nur insoweit Anwendung, als er mit dem späteren Vertrag vereinbar ist. ${ }^{32}$ Die „Ergänzungs“-Klausel des Vertrages von Aachen spricht für eine Umkehrung dieser Anwendungsregel: Der Vertrag von Aachen findet nur insoweit Anwendung, als er mit dem Élysée-Vertrag vereinbar ist. Konflikte in den völkerrechtlichen Verpflichtungen durch die beiden Verträge sind allerdings zumindest derzeit nicht erkennbar.

\section{Das Integrationsziel des Vertrags von Aachen}

Seinem „Ergänzungscharakter“ trägt bereits der Titel des Vertrages von Aachen Rechnung. An die Seite des Élysée-Vertrages als Vertrag „über die französisch-deutsche Zusammenarbeit“ tritt nunmehr ein Vertrag „über die deutsch-französische Zusammenarbeit und Integration“. Die Einbindung des „Integrations“-Ziels kann zwar an Integrationsvorstellungen der Präambel des EU-Vertrages anknüpfen, in der auf den „Prozess der europäischen Integration“,33 das Voranschreiten der „europäische(n) Integration“ 34 sowie „Fortschritte bei der wirtschaftlichen Integration“ “35 abgestellt wird. Im deutsch-französischen Vertragsverhältnis stellt dieses Integrationsziel indessen juristisches Neuland dar: Zwar ist in der dem Vertrag aus 1963 vorgeschalteten „Gemeinsamen Erklärung“ die „Erkenntnis“ festgehalten, dass „die Verstärkung der Zusammenarbeit zwischen den beiden Ländern einen unerlässlichen Schritt auf dem Wege zu dem vereinigten Europa bedeutet, welches das Ziel beider Völker ist“. In-

32 Vgl. hierzu z.B. Vranes, Lex Superior, Lex Specialis, Lex Posterior - Zur Rechtsnatur der "Konfliktlösungsregeln", ZaöRV 2005/65, S. 391 ff.

33 Absatz 1 der Präambel des EUV.

34 Absatz 14 der Präambel des EUV.

35 Absatz 9 der Präambel des EUV. 
dessen ist diese, aus der Präambel des Grundgesetzes ${ }^{36}$ vertraute Finalität ${ }^{37}$ auf Europa als Ganzes ausgerichtet. Das Integrationsziel des Vertrages von Aachen ist demgegenüber, was sich aus der französischen Sprachfassung noch deutlicher als aus der deutschen Sprachfassung ergibt, auf die beiden Vertragsstaaten unmittelbar ausgerichtet.

Eine Integrations-Perspektive ist bislang für Deutschland zwar nur im Kontext der EU vertraut. ${ }^{38}$ Eine spezifisch deutsch-französische Integrationsdynamik und -möglichkeit spielt in den Verfassungstexten Deutschlands wie Frankreichs bislang keine Rolle. Weder französisches noch deutsches Verfassungsrecht versperrt allerdings generell Integrationsschritte außerhalb des vertraglichen, aber innerhalb des geographischen Rahmens der EU. ${ }^{39}$

\section{Organisations- und Verfahrensrecht als Integrationsrecht}

Organisatorische Aspekte standen 1963 im Mittelpunkt des Élysée-Vertrages. ${ }^{40}$ Vereinbart wurden u.a.:

- grundsätzlich zweimal jährlich Treffen der Staats- und Regierungschefs, ${ }^{41}$

- mindestens quartalsmäßige Treffen der Außenminister ${ }^{42}$ der Verteidigungsminis$\operatorname{ter}^{43}$ sowie des französischen Erziehungsministers mit derjenigen Persönlichkeit, die auf deutscher Seite benannt wird, um die Ausführung des Programms der $\mathrm{Zu}$ sammenarbeit auf kulturellem Gebiet zu verfolgen, ${ }^{44}$

36 Die französische Verfassung kennt eine solche über den jeweils konkreten Integrationsstand der EU auf primärrechtlicher Grundlage hinausreichenden europäischen Finalitätsansatz zumindest nicht ausdrücklich.

37 Vgl. hierzu z.B. Pernice, Zur Finalität Europas, 2005.

38 Art. 23 Abs. 1 GG schafft hierfür die verfassungsrechtliche Basis in Deutschland, indem er bestimmt, dass die Bundesrepublik Deutschland „zur Verwirklichung eines vereinten Europas... bei der Entwicklung der Europäischen Union mit(wirkt), die demokratischen, rechtsstaatlichen, sozialen und föderativen Grundsätzen und dem Grundsatz der Subsidiarität verpflichtet ist und einen diesem Grundgesetz im wesentlichen vergleichbaren Grundrechtsschutz gewährleistet".

39 So kann der Bund nach Art. 24 Abs. 1 GG durch Gesetz Hoheitsrechte auf zwischenstaatliche Einrichtungen übertragen. Soweit die Länder für die Ausübung der staatlichen Befugnisse und die Erfüllung der staatlichen Aufgaben zuständig sind, können sie gemäß Absatz 1a dieser Norm mit Zustimmung der Bundesregierung Hoheitsrechte auf grenznachbarschaftliche Einrichtungen übertragen. Zu letzterem vgl. Kotzur, Grenznachbarschaftliche Zusammenarbeit in Europa. Der Beitrag von Art. 24 Abs. 1a GG zu einer Lehre vom kooperativen Verfassungs- und Verwaltungsstaat, 2004.

40 Vgl. Klein, Der Élysée-Vertrag vom 22. Januar 1963, S. 254 f.

41 Ziffer I. 1. des Vertrages.

42 Ziffer I. 2. Satz 2 des Vertrages.

43 Ziffer I. 3. Buchst. a) Satz 1 des Vertrages.

44 Ziffer I. 3. Buchst. a) Satz 2 des Vertrages. 
- mindestens zweimonatliche Treffen der Generalstabschefs beider Staaten ${ }^{45}$ sowie des für Jugendfragen zuständigen Bundesministers mit seinem französischen Pendant ${ }^{46}$ sowie

- monatliche Treffen derjenigen leitenden Beamten der beiden Außenministerien, denen die politischen, wirtschaftlichen und kulturellen Angelegenheiten obliegen. ${ }^{47}$

In Umsetzung der in den Schlussbestimmungen des Élysée-Vertrages angesprochenen Anpassungen kam es seither zu einer weiteren Verdichtung des organisatorischen Geflechtes der Zusammenarbeit:

- Am 22. Januar 1988, 25 Jahre nach Unterzeichnung des Vertrages, setzten Bundeskanzler Helmut Kobl und der französische Staatspräsident François Mitterrand mit einem Protokoll zum Vertrag ${ }^{48}$ einen „Deutsch-französischen Verteidigungs- und Sicherheitsrat" und mit einem weiteren Protokoll zum Vertrag ${ }^{49}$ einen „Deutsch-französischen Finanz- und Wirtschaftsrat“ ein.

- Seit 2001 finden darüber hinaus im Rahmen des sog. „Blaesheim“-Formats informelle Treffen zwischen beiden Regierungschefs in 6- bis 8-wöchentlichem Turnus statt. ${ }^{50}$

- In einer Gemeinsamen Erklärung von Bundeskanzler Gerhard Schröder und Staatspräsident Jacques Chirac zum 40. Jahrestag der Unterzeichnung des ÉlyséeVertrags wurde am 22. Januar 2003 festgehalten, dass die seit dem 1963 halbjährlich stattfindenden Regierungskonsultationen (Gipfel) künftig in Form von gemeinsamen Ministerräten abgehalten werden. ${ }^{51}$ Zugleich wurde die Einrichtung eines Beauftragten (Generalsekretärs) für die deutsch-französische Zusammenarbeit in beiden Staaten geschaffen. ${ }^{52}$

Durch Art. 23 des Vertrages von Aachen findet die letztgenannte Organisationsreform eine vertragliche Basis: Treffen zwischen den Regierungen beider Staaten finden danach mindestens einmal jährlich, abwechselnd in der Bundesrepublik Deutschland und in der Französischen Republik, statt. ${ }^{53}$ Nach Inkrafttreten des Vertrags verabschiedet der Deutsch-Französische Ministerrat eine mehrjährige Vorhabenplanung für die deutsch-französische Zusammenarbeit. Die mit der Vorbereitung dieser Treffen betrauten Beauftragten für die deutsch-französische Zusammenarbeit überwachen

45 Ziffer I. 3. Buchst. b) des Vertrages.

46 Vgl. Ziffer I. 3. Buchst. c) des Vertrages.

47 Ziffer I. 2. Satz 3 des Vertrages.

48 Abrufbar unter: http://www.france-allemagne.fr/IMG/pdf/VerteidigungsratProtokolls8. pdf (05.03.2019).

49 Abrufbar unter: http://www.france-allemagne.fr/Protokoll-uber-die-Errichtung-des,0369 .html (05.03.2019).

50 https://www.france-allemagne.fr/Blaesheim-Treffen,1224.html (05.03.2019).

51 Ziffer 36 der Erklärung; abrufbar unter https://www.france-allemagne.fr/Gemeinsame-Er klarung-zum-40,366.html (05.03.2019).

52 Ziffer 41 der Erklärung.

53 Vertreter der Länder und der französischen Regionen sowie des Ausschusses für grenzüberschreitende Zusammenarbeit, der durch Art. 14 des Vertrages eingerichtet wird, können nach Art. 26 des Vertrages eingeladen werden, am Deutsch-Französischen Ministerrat teilzunehmen. 
die Umsetzung dieser Agenda und erstatten dem Ministerrat darüber Bericht. Durch Art. 24 des Vertrages erfährt zudem die Praxis wechselseitiger Teilnahme an Kabinettssitzungen eine vertragliche Verfestigung und Verstetigung: Mindestens einmal im Quartal nimmt danach ein jeweils wechselndes Mitglied der Regierung eines der beiden Staaten an einer Kabinettssitzung des anderen Staates teil. Das französische Regierungsmitglied wird damit nicht Teil des Organs Bundesregierung (Art. 62 GG), das deutsche Regierungsmitglied nicht Teil der französischen Regierung i.S. des Titels IV der französischen Verfassung. Allerdings gelten die jeweiligen Vertraulichkeitsbestimmungen für die Regierungsmitglieder auch für den Gast des Vertragspartners: Mitteilungen über Ausführungen einzelner Regierungsmitglieder, über das Stimmenverhältnis und über den Inhalt der Niederschrift ohne besondere Ermächtigung des Bundeskanzlers sind daher z.B. auch für das französische teilnehmende Regierungsmitglied unzulässig. ${ }^{54}$ Ihre Grenze findet diese Vertraulichkeit allerdings im Zweck der Teilnahme, namentlich über längerfristig wirksame, für das deutsch-französische Verhältnis bzw. die EU-Zusammenarbeit bedeutsame politische Entwicklungstendenzen informiert zu sein. So wie der an Sitzungen des Kabinetts nach $\$ 23$ der Geschäftsordnung der Bundesregierung regelmäßig teilnehmende Chef des Bundespräsidialamtes im Stande ist, die beratende Rolle des Bundespräsidenten gegenüber der Bundesregierung - je nach Sach- und Rechtsfrage i.S. eines Mahnens und Warnens oder eines Bestärkens und Ermutigens - vorzubereiten, so ist das Regierungsmitglied des Partnerstaates in der Lage, eine beratende Rolle im Blick auf europäische Angelegenheiten auszufüllen. Dem entspricht es, diesem Regierungsmitglied in der Sitzung zumindest ein Rede- und Fragerecht einzuräumen.

Art. 25 des Vertrages enthält zudem eine Evaluierungs- und Anpassungsklausel zum organisatorischen Gefüge der deutsch-französischen Zusammenarbeit. ${ }^{55}$

Die Organisationsbestimmungen im Kapitel 6 des Vertrages werden nicht zuletzt durch folgende organisationsrelevante Regelungen ergänzt:

- Über Art. 4 Abs. 4 des Vertrages erfährt der „Deutsch-Französische Verteidigungsund Sicherheitsrat" eine ausdrückliche vertragliche Basis als „politisches Steuerungsorgan" für die beiderseitigen Verpflichtungen nach Art. 4 Abs. 1 bis 3 des Vertrages. ${ }^{56}$

- Auch der „Deutsch-Französische Finanz- und Wirtschaftsrat“ wird vertraglich verankert: Nach Art. 20 Abs. 1 Satz 2 fördert er die bilaterale Rechtsharmonisierung und stimmt die wirtschaftspolitischen Maßnahmen zwischen den Vertragsparteien regelmäßig ab, um so die Konvergenz zwischen beiden Staaten zu befördern und die Wettbewerbsfähigkeit ihrer Volkswirtschaften zu verbessern.

54 Vgl. zur Vertraulichkeitspflicht $\$ 22$ Abs. 3 der Geschäftsordnung der Bundesregierung.

55 Die Räte, Strukturen und Instrumente der Zusammenarbeit werden danach regelmäßig, erstmalig bereits binnen sechs Monaten nach Inkrafttreten des Vertrags, überprüft und gegebenenfalls unverzüglich an die gemeinsam vereinbarten Ziele angepasst. Die Beauftragten für die deutsch-französische Zusammenarbeit bewerten regelmäßig die erzielten Fortschritte. Sie unterrichten die Parlamente und den Deutsch-Französischen Ministerrat über den Gesamtfortschritt der Zusammenarbeit.

56 Dieser Rat wird nach Art. 4 Abs. 4 Satz 2 des Vertrages „regelmäßig auf höchster Ebene zusammentreten“. 
- Nach Art. 6 Satz 2 des Vertrags richten die Vertragsstaaten eine „gemeinsame Einheit für Stabilisierungsoperationen in Drittstaaten“ ein.

- Gemäß Art. 14 des Vertrages richten beide Staaten einen „Ausschuss für grenzüberschreitende Zusammenarbeit" ein, der Interessenträger wie nationale, regionale und lokale Gebietskörperschaften, Parlamente und grenzüberschreitende Einheiten wie Eurodistrikte und, falls erforderlich, die betroffenen Euroregionen umfasst. Dieser Ausschuss koordiniert alle die Vertragsstaaten betreffenden Aspekte der grenzüberschreitenden Raumbeobachtung, entwirft eine gemeinsame Strategie zur Ermittlung von Schwerpunktvorhaben, stellt fortlaufend die in Grenzregionen bestehenden Schwierigkeiten fest und erarbeitet Vorschläge für den Umgang mit ihnen; darüber hinaus analysiert er die Auswirkungen neuer Rechtsvorschriften auf die Grenzregionen.

Eine prozedurale Ausrichtung auf eine verstärkte deutsch-französische Zusammenarbeit erfolgt aber nicht nur durch solche von beiden Vertragsstaaten getragene Organisationseinheiten, sondern auch durch Verfahrensabsprachen in Bezug auf exekutives Verhalten:

- Beide Staaten halten laut Art. 2 Satz 1 vor großen europäischen Treffen regelmäßig Konsultationen auf allen Ebenen ab und bemühen sich so, gemeinsame Standpunkte herzustellen und gemeinsame Äußerungen der Minister herbeizuführen. "Große europäische Treffen" sind bei systematischer und teleologischer Auslegung nicht nur solche auf Ebene der EU, sondern auch solche im Rahmen des Europarates und der OSZE. ${ }^{57}$ Die Konsultationspflicht begründet ein pactum de negotiando, ${ }^{58}$ bei dem es zum einen darum geht, unterschiedliche Positionen zwischen den Vertragsstaaten zu erkennen und im Ergebnis der Konsultationen nach Möglichkeit zu einer gemeinsamen Position zu gelangen. ${ }^{59}$ Eine Pflicht, stets den gleichen Standpunkt einzunehmen oder sich gemeinsam zu äußern, wird durch die Klausel allerdings nach deren klarem Wortlaut als bloßer Bemühenspflicht nicht begründet.

57 Verfahrensmäßige Prüfvorbehalte in vorbereitenden Gremien und Stimmenthaltungen in Entscheidungsgremien können dabei ein Instrument sein, einen offenen Dissens zu vermeiden, der mit der prozeduralen Regelung des Art. 2 Satz 1 in Widerspruch stehen könnte; vgl. zu solchen Überlegungen im Zusammenhang mit geplanten EU-Regulierungen zur Stärkung der Transparenz im Steuerrecht, bei denen eine unterstützende Position Frankreichs der an der Wahrung des Steuergeheimnisses ausgerichteten deutschen Linie gegenübersteht, Gammerlin/Müblaner, Berlin blockiert, Süddeutsche Zeitung Nr.45 v. 22.02.2019, S. 19 .

58 Vgl. hierzu Beyerlin, Pactum de contrahendo und pactum de negotiando im Völkerrecht?, ZaöRV 1976/36, S. 407, $420 \mathrm{ff}$.

59 Ein dem Inkrafttreten des Vertrages von Aachen vorgelagertes Beispiel der Handhabung dieser zentralen (nicht zuletzt auch europa-) rechtspolitischen Verfahrensregelung stellt die Entwicklung einer gemeinsamen deutsch-französischen Haltung zur Novelle der sog. Gasrichtlinie der EU (Richtlinie 2009/73/EG des Europäischen Parlaments und des Rates vom 13. Juli 2009 über gemeinsame Vorschriften für den Erdgasbinnenmarkt) und damit inzident auch zur Zukunft des Nord Stream 2-Projekts dar; vgl. hierzu z.B. http://www.spiegel.de/wirtschaft/soziales/nord-stream-2-deutschland-und-frankreich-einigen-sich-offenbar-auf-kompromiss-a-1252308.html (05.03.2019). 
- Nach Art. 3 Satz 2 des Vertrages konsultieren beide Staaten einander in Angelegenheiten der Außenpolitik, der Verteidigung, der äußeren und inneren Sicherheit und der Entwicklung mit dem Ziel, gemeinsame Standpunkte bei allen wichtigen Entscheidungen festzulegen, die ihre gemeinsamen Interessen berühren, und, wann immer möglich, gemeinsam zu handeln. Diese Konsultationspflicht hat neben Entscheidungen auf Ebene der EU, des Europarates und der OSZE nicht zuletzt auch Entscheidungen im Rahmen der NATO und der UN zum Gegenstand.

- Gemäß Art. 5 des Vertrages weiten beide Staaten die Zusammenarbeit zwischen ihren Außenministerien, einschließlich ihrer diplomatischen Missionen und konsularischen Vertretungen, aus. ${ }^{60}$

- Nach Art. 6 Satz 2 des Vertrages führen die Regierungen beider Staaten gemeinsame Maßnahmen im Hinblick auf Aus- und Fortbildung und Einsätze bei der Bekämpfung des Terrorismus und der organisierten Kriminalität sowie im Bereich der Justiz, der Nachrichtendienste und der Polizei durch und richten eine „gemeinsame Einheit für Stabilisierungsoperationen in Drittstaaten“ ein.

- Zudem richten beide Staaten entsprechend Art. 7 Satz 2 des Vertrages einen jährlichen Dialog auf politischer Ebene im Bereich der internationalen Entwicklungspolitik ein, um die Koordinierung von Politikplanung und -umsetzung zu intensivieren.

Diese umfassenden Teilnahme-, qualifizierten Konsultations-, ${ }^{61}$ Koordinierungs-, Aus- und Fortbildungs-, Austausch-, Dialog- und Abstimmungsverpflichtungen dürften im bi- und multilateralen Verhältnis von EU-Mitgliedstaaten zueinander beispiellos sein. Sie begrenzen nicht nur die Risiken nationaler Alleingänge wie beim deutschen Atomausstieg 2009 für die europäische Solidarität, ${ }^{62}$ sondern fördern nicht zuletzt das Entstehen eines gemeinsamen kulturellen Verständnisses aktueller und zukünftiger Herausforderungen für die beiden Staaten wie für die EU und sind damit in hohem Maße integrationsfördernd im deutsch-französischen Verhältnis. Ob diese Wirkung sich auch im besonders sensiblen, durch unterschiedliche historische Erfahrungen und Belastungen wie auch unterschiedliche parlamentarische Mitwirkungserfordernisse geprägten militärstrategischen Bereich zeitnah einstellen wird, erscheint allerdings fraglich. ${ }^{63}$ Zudem wirkt sich der aufgezeigte diskursive Vernetzungsansatz im Kern nur auf der Ebene des Staates (einschließlich seiner kommunalen Ebene),

60 Sie werden hierzu Austausche zwischen ihrem Führungspersonal durchführen sowie Austauschprogramme zwischen ihren Ständigen Vertretungen bei den Vereinten Nationen in New York, insbesondere zwischen den Sicherheitsratsstäben, den Ständigen Vertretungen bei der NATO und den Ständigen Vertretungen bei der EU sowie zwischen den für die Koordinierung der europapolitischen Maßnahmen zuständigen Stellen beider Staaten einrichten.

61 Vgl. hierzu bereits für den Vertrag aus 1963 Jansen, Das Entstehen des deutsch-französischen Vertrages vom 22. Januar 1963, a.a.O., S. 267.

62 Vgl. Thorel, Der Aachener Vertrag vom 22.01.2019. Nur ein symbolischer Akt oder auch politisch bedeutend?, cepAdhoc 22.01.2019, S. 3 f.

63 Vgl. Thorel, Der Aachener Vertrag vom 22.01.2019. Nur ein symbolischer Akt oder auch politisch bedeutend?, cepAdhoc 22.01.2019, S. 2 . 
nicht im gesellschaftlichen Raum aus. In diesen Raum hinein wirken allerdings weitere institutionelle Neuerungen:

- An die Seite des staatlich dominierten „Deutsch-Französischen Finanz- und Wirtschaftsrat" tritt nach Art. 20 Abs. 2 des Vertrages ein durch diesen Vertrag eingerichteter deutsch-französischer „Rat der Wirtschaftsexperten“, der sich aus zehn unabhängigen Fachleuten zusammensetzt und das Ziel verfolgt, ihren Regierungen wirtschaftspolitische Empfehlungen zu unterbreiten. Die konzeptionelle und organisatorische Orientierung dieser neuen Einrichtung am „Sachverständigenrat zur Begutachtung der gesamtwirtschaftlichen Entwicklung“ ist evident. Die Einrichtung des neuen Rates kann einen Beitrag dazu leisten, in beiden Staaten die jeweils bislang dominierenden volkswirtschaftlichen Ansätze in der Beantwortung wirtschafts-, sozial- und umweltschutzpolitischer Herausforderungen für eine methodenpluralistische Herangehensweise zu öffnen. ${ }^{64}$

- Nach Art. 22 des Vertrages werden „Interessenträger und einschlägige Akteure“ aus beiden Staaten in einem „deutsch-französischen Zukunftswerk“ „zusammengebracht", um sich mit Transformationsprozessen in ihren Gesellschaften auseinanderzusetzen. Rechtliche Natur, Zusammensetzung, Organisation und Verfahren dieses „Zukunftswerks“ sind ebenso wie dessen Einwirkungsmöglichkeiten auf die politischen Entscheidungsprozesse in den Vertragsstaaten vertraglich ungeregelt, ${ }^{65}$ was eine zusätzliche exekutive Gestaltungsmacht in Bezug auf dieses Instrument gesellschaftlicher Teilhabe an der Entwicklung der deutsch-französischen Zusammenarbeit eröffnet.

\section{Der Vertrag von Aachen und die parlamentarische Ausgestaltung und Kontrolle von Integrationsverdichtungen}

Im letzten Absatz der Präambel des Vertrages wird die zentrale Rolle anerkannt, welche der Zusammenarbeit zwischen dem Deutschen Bundestag und der französischen Nationalversammlung, insbesondere durch ein Parlamentsabkommen, ${ }^{66}$ als einer wichtigen Dimension der engen Beziehungen zwischen ihren Staaten zukommt. Der

64 Vgl. zur Pluralismusforderung z.B. Ehnts/Zeddies, Die Krise der VWL und die Vision einer Pluralen Ökonomik, Wirtschaftsdienst 2016/96, S. 769 ff.; Heise, Pluralismus in den Wirtschaftswissenschaften, 2016.

65 Die Einordnung dieses Zukunftswerks als „Dialogforum für Transformationsprozesse in unseren Gesellschaften “ in der anlässlich der Unterzeichnung des Vertrags von Aachen vereinbarten „Deutsch-Französische(n) Agenda“ mit „Prioritäre(n) Vorhaben in Umsetzung des Vertrags von Aachen“, abrufbar unter: https://www.auswaertiges-amt.de/blob/21804 24/5dfc5a527453466b5ebdcae01341a2bb/190123-15punkte-breg-data.pdf (05.03.2019) bringt keinen nennenswerten zusätzlichen juristischen Erkenntnisgewinn.

66 Vgl. die Unterrichtung durch den Präsidenten des Deutschen Bundestages - Entwurf eines Deutsch-Französischen Parlamentsabkommens, BT-Drs. 19/6220 v. 30.11.2018. Zur Empfehlung zur Annahme dieses Abkommens vgl. BT-Drs. 19/8540 v. 19.03.2019. 
Vertrag von Aachen ist mithin auf eine Ergänzung aus dem parlamentarischen Raum heraus angelegt. ${ }^{67}$

Aber auch im Vertrag von Aachen selbst findet die parlamentarische Dimension der Zusammenarbeits- und Integrationsverpflichtung an mehreren Stellen einen Ausdruck:

- Art. 14 Satz 1 des Vertrages bestimmt die Einbindung der Parlamente in die Struktur des neuen Ausschusses für grenzüberschreitende Zusammenarbeit.

- Art. 25 Satz 4 sieht eine Berichtspflicht der Beauftragten für die deutsch-französische Zusammenarbeit über die Fortschritte in der deutsch-französischen Zusammenarbeit vor.

- Art. 2 Satz 1 des Vertrags, wonach beide Staaten vor großen europäischen Treffen regelmäßig Konsultationen „auf allen Ebenen“ abhalten, kann parlamentsfreundlich dahin ausgelegt werden, dass hier auch die Ebene der Volksvertretungen angesprochen ist. Auch die in Satz 2 dieser Regelung vorgesehene Abstimmungspflicht bei der Umsetzung von europäischem Recht weist erkennbar parlamentarisches Beteiligungspotential auf.

\section{Die Präambel des Vertrags von Aachen}

\section{Zur rechtlichen Bedeutung der Präambel}

Vergleicht man die Aufbaustruktur der Verträge von 1963 und 2019, so fällt zunächst auf, dass der Vertrag von 1963 keine Präambel, aber eine dem Vertrag vorangestellte und von ihm ausdrücklich in Bezug genommene „Gemeinsame Erklärung“ kennt, die - im Unterschied zum Vertrag selbst - nur von Bundeskanzler Adenaner und dem französischen Staatspräsidenten de Gaulle unterzeichnet ist und ihrerseits auf den Vertrag verweist. ${ }^{6}{ }^{2}$ Der Vertrag von 2019 kennt demgegenüber eine solche „Gemeinsame Erklärung" nicht, weist dafür aber eine Präambel auf.

"Gemeinsamer Erklärung" wie Präambel kommt unter Zugrundelegung völkervertragsrechtlicher Auslegungsmethoden Interpretationsrelevanz im Blick auf den jeweiligen Vertragskorpus zu. In Bezug auf die Erklärung folgt dies aus der wechselseitigen Inbezugnahme in Verbindung mit - dem auch insoweit Völkergewohnheitsrecht wiedergebenden - Art. 31 Abs. 1, 2 Buchst. a) WVRK: Da-

67 Nach dem am 25. März 2019 unterzeichneten Parlamentsabkommen (vgl. https:// www.bundestag.de/dokumente/textarchiv/2019/kw13-deutsch-franzoesische-versammlung-630114 [05.03.2019]) umfasst diese Ergänzung u.a. die Gründung einer „DeutschFranzösischen Parlamentarischen Versammlung" (sie soll u.a. die Anwendung der vertraglichen Bestimmungen und die Umsetzung und die Evaluierung der auf diesen Verträgen beruhenden Projekte überwachen, die Deutsch-Französischen Ministerräte und die Arbeit des Deutsch-Französischen Verteidigungs- und Sicherheitsrats begleiten und Vorschläge zu Fragen formulieren, die die deutsch-französischen Beziehungen betreffen, mit dem Ziel, eine Konvergenz des deutschen und des französischen Rechts anzustreben) und eine verstärkte Zusammenarbeit zwischen dem Deutschen Bundestag und der Assemblée nationale (u.a. auf Präsidiums- und Ausschuss-Ebene).

68 BGBl. 1963, II, S. 706; dazu Klein, Der Élysée-Vertrag vom 22. Januar 1963, S. 253. 
nach ist ein Vertrag nach Treu und Glauben in Übereinstimmung mit der gewöhnlichen, seinen Bestimmungen „in ihrem Zusammenhang" zukommenden Bedeutung und im Lichte seines Zieles und Zweckes auszulegen. Für die Auslegung eines Vertrags bedeutet der Zusammenhang außer dem Vertragswortlaut samt Präambel und Anlagen u.a. auch ,jede sich auf den Vertrag beziehende Übereinkunft, die zwischen allen Vertragsparteien anlässlich des Vertragsabschlusses getroffen wurde“. Selbiges ist bei der Gemeinsamen Erklärung gegeben.

In Bezug auf die Präambel des Vertrages von Aachen folgt die Interpretationsrelevanz gleichfalls aus der soeben dargestellten allgemeinen völkerrechtlichen Auslegungsmethodik. Im Völkerrecht zählen Präambeln, die in Art. 31 Abs. 2 Buchst. a) WVRK ausdrücklich als Bestandteil des auslegungsbedeutsamen „Zusammenhangs“ genannt sind, schon lange zum normativen Hausgut völkerrechtlicher Verträge. ${ }^{69}$ Insbesondere nennen die Parteien in den Präambeln häufig - so auch im Vertrag von Aachen - die mit dem Vertragsschluss verfolgte Zielsetzung. Die oftmals schwierig zu beantwortende Frage nach dem Ziel des Vertrages kann so von der Präambel verbindlich geklärt werden. Ihr kommt dann namentlich bei einer teleologischen, am Sinn und Zweck des Vertrages ausgerichteten Auslegung eine zentrale Bedeutung zu.

Der Ableitung eigenständiger Rechtspflichten aus Präambeln stehen Staatenpraxis und Völkerrechtslehre jedoch skeptisch gegenüber. Denn völkerrechtlich spricht Vieles für die These, dass die Verortung einer Aussage in der Präambel bedeutet, dass die Vertragsparteien hier keine eigenständigen Rechtspflichten begründen wollten. ${ }^{70}$

Dieser völkerrechtliche Befund wird durch die Einordnung der rechtlichen Bedeutung von Präambeln im Europarecht aufgegriffen und auch durch eine rechtsvergleichende Analyse der Bedeutung der Präambeln in den Verfassungsordnungen der Vertragsstaaten des Vertrages von Aachen im Kern bestätigt.

Präambeln sind auch dem primären EU-Recht seit jeher vertraut und finden sich aktuell sowohl den Artikeln des EUV wie des AEUV vorgeschaltet. Die Präambeln sind Bestandteile dieser Verträge. ${ }^{71}$ Sie nennen die Ziele, Motive und Grundsätze der Vertragsparteien, die für die Gründung der EU bzw. für die Verständigung auf deren Arbeitsweise maßgebend waren und sind somit ein wichtiger Anhaltspunkt für die Auslegung des Unionsrechts. ${ }^{72}$ Zudem beschreiben die Präambeln auch den Aufgaben- und Arbeitsbereich der EU und beschränken somit ihr Tätigkeitsfeld. ${ }^{73}$ Demnach kann die EU auch in Wahrnehmung ihrer Vertragsabrundungskompetenz nach Art. 352 AEUV die in den Präambeln genannten Ziele - zumindest in Form einer

69 Vgl. z.B. Mbengue, Preamble, in: Wolfrum (ed.), The Max Planck Encyclopedia of Public International Law, Vol. VIII, 2012, S. $397 \mathrm{ff}$.

70 Vgl. Naumann, Eine religiöse Referenz in einem Europäischen Verfassungsvertrag, 2008, S. $85 \mathrm{ff}$.

71 Vgl. z.B. auch Terhechte, in: Grabitz/Hilf/Nettesheim (Hrsg.), Das Recht der Europäischen Union, Stand 2019, Präambel EUV Rn. 9.

72 Vgl. z.B. auch Kulow, Inhalte und Funktionen der Präambel des EG-Vertrages, 1979, S. 29 ff.; Terbechte, in: Grabitz/Hilf/Nettesheim (Hrsg.), Das Recht der Europäischen Union, Stand 2019, Präambel EUV Rn. 10.

73 Zur Auslegung des Gemeinschaftsrechts im Lichte der Präambel durch den EuGH vgl. z.B. EuGH, Rs. 374/87, Orkem, S. 3283 Rn. 19. 
Auslegungshilfe für die nähere begriffliche Bestimmung an anderer Stelle geregelter Ziele der EU - berücksichtigen. Aufgrund der weiten Fassung der Präambeln bedeutet dies zwar einerseits keine starke Beschränkung der Unionsaktivitäten, ${ }^{74}$ allerdings ist andererseits der Gehalt der Präambel des EUV ohnedies weithin in dem umfangreichen Korpus von Werten, Zielen und Aufgaben der EU nach Art. 2 bis 6 EUV gespiegelt. ${ }^{75}$ Dies unterscheidet die europäischen Verträge vom Vertrag von Aachen, in dem der Aussagegehalt der Präambel in Teilen über denjenigen der Vertragsartikel hinausreicht.

Präambeln sind zudem auch Verfassungstradition beider Vertragsstaaten und dort jeweils als rechtlich bedeutsam anerkannt. In Deutschland hat das Bundesverfassungsgericht schon früh in seiner Entscheidung im KPD-Verbotsverfahren 1956 der Präambel des Grundgesetzes normative Wirkung zugemessen: ${ }^{76}$ Die Präambel sei zwar einerseits „politisches Bekenntnis, feierlicher Aufruf des Volkes zu einem Programm der Gesamtpolitik“. Darüber hinaus habe der Vorspruch aber „auch rechtlichen Gehalt“. Zu diesem zählten nicht nur „rechtlich erhebliche Feststellungen und Rechtsverwahrungen, die bei der Auslegung des Grundgesetzes beachtet werden müssen". Vielmehr ließen sich hieraus auch Rechtspflichten ableiten. Dabei sei aber offensichtlich, dass auf solche Gebote nicht das Verlangen gestützt werden könne, die Organe der Bundesrepublik müssten bestimmte Handlungen zum Zwecke der Verwirklichung des Programms der Präambel vornehmen. Denn den zu politischem Handeln berufenen Organen der Bundesrepublik müsse es überlassen bleiben zu entscheiden, welche Wege sie zur Herbeiführung der Ziele der Präambel als politisch richtig und zweckmäßig ansehen. In späteren Entscheidungen hat das BVerfG auch der Erwähnung des vereinten Europas in der Präambel des GG Rechtswirkungen zugesprochen. Die „Offenheit für Bindungen in der Völkerrechtsgemeinschaft und in dem engeren Rechtsverbund einer zwischenstaatlichen Gemeinschaft" sei „in einem demokratischen Staat angelegt, der - wie es die Präambel des Grundgesetzes voraussetzt und die Art. 23 und 24 GG ausdrücklich regeln - als gleichberechtigtes Glied in zwischenstaatlichen Einrichtungen und insbesondere bei der Entwicklung der Europäischen Union mitwirken will“. ${ }^{77} \mathrm{Im}$ Zuge dieser Rechtsprechungslinie hat das BVerfG auch die „offene Staatlichkeit“ der Bundesrepublik Deutschland ${ }^{78}$ sowie die „Europarechtsfreundlichkeit des Grundgesetzes“ als u.a. in der Präambel des GG angelegt erachtet. ${ }^{79}$ Diese „offene Staatlichkeit“ nach (u.a.) der Präambel des GG ist auch für zwischenstaatliche Integrationsschritte Deutschlands bi- oder multilateralen $\mathrm{Zu}$ schnitts außerhalb der Ebene der EU bedeutsam.

74 Vgl. Rossi, in: Calliess/Ruffert, (Hrsg.) EUV/AUV, 5. Aufl. 2016, Art. 352 AEUV, Rn. 14, 36; Streinz, in: ders. (Hrsg.), EUV/AEUV, 3. Aufl. 2018, Art. 352 AEUV, Rn. 29.

75 Vgl. Terhechte, in: Grabitz/Hilf/Nettesheim (Hrsg.), Das Recht der Europäischen Union, Stand 2019, Präambel EUV, Rn. 14; zu den einzelnen Zielen z.B. Streinz, in: ders. (Hrsg.), EUV/AEUV, 3. Aufl. 2018, Präambel EUV, Rn. $4 \mathrm{ff}$.

76 BVerfGE 5, S. 85, $127 \mathrm{f}$.

77 BVerfGE 89, S. 155, 183.

78 BVerfGE 123, S. 267, 321.

79 BVerfGE 142, S. 123, 197. 
Deutlich weitreichender sind im Übrigen die Auswirkungen der Präambel in Frankreich. ${ }^{80}$ Erst über die Anerkennung der normativen Kraft der Präambel der Verfassung aus 1958 gelingt dort eine judikative Kontrolle der Wahrung der Grundrechte - startend mit einer grundlegenden Entscheidung des Conseil constitutionnel aus dem Jahr $1971 .{ }^{81}$ Dieser im Ausgangspunkt grundrechtlich motivierten normativen Bindekraft kommt indessen auch Bedeutung für die sonstigen Ausführungen der Präambel zu, zu denen auch ein für die europäische Integration bedeutsamer Aussagegehalt zählt: Eine allgemeine Ermächtigungsklausel für entsprechende Integrationsschritte findet sich in Absatz 15 der Präambel der Verfassung von 1946, die über einen entsprechenden Verweis in der Präambel der Verfassung von 1958 in diese integriert ist. ${ }^{82}$ Beide Verpflichtungen wirken auch in Bezug auf etwaige Souveränitätseinschränkungen durch die deutsch-französischen Verträge von 1963 und 2019.

Präambeln können mithin nach der deutschen wie nach der französischen Verfassungstradition eigenständige Rechtssätze enthalten, wenn sich der nachfolgende Verfassungstext als lückenhaft erweist. Daneben bringen Präambeln nach dieser gemeinsamen Traditionslinie der zweiten Hälfte des 20. Jahrhunderts die besondere Bedeutung der in ihnen angesprochenen Gesichtspunkte für den Verfassungsgeber zum Ausdruck. Dieser betont hier, welche Wertentscheidungen für ihn von besonderer Bedeutung sind. Dies ist in Auslegungsfragen und Abwägungsentscheidungen zu berücksichtigen. ${ }^{83}$

Diese Auslegungs- und Abwägungsrelevanz, die mithin bei einer wertenden $\mathrm{Zu}$ sammenschau völker- und europarechtlicher wie rechtsvergleichender Ansätze der Einordnung von Präambeln gemeinsam ist, ist auch mit Blick auf die Präambel zum Vertrag von Aachen gegeben.

\section{Die politische Programmatik der Präambel im Lichte der Präambel- Rechtskultur der europäischen Verträge - eine Auswahl}

Während der erste Absatz der Präambel ausschließlich auf das deutsch-französische Verhältnis bezogen und retrospektiv ausgerichtet ist, indem die historische Errungenschaft der Aussöhnung zwischen dem deutschen und dem französischen Volk anerkannt wird, zu welcher der Elysee-Vertrag vom 22. Januar 1963 einen außerordentlichen Beitrag geleistet habe und aus der ein beispielloses Geflecht bilateraler Beziehungen zwischen ihren Zivilgesellschaften und staatlichen Stellen auf allen Ebe-

80 Vgl. hierzu im Folgenden Naumann, Eine religiöse Referenz in einem Europäischen Verfassungsvertrag, 2008, S. $45 \mathrm{ff}$.

81 CC, Decision n ${ }^{\circ}$ 71-44 DC, Liberté d'association, Rec., 29.

82 Danach stimmt Frankreich unter dem Vorbehalt der Gegenseitigkeit den zur Organisation und Verteidigung des Friedens notwendigen Einschränkungen seiner Souveränität zu. Diesem Passus ist im 14. Absatz der Präambel aus 1946 die Selbstverpflichtung vorangestellt, wonach sich die französische Republik ihrer Überlieferung getreu nach den Regeln des Völkerrechts richtet. Vgl. hierzu auch Scheffler, Das französische Verfassungsverständnis angesichts der Anforderungen des EG/EU-Rechts, Zao'RV 2007/67, S. 43, 49.

83 Vgl. Naumann, Eine religiöse Referenz in einem Europäischen Verfassungsvertrag, 2008, S. $56 \mathrm{ff}$. 
nen entstanden sei ${ }^{84}$ ist bereits im zweiten Absatz der Präambel eine Öffnung der Perspektive des Vertrags über das deutsch-französische Verhältnis wie auch über die Gegenwart und nahe Zukunft hinaus angelegt: Die Vertragsparteien sind danach von der Überzeugung geleitet, „dass es an der Zeit ist, ihre bilateralen Beziehungen auf eine neue Stufe zu heben und sich auf die Herausforderungen vorzubereiten, vor denen beide Staaten und Europa im 21. Jahrhundert stehen, und mit dem Ziel, die Konvergenz ihrer Volkswirtschaften und ihrer Sozialmodelle zu erhöhen, die kulturelle Vielfalt zu fördern und ihre Gesellschaften und ihre Bürgerinnen und Bürger enger zusammenzubringen".

Bereits diese Passage der Präambel nimmt Europa in den Blick, wobei sie sich programmatischer Ansätze bedient, wie sie aus der Präambel des EU-Vertrages bekannt sind: Die "Stufen“-Konzeption knüpft unmittelbar an den 1. Absatz der Präambel des EUV an, wonach die Mitgliedstaaten der EU entschlossen sind, „den mit der Gründung der Europäischen Gemeinschaften eingeleiteten Prozess der europäischen Integration auf eine neue Stufe zu heben“. Das dynamische, prozesshaft auf eine stete Verbesserung und Verdichtung angelegte „Stufen“-Verständnis der Integration ${ }^{85}$ ist zudem aus der Entwicklungsgeschichte der Europäischen Währungsunion vertraut, allerdings fehlen sowohl in Bezug auf die Präambel des EU-Vertrages als auch in Bezug auf die Präambel des Vertrages von Aachen der „Stufen“-Regulierung des Übergangs zur Währungsunion vergleichbare konzeptionelle Konkretisierungen, regulatorische Rahmensetzungen und hierbei nicht zuletzt auch zeitliche Fristsetzungen. ${ }^{86}$

Das in der Präambel des Vertrages von Aachen genannte Ziel, die kulturelle Vielfalt zu fördern, findet sich in dieser Form zwar weder in der Präambel des EUV noch derjenigen des AEUV. Es ist allerdings als Zielsetzung aus Art. 3 Abs. 3 wie Art. 167 Abs. 1 AEUV $^{87}$ vertraut - dort allerdings noch in Richtung auf eine bloße „Wahrung“ der kulturellen Vielfalt ausgerichtet. Das dynamische Förder-Ziel greift deutlich über ein bloßes statisches Wahren hinaus. Es knüpft in seiner auf stärker aktives kulturelles Wirken ausgerichteten Formulierung an die UNESCO-Konvention über den Schutz und die Förderung der Vielfalt kultureller Ausdrucksformen vom 20. Oktober 2005 an, die maßgeblich auf französische kulturpolitische Initiativen zurückgeht, auch von

84 Diese Einordnung entspricht der aus den Erklärungen anlässlich der jüngeren Jubiläen des Vertrages bekannten gemeinsamen Bewertung.

85 Vgl. hierzu z.B. auch Stabl, Europäische Integration als Zivilisationsprozess, in: Dorner u.a. (Hrsg.), Europäische Integrationsperspektiven: Ambivalenzen der Entwicklung und Lösungsansätze, 2013, S. 97, 106; Vormbaum, Schutz der Rechtsgüter von EU-Staaten durch das deutsche Strafrecht, 2005, S. 41 f.

86 Vgl. hierzu z.B. Horn, Europäische Währungseinheit oder Wettbewerb der Währungen?, in: Baur u.a. (Hrsg.), Recht und Wirtschaft der Europäischen Union, 1997, S. 44, 55 ff.; Nicolaysen, Rechtsfragen der Währungsunion, 1993, S. $19 \mathrm{ff}$.

87 Vgl. hierzu z.B. Ress/Ukrow, in: Grabitz/Hilf/Nettesheim (Hrsg.), Das Recht der Europäischen Union, Stand 2018, Art. 167 AEUV, Rn. 93 ff. 
Deutschland ratifiziert ist ${ }^{88}$ und den kulturpolitischen Aktivitäten der EU, die der Konvention beigetreten ist, ${ }^{89}$ zunehmend als Orientierungsrahmen dient.

Die Vorbereitung auf Herausforderungen des noch jungen 21. Jahrhunderts ist als Ziel der Präambel-Programmatik der europäischen Verträge demgegenüber bislang fremd. Die in den Kapiteln 1 bis 5 des Vertrages von Aachen adressierten politischen Aufgaben dürften unter diese Herausforderungen fallen, ohne diese zwingend vollständig zu definieren; manche (zumindest vordergründig bestehende) Lücke im operativen wie im programmatischen Teil dieser Kapitel wie z.B. bei Fragestellungen der Durchbrechung der steten geographischen Erweiterung des Integrationsprozesses der EU durch den Brexit, ${ }^{90}$ der Abrüstung und Rüstungskontrolle, ${ }^{91}$ des kohärenten Umgangs mit der Macht der GAFA ${ }^{92}$ oder von Datenschutz und -sicherheit sowie Verbraucherschutz im Prozess der Globalisierung ${ }^{93}$ und von Gesundheit und Pflege im Zeitalter demographischen Wandels ${ }^{94}$ spricht ebenso gegen eine abschließende begriffliche Bestimmung der Herausforderungen für die deutsch-französische Zusammenarbeit und Integration durch die im eigentlichen Vertragstext angesprochenen Themenstellungen wie die Zeitperspektive „21. Jahrhundert“, das bislang noch nicht einmal zu einem Fünftel durchschritten ist, sowie die Dynamik globaler Prozesse wie auch der rechtlichen Reaktion des EU-Rechts auf neue Herausforderungen. ${ }^{95}$

Neu ist in der Präambel-Historie auch das Ziel, die Gesellschaften der Vertragsstaaten und ihre Bürgerinnen und Bürger enger zusammenzubringen. Dieses Ziel weist zwar erkennbare sprachliche Berührungspunkte zur im 13. Absatz der Präambel

88 BGBl. 2007, II, S. 234 ff. Vgl. hierzu z.B. Bredimas, La Convention de l'Unesco sur la diversité culturelle et les règles de l'Organisation mondiale du commerce", Annuaire international des droits de l'Homme 2008/3, S. 271 ff.; Graber, The New UNESCO Convention on Cultural Diversity: A Counterbalance to the WTO?, Journal of International Economic Law 2006/9, S. 553 ff.; Hanania (ed.), Cultural Diversity in International Law, 2014; Ress/ Ukrow, Art. 167 AEUV, Rn. 64 f.; Sucker, Der Schutz und die Förderung kultureller Vielfalt im Welthandelsrecht, 2018; Voon, UNESCO and the WTO - A Clash of Cultures, ICLQ 2006/55, S. $635 \mathrm{ff}$.

89 Beschluss des Rates vom 18. Mai 2006 über den Abschluss des Übereinkommens zum Schutz und zur Förderung der Vielfalt kultureller Ausdrucksformen (2006/515/EG), ABl. L 201/15 v. 30.7.2015.

90 Vgl. hierzu aus juristischer Perspektive z.B. http://www.germanlawjournal.com/brexit-su pplement (05.03.2019).

91 Deren Bedeutung dürfte spätestens nach der Ankündigung des Rückzugs aus dem INFVertrages, abrufbar unter https://www.state.gov/t/avc/trty/102360.htm\#text (05.03.2019) durch die USA, https://www.state.gov/secretary/remarks/2019/02/288722.htm (05.03.2019) und Russland, http://en.kremlin.ru/events/president/news/59763 (05.03.2019) weiter wachsen.

92 Vgl. hierzu auch Teltschik, Russisches Roulette, S. 12; Dittrich, Online Platforms and how to regulate them: An EU Overview, Bertelsmann Stiftung Policy Paper Nr. 2018/227; Moore/Tambini (eds.), Digital Dominance: The Power of Google, Amazon, Facebook, and Apple, 2018.

93 Vgl. z.B. Zuboff, Das Zeitalter des Überwachungskapitalismus, 2018.

94 Vgl. hierzu bereits Ukrow, Der Kern eines vereinten Europas. 10-Punkte-Plan für eine deutsch-französische Konföderation, EUROPA aktiv 2016/4, S. 3.

95 Vgl. hierzu z.B. Rösler, Europäische Gerichtsbarkeit auf dem Gebiet des Zivilrechts, 2012, S. $245 \mathrm{ff}$.; Nolte, Das Verfassungsrecht vor den Herausforderungen der Globalisierung, VVDStRL 67 (2008), S. $129 \mathrm{ff}$. 
des EUV festgehaltenen Entschlossenheit, „den Prozess der Schaffung einer immer engeren Union der Völker Europas, in der die Entscheidungen entsprechend dem Subsidiaritätsprinzip möglichst bürgernah getroffen werden, weiterzuführen“, und zum im 1. Absatz der Präambel des AEUV dokumentierten „festen Willen, die Grundlagen für einen immer engeren Zusammenschluss der europäischen Völker zu schaffen“, auf. Während die Dynamik und Finalität des Integrationsprozesses, die im Ziel der „immer engeren Union“ angesprochen ist, allerdings in den Präambeln der europäischen Verträge ,(staats-)volks"-bezogen definiert und ausgerichtet ist, ${ }^{96}$ ist das Verständnis von Dynamik und Finalität im deutsch-französischen Vertragsverhältnis bürger- und gesellschaftsbezogen. Damit wird der „citoyen“ zum Gegenstand des gemeinsamen deutsch-französischen Integrationskonzeptes - der Bürger, der politische Partizipation beansprucht, und der dafür die ihm von der deutschen wie der französischen Verfassung gewährten politischen Freiheitsrechte ausschöpft. Der Bürger nimmt Integration nicht mehr bloß als von der Staatsmacht gesteuerten politischen Prozess wahr, sondern ist - insbesondere auch mittels grenzüberschreitenden Engagements - aufgerufen, Integrationsprogramm und -tempo mitzubestimmen. Gleiches gilt für die mitgliedstaatlichen Gesellschaften, innerhalb derer sich Bürger an der öffentlichen Willensbildung teilnehmend zusammenfinden. In dieser Anknüpfung der Präambel kommt im Blick auf die Finalität der Integration zweierlei zum Ausdruck: zum einen eine Betonung des Subsidiaritätsprinzips durch die Adressierung nichtstaatlicher Kräfte, zum anderen aber auch ein Modell für eine Fortentwicklung der Integrationsperspektive der EU jenseits der Anmutung, es handele sich um ein rein von staatlicher Seite getragenes Elitenprojekt.

Nach dem dritten Absatz der Präambel des Vertrages von Aachen handeln die Vertragsstaaten in der Überzeugung, dass die enge Freundschaft zwischen Deutschland und Frankreich für eine geeinte, leistungsfähige, souveräne und starke Europäische Union entscheidend gewesen ist und ein unverzichtbares Element bleibt. Dieses selbstbewusste Bekenntnis zur Rolle Deutschlands und Frankeichs als Motoren der europäischen Integration dürfte integrationsgeschichtlich nur schwer in Frage zu stellen sein. ${ }^{97}$ Bemerkenswerter als das zeitgeschichtliche Eigenlob in der Präambel ist juristisch die Einordnung der Europäischen Union als „souverän“. Diese Einordnung knüpft an die erwähnte Sorbonne-Rede von Präsident Macron an. Damit mag die Einordnung einen europapolitischen Ausgangspunkt haben, wobei der Souveränitätsbegriff in dieser Rede weniger in Bezug auf den Charakter als in Bezug auf die

96 Vgl. z.B. Kirchhof, Die rechtliche Struktur der Europäischen Union als Staatenverbund, in: von Bogdandy (Hrsg.), Europäisches Verfassungsrecht: Theoretische und dogmatische Grundzüge, 2003, S. $893 \mathrm{f}$.

97 Der Vertrag von Maastricht als erster Vertrag über die Europäische Union ist nach bislang vorliegenden zeitgeschichtlichen Untersuchungen ebenso durch das Gespann Kobl/Mitterand vorangetrieben worden wie der Vertrag von Lissabon durch deutsch-französische Abstimmungsrunden. Vgl. z.B. Schild, Pariser Pragmatismus - Französische EU-Vertragsreformpolitik von Amsterdam bis Lissabon, in: Leiße (Hrsg.), Die Europäische Union nach dem Vertrag von Lissabon, 2010, S. 23 ff.; Woyke, Deutsch-französische Beziehungen seit der Wiedervereinigung, 2. Aufl. 2004. 
Fähigkeiten Europas Verwendung fand. ${ }^{98}$ Indessen handelt es sich bei dem Vertrag nicht nur um ein Instrument politischer Steuerung, sondern auch um ein solches rechtlicher Vorgaben, was auch dem „Souveränitäts“-Begriff des Vertrags, der in Bezug auf die EU deutlich wesens-, nicht zielorientiert genutzt wird, im Ansatz rechtliche Relevanz zukommen lässt. Dies wiederum mündet in rechtliche Probleme: Denn der traditionelle völker- und staatsrechtliche Begriff der „Souveränität“ wird als umfassende Herrschaftsgewalt im Außen- und Innenverhältnis verstanden. ${ }^{99}$ Eine solche „Souveränität“ fehlt der EU indessen nach dem ausdrücklich in Art. 5 Abs. 1 Satz 1 EUV verankerten „Grundsatz der begrenzten Einzelermächtigung“. Insofern stellt sich die Einordnung der EU als „souverän“ bestenfalls als politische Leerformel dar, zumal auch in der Integrationsperspektive nach der Judikatur des BVerfG ein Weg zu einer rechtlich souveränen EU mit dem Integrationsprogramm des Grundgesetzes nicht in Deckung steht: Souverän bleiben nach der in seiner Lissabon-Entscheidung fixierten Integrationskonzeption aus Sicht des BVerfG die Mitgliedstaaten der EU und wird nicht diese selbst. ${ }^{100}$ Die Einordnung der EU als „souverän“ ist daher geeignet, Desinformation in Bezug auf den Vertrag von Aachen als Instrument des Völkerrechts zu befördern.

Im vierten Absatz der Präambel des Vertrages von Aachen wird erstmals auch das Verhältnis der deutsch-französischen Integrationszielsetzung zum Integrationsziel der EU angesprochen: Danach soll nicht nur die deutsch-französische Zusammenarbeit in der Europapolitik mit dem Ziel verstärkt werden, „die Einheit, die Leistungsfähigkeit und den Zusammenhalt Europas zu fördern“, diese Zusammenarbeit soll „Zugleich allen Mitgliedstaaten der Europäischen Union offen [ge]halten [werden]“. Dies geht über den Absatz 2 der Schlussbestimmungen des Élysée-Vertrages deutlich hinaus, der lediglich vorsieht, dass die Regierungen der beiden Vertragsstaaten „die Regierungen der übrigen Mitgliedstaaten der Europäischen Gemeinschaft über die

98 „Europa allein kann, mit einem Wort, eine echte Souveränität gewährleisten, d.h. unsere Fähigkeit, in der heutigen Welt zu existieren, um unsere Werte und Interessen zu verteidigen. Es gibt eine europäische Souveränität, die aufgebaut werden muss, und es besteht die Notwendigkeit, diese aufzubauen.".

99 Vgl. z.B. Combacau/Sur, Droit international public, 12. Aufl. 2016, S. 236 f.; Dupuy/Kerbrat, Droit international public, 14. Aufl. 2018, Rn. 32 ff.; Shaw, International Law, 8. Aufl. 2017, S. 166 f., 379 ff.; Verdross/Simma, Universelles Völkerrecht, 3. Aufl. 1984, S. 25 ff.; von Bogdandy/Schill, Die Achtung der nationalen Identität unter dem reformierten Unionsvertrag, ZaöRV 2010/70, S. 701, 709.

100 „Die vom Demokratieprinzip im geltenden Verfassungssystem geforderte Wahrung der Souveränität im vom Grundgesetz angeordneten integrationsoffenen und völkerrechtsfreundlichen Sinne bedeutet für sich genommen nicht, dass eine von vornherein bestimmbare Summe oder bestimmte Arten von Hoheitsrechten in der Hand des Staates bleiben müssten. Die von Art. 23 Abs. 1 Satz 1 GG erlaubte Mitwirkung Deutschlands an der Entwicklung der Europäischen Union umfasst ... auch eine politische Union ... (als) die gemeinsame Ausübung von öffentlicher Gewalt, einschließlich der gesetzgebenden, bis hinein in die herkömmlichen Kernbereiche des staatlichen Kompetenzraums. ... Die europäische Vereinigung auf der Grundlage einer Vertragsunion souveräner Staaten darf allerdings nicht so verwirklicht werden, dass in den Mitgliedstaaten kein ausreichender Raum zur politischen Gestaltung der wirtschaftlichen, kulturellen und sozialen Lebensverhältnisse mehr bleibt“; BVerfGE 123, S. 267, 327 f. 
Entwicklung der deutsch-französischen Zusammenarbeit laufend unterrichtet halten“. Eine Beitrittsklausel für die anderen Partner der damaligen EWG fehlt. Während man damals den anderen Partnern nicht das Gefühl geben wollte, unter politischen Druck gesetzt zu werden, ${ }^{101}$ ist die jetzige Öffnungsklausel Ausdruck der Sensibilität gegenüber Befürchtungen vor einer deutsch-französischen Dominanz in der EU Befürchtungen, die durch einen Austritt des Vereinigten Königreichs aus der EU noch gestärkt werden können. Der Öffnungsklausel kann insbesondere bei einer Reaktivierung des sog. Weimarer Dreiecks mit Polen Bedeutung zukommen.

Mit dem 5. Absatz der Präambel des Vertrags von Aachen werden die Grundsätze, ${ }^{102}$ (Grund-) Rechte, ${ }^{103}$ (Grund-) Freiheiten des Binnenmarktes ${ }^{104}$ sowie des Raums der Freiheit, der Sicherheit und des Rechts ${ }^{105}$ und die Werte ${ }^{106}$ der EU in Bezug genommen. Durch sie soll nach der Konzeption der Vertragsparteien die Rechtsstaatlichkeit nicht nur in der gesamten EU gewahrt, sondern auch über sie hinaus gefördert werden. Die herausgehobene Rolle, die die Vertragsparteien damit der Rechtsstaatlichkeit beimessen, dürfte nicht zuletzt auch den dieses Prinzip gefährdenden Entwicklungen in einzelnen Mitgliedstaaten der EU wie Polen, Ungarn ${ }^{107}$ und Rumänien geschuldet sein. Die Förder-Perspektive für Rechtsstaatlichkeit jenseits der EU, die z.B. an Rechtsstaats-Dialoge Deutschlands mit China ${ }^{108}$ und Vietnam ${ }^{109}$ anknüpft, unterstreicht die auch für das auswärtige Handeln der EU bestehende Bedeutung der Werteordnung der EU. ${ }^{110}$

Im 7. bis 9. Absatz der Präambel wird das gemeinsame Bekenntnis Deutschlands und Frankreichs zu Regelwerken und Regulierungskonzeptionen betont, die die doppelte Nachkriegszeit nach dem Ende des Zweiten Weltkrieges 1945 und des Kalten Krieges 1989/1990 geprägt haben. Diesem Bekenntnis kommt besondere Bedeutung in einem Moment zu, in dem diese rechtliche Ordnungsstruktur (auch) von und in Staaten, die bislang der westlichen Wertegemeinschaft zugerechnet wurden, in Frage gestellt wird. Ein „offene(r), faire(r) und regelbasierte(r) Weltmarkt, dessen Zugang auf Gegenseitigkeit und Nichtdiskriminierung beruht und für den hohe Umwelt- und Sozialstandards gelten", 111 ist in Zeiten des "America first" ebenso unter Rechtferti-

101 Vgl. Klein, Der Élysée-Vertrag vom 22. Januar 1963, S. 254.

102 Vgl. Art. 1 - 17 EUV, Art. 1 - 17 AEUV.

103 Vgl. Art. 6 EUV i.V.m. der Charta der Grundrechte der EU und der EMRK.

104 Vgl. Art. 26 - 66 AEUV.

105 Vgl. Art. 67 AEUV.

106 Vgl. Art. 2 EUV.

107 Vgl. hierzu z.B. Ukrow, Jenseits der Grenze - Rechtspopulismus in Polen und Ungarn, vorgänge Nr. 2018/224, S. 57, $60 \mathrm{ff}$.

108 Vgl. https://www.bmjv.de/DE/Themen/EuropaUndInternationaleZusammenarbeit/De utschChinesischerRechtsstaatsdialog/DeutschChinesischerRechtsstaatsdialog_node.html (05.03.2019).

109 Vgl. https://www.bmjv.de/DE/Themen/EuropaUndInternationaleZusammenarbeit/De utschVietnamesischerRechtsstaatdialog/DeutschVietnamesischerRechtsstaatdialog_node .html (05.03.2019).

110 Vgl. hierzu z.B. Damm, Die Europäische Union im universellen Völkergewohnheitsrecht, 2016, S. 51; Frenz, Handbuch Europarecht. Band 6: Institutionen und Politiken, 2011, Rn. $4984 \mathrm{ff}$.

111 7. Absatz der Präambel des Vertrages von Aachen. 
gungsdruck geraten wie eine „internationale, regelbasierte und auf Multilateralismus gründende Ordnung, in deren Zentrum die Vereinten Nationen stehen “. ${ }^{112}$ Mit diesen Bekenntnissen steuern die Vertragsparteien nicht zuletzt über die erstmalige gemeinsame Verankerung des „Multilateralismus“ als Regulierungsmethode in ihrem vertraglichen Beziehungsgeflecht auf eine Rolle als gemeinsame Schutzmacht gegen unilaterale Auflösungen von Regelnetzwerken $\mathrm{zu}$ und unterstreichen zugleich die Einbettung ihrer bilateralen Zusammenarbeits- und Integrationsbemühungen in einen mit dritten Staaten entwickelten Ordnungsrahmen.

\section{Die wirtschafts-, sozial- und steuerpolitische Kohärenz-Konzeption des Vertrages von Aachen}

Bemerkenswert ist die Öffnung der spezifischen Konvergenzperspektive im Vertrag von Aachen im Vergleich zu derjenigen der europäischen Verträge: Während die Präambel des EUV, ${ }^{113}$ wie auch der Vertragstext des AEUV - jenseits der allgemeinen Kohärenzverpflichtung nach Art. 7 AEUV ${ }^{114}$ - lediglich die Stärkung und die Konvergenz der mitgliedstaatlichen Volkswirtschaften herbeizuführen politisch und rechtlich fordert, ${ }^{115}$ gibt die Präambel des Vertrags von Aachen das (politische, aber auch rechtlich bedeutsame) Ziel vor, die Konvergenz der Volkswirtschaften und der Sozialmodelle der Vertragsparteien zu erhöhen. Damit greift der Vertrag eine Parallelität wirtschafts- und sozialpolitischer und -rechtlicher Integrationsschritte auf, wie sie im Zusammenhang mit der vertraglichen Entwicklung zur deutschen Wiedervereinigung aus dem Ansatz des Vertrags zur Schaffung einer Wirtschafts-, Währungsund Sozialunion ${ }^{116}$ vertraut ist. Bereits an dieser Stelle der Präambel wird das Bemühen erkennbar, Vorwürfen zu begegnen, die bisherige Integrationsverdichtung leide unter einer sozialen Schieflage.

Diese strategische Überlegung wird im 6. Absatz der Präambel konkretisiert und ergänzt: danach sind die Vertragsparteien bestrebt, „auf eine soziale und wirtschaftliche Aufwärtskonvergenz in der Europäischen Union hinzuarbeiten, die gegenseitige

112 8. Absatz der Präambel des Vertrages von Aachen.

113 8. Absatz der Präambel des EUV.

114 Danach achtet die EU „auf die Kohärenz zwischen ihrer Politik und ihren Maßnahmen in den verschiedenen Bereichen und trägt dabei unter Einhaltung des Grundsatzes der begrenzten Einzelermächtigung ihren Zielen in ihrer Gesamtheit Rechnung“.

115 Die außen- und sicherheitspolitische Konvergenzperspektive des Art. 24 Abs. 2 EUV („Die Union verfolgt, bestimmt und verwirklicht im Rahmen der Grundsätze und Ziele ihres auswärtigen Handelns eine Gemeinsame Außen- und Sicherheitspolitik, die auf einer Entwicklung der gegenseitigen politischen Solidarität der Mitgliedstaaten, der Ermittlung der Fragen von allgemeiner Bedeutung und der Erreichung einer immer stärkeren Konvergenz des Handelns der Mitgliedstaaten beruht", Hervorhebung d. Verf.), die im Protokoll Nr. 10 zum EUV über die ständige strukturierte Zusammenarbeit nach Art. 42 EUV aufgegriffen wird, kann an dieser Stelle unberücksichtigt bleiben.

116 Gesetz zu dem Vertrag vom 18. Mai 1990 über die Schaffung einer Währungs-, Wirtschafts- und Sozialunion zwischen der Bundesrepublik Deutschland und der Deutschen Demokratischen Republik v. 25.6.1990, BGBl. 1990 II S. 518 ff.; vgl. hierzu Grosser, Das Wagnis der Währungs-, Wirtschafts- und Sozialunion, 1998. 
Solidarität zu stärken und im Einklang mit den Grundsätzen der europäischen Säule sozialer Rechte auf eine fortwährende Verbesserung der Lebens- und Arbeitsbedingungen hinzuwirken, wobei ein besonderes Augenmerk auf die Stärkung und Selbstbestimmung von Frauen sowie die Gleichstellung der Geschlechter gerichtet wird“. Während der Begriff der „Aufwärtskonvergenz" bisher selbst in unverbindlichen Rechtsakten der EU nicht vorkommt, sondern einer Pressemitteilung der Europäischen Kommission ${ }^{117}$ im Zusammenhang mit dem Vorschlag einer europäischen Säule sozialer Rechte ${ }^{118}$ entstammt, mithin durch den Vertrag von Aachen erstmals zum Rechtsbegriff wird, handelt es sich bei den frauenrechtlichen Ausführungen des Absatzes um „acquis communautaire“, wobei die Vorreiterrolle der EU bei der Bekämpfung der Diskriminierung von Frauen ${ }^{119}$ zu den Leuchttürmen europäischer Integrationsgeschichte zählt, deren Licht allzu oft in den Schatten fehlender offensiver Hinweise auf sozialpolitische Erfolge der EU gestellt wird.

In Artikel 1 Satz 3 des Vertrages erfährt diese Erweiterung des Kohärenz-Zusammenhangs eine zusätzliche Profilierung: Danach bemühen sich die Vertragsstaaten um die Vollendung des Binnenmarkts, wirken auf eine wettbewerbsfähige, sich auf eine starke industrielle Basis stützende Union als Grundlage für Wohlstand hin und „fördern so die wirtschaftliche, steuerliche und soziale Konvergenz" sowie die Nachhaltigkeit in allen ihren Dimensionen. Mit dieser auf die EU ausgerichteten Einbeziehung steuerrechtlicher Fragen in die wirtschafts- und sozialpolitische und-rechtliche Kohärenzprogrammatik stärken Deutschland und Frankreich die bislang nur bedingt erfolgreichen Bemühungen um eine steuerrechtliche Harmonisierung als Bestandteil des europäischen Integrationsprozesses. Gerade im Blick auf neue steuerrechtliche Herausforderungen durch die Digitalisierung wie die Einführung einer Finanzmarkttransaktionsteuer ${ }^{120}$ oder die Einführung einer sog. Digitalsteuer ${ }^{121}$ kommt ggf. zwischen beiden Vertragsstaaten abgestimmten Schritten einer verstärkten steuerrechtlichen Zusammenarbeit in einem nicht sämtliche Mitgliedstaaten der EU umfassenden Rahmen besondere Bedeutung zu.

Ergänzt wird dieser Ansatz allerdings nur in Bezug auf die wirtschaftliche Kohärenz durch Art. 20 Abs. 1 Satz 1 des Vertrages. Danach vertiefen beide Staaten die Integration ihrer Volkswirtschaften hin zu einem „deutsch-französischen Wirtschaftsraum mit gemeinsamen Regeln“. Die historische Erfahrung zeigt einen engen

117 http://europa.eu/rapid/press-release_IP-17-1007_de.htm (05.03.2019).

118 Die feierlich von Kommission, Parlament und Rat am 17. November 2017 proklamierte „Europäische Säule sozialer Rechte“ ist abrufbar unter: https://ec.europa.eu/commission/ sites/beta-political/files/social-summit-european-pillar-social-rights-booklet_de.pdf (05.03.2019).

119 Vgl. hierzu z.B. Langenfeld, Die Gleichbehandlung von Mann und Frau im Europäischen Gemeinschaftsrecht, 1989.

120 Ziffer 14 der Deutsch-Französischen Agenda verweist insoweit auf die Zusammenarbeit im Bereich der Finanzdienstleistungen und Finanzmärkte auf EU-Ebene, mit dem Ziel, „sich gemeinsam für hohe Regulierungsstandards, auch für den Bereich nachhaltiges Finanzwesen," einzusetzen.

121 Vgl. hierzu Ukrow, Österreich und Spanien wollen Digitalsteuer einführen, MMR-Aktuell 2019/02. 
Zusammenhang zwischen der Bildung integrierter Wirtschaftsräume und der Vereinheitlichung von Marktregeln. ${ }^{122}$ Vor diesem Hintergrund kann es nicht überraschen, dass aktuell auf zivilgesellschaftlich-rechtswissenschaftlicher Basis Überlegungen für ein deutsch-französisches Wirtschaftsgesetzbuch existieren, ${ }^{123}$ an die - auch aufbauend auf die Sorbonne-Rede von Staatspräsident Macron $^{124}$ - die vertragliche Verpflichtung zur Entwicklung eines deutsch-französischen Wirtschaftsraums mit gemeinsamen Regeln anknüpfen kann. ${ }^{125}$ Eine vergleichbare Regelung für einen Sozialraum ist im Vertrag allerdings nicht vorhanden; das Thema „Beschäftigung“ wird - ungeachtet von Regelungsvorbildern wie Art. 9 und Art. 145 ff. AEUV - nicht adressiert. ${ }^{126}$

Beide Staaten verstärken zudem nach Art. 21 des Vertrages ihre Zusammenarbeit im Bereich der Forschung und des „digitalen Wandels“, einschließlich der Themen Künstliche Intelligenz ${ }^{127}$ und Sprunginnovationen. ${ }^{128}$ Sie werden sich für ethische Leitlinien für neue Technologien auf internationaler Ebene einsetzen. ${ }^{129}$ Sie rufen deutsch-französische Initiativen zur Förderung von Innovationen ins Leben, die offen für eine Zusammenarbeit auf europäischer Ebene sind. Beide Staaten werden einen Koordinationsprozess und eine gemeinsame Finanzierung einrichten, um gemeinsame

122 Vgl. aus handelsrechtlicher Perspektive Magnus, Die Gestalt eines Europäischen Handelsgesetzbuches in: Basedow u.a. (Hrsg.), Festschrift für Ulrich Drobnig, 1998, S. 57, 61; Lebmann, Braucht Europa ein Handelsgesetzbuch?, ZHR 2017/181, S. 9, 15 ff.

123 Vgl. hierzu Lehmann, Das Europäische Wirtschaftsgesetzbuch - Eine Projektskizze, GPR 2017/14, S. $261 \mathrm{ff}$.

124 „Pourquoi ne pas se donner d'ici à 2024 l'objectif d'intégrer totalement nos marchés en appliquant les mêmes règles à nos entreprises, du droit des affaires au droit des faillites?".

125 Die Europäische Kommission hat ein solches gemeinsames Wirtschaftsgesetzbuch als eine Option in ihr Weißbuch zur Zukunft Europas (KOM(2017) 2025, S. 21) aufgenommen.

126 Auch die Deutsch-Französische Agenda ist in ihrem sozialen Teil wenig ambitioniert: Ziffer 13 sieht lediglich die Einrichtung einer Sachverständigengruppe im Bereich Soziales, einschließlich der Tarifpartner, zum Thema „Zukunft der Arbeit" vor.

127 Ziffer 10 der Deutsch-Französischen Agenda sieht insoweit die Einrichtung eines deutschfranzösischen Forschungs- und Innovationsnetzwerks („virtuelles Zentrum“) für Künstliche Intelligenz auf Basis der bestehenden Strukturen beider Länder vor.

128 Sprunginnovationen sind solche Innovationen, die eine radikale technologische Neuerung beinhalten. Sie haben das Potenzial, bislang bekannte Techniken und Dienstleistungen bahnbrechend zu verändern und zu ersetzen. Vgl. zur Förderung solcher Innovationen im nationalen Rahmen https://www.bundesregierung.de/breg-de/aktuelles/sprunginnovati onen-foerdern-1527000 (05.03.2019).

129 Ziffer 12 der Deutsch-Französischen Agenda verweist insoweit auf den Einsatz für ethische Leitlinien für neue Technologien und gemeinsame Werte in den Bereichen Digitalisierung und Digitale Gesellschaft auf internationaler Ebene. 
Forschungs- und Innovationsprogramme zu fördern. ${ }^{130}$ Dieser Ansatz unterstreicht die Offenheit auch Deutschlands für eine aktive Industriepolitik im Ergebnis des Vertrags von Aachen. ${ }^{131}$ Nationale Industriestrategien fügen sich in einen solchen Ansatz ein. ${ }^{132}$ In deren Ergebnis bedarf es allerdings ggf. der Anpassung wettbewerbsrechtlicher Vorgaben der EU zur Vermeidung von Rechtsverstößen.

\section{E. Die deutsch-französische Zusammenarbeit und die immer engere Union}

\section{Einführung}

Das gute Verständnis und die enge Abstimmung zwischen Deutschland und Frankreich irritieren andere EU-Mitgliedstaaten manchmal, sagte EU-Kommissionspräsident Jean-Claude Juncker bei der Unterzeichnung des Vertrags von Aachen. Aber diese Irritation werde zu echtem Schmerz, wenn Frankreich und Deutschland mal nicht im Einvernehmen seien. „Ohne die deutsch-französische Freundschaft kriegen wir das nicht hin, was unser Auftrag, auch der Auftrag der Geschichte, ist: nämlich Europa in Frieden und Freiheit zusammenzuführen", betonte Juncker. Die Freundschaft zwischen den beiden großen Nachbarländern im Zentrum Europas sei eine „Notwendigkeit“. Unter Streit und Krieg zwischen Deutschen und Franzosen hätten die Nachbarn, besonders die kleinen Länder, oft sehr gelitten. Die Aussicht, dass dies nie mehr passieren wird, gebe Europa die Ruhe, die der Kontinent brauche, um zu gedeihen. „Und so ist die deutsch-französische Freundschaft der Garant für eine friedliche Zukunft in Europa - wenn Deutsche und Franzosen ihre Freundschaft, und das tun sie, mit anderen teilen", sagte Juncker. ${ }^{133}$

Jenseits und unabhängig von dieser politischen Einordnung stellen sich Rechtsfragen, die der EU-Kommissionspräsident verklausuliert anspricht.

130 Die Deutsch-französische Agenda nimmt hier insbesondere den Raumfahrtsektor in den Blick. Nach Ziffer 11 der Agenda stehen bei der Zusammenarbeit in diesem Sektor drei zentrale Felder im Mittelpunkt: die Förderung einer gemeinsamen Strategie für ein innovativeres Europa im Bereich neue Weltraumwirtschaft, die Zusammenarbeit zur Erhöhung der Wettbewerbsfähigkeit der Weltraumindustrie, insbesondere durch optimale industrielle Rahmenbedingungen sowie die Konsolidierung des unabhängigen europäischen $\mathrm{Zu}$ gangs zum Weltraum durch Investitionen in Forschung und Entwicklung, Rationalisierungen in der Industrie und Vorrang für europäische Trägerraketen.

Mit Blick auf die Offenheit der deutsch-französischen Zusammenarbeit für dritte EUMitgliedstaaten verdient z.B. das weltraumwirtschaftliche Engagement Luxemburgs, zuletzt durch die Gründung einer eigenen Weltraumagentur, https://space-agency.public.l $\mathrm{u} / \mathrm{en} . \mathrm{html}$ (05.03.2019), besondere Beachtung.

$131 \mathrm{Vgl}$. das „Deutsch-französische Manifest für eine europäische Industriepolitik“ v. 19.02.2019, abrufbar unter: https://www.bmwi.de/Redaktion/DE/Downloads/F/franc o-german-manifesto-for-a-european-industrial-policy.pdf?_blob=publicationFile\&v $=2$ (05.03.2019).

132 Vgl. Altmaier, Nationale Industriestrategie 2030. Strategische Leitlinien für eine deutsche und europäische Industriepolitik, 5. Februar 2019, https://www.bmwi.de/Redaktion/D E/Downloads/M-O/nationale-industriestrategie.pdf?__blob=publicationFile\&v=22 (05.03.2019).

133 Vgl. EU-NACHRICHTEN Nr. 02/2019, S. 3. 


\section{Verstärkte Zusammenarbeit als Chance und Risiko für das Gelingen einer immer engeren Union}

(Auch) die bilaterale verstärkte deutsch-französische Zusammenarbeit ist Ausdruck von fortdauernden, über Art. 20 EUV primärunionsrechtlich gesteuerten Bemühungen, den Spagat zwischen Erweiterung und Vertiefung des europäischen Integrationsprozesses zu meistern, die unter den Mitgliedstaaten bestehende Heterogenität von Interessen, Kapazitäten und Vorprägungen politischen Handelns zu überbrücken und der wachsenden Komplexität der Regelungsanforderungen in einem durch Prozesse der Digitalisierung und Globalisierung wesentlich geprägten gesellschaftlichen, ökonomischen und ökologischen Umfeld zu entsprechen. ${ }^{134}$ Jedwede verstärkte Zusammenarbeit zwischen einzelnen Mitgliedstaaten der EU bewegt sich im Spannungsfeld von Grenzen der Integrationsfähigkeit der einzelnen Mitgliedstaaten einerseits, Zerbrechlichkeit des Integrationsgefüges andererseits. ${ }^{135}$

Die durch den Vertrag von Aachen um eine Integrationsperspektive erweiterte deutsch-französische Zusammenarbeit auf der Grundlage des Élysée-Vertrags kann als ein weiteres Element in der europäischen Vertragsarchitektur angesehen werden, die zunehmend weniger durch einen festen unitarisierenden Block allgemein für die Gesamtheit der EU-Mitgliedstaten geltender Regelungen als durch ein komplexes Nebeneinander und Aufeinanderwirken völkerrechtlicher wie supranationaler Integrationsmechanismen und -methoden gekennzeichnet ist. ${ }^{136}$

Jedwede Form verstärkter Zusammenarbeit zwischen einzelnen Mitgliedstaaten der EU, sei es eine solche auf der Grundlage des Art. 20 EUV, sei es eine solche im autonom bestimmten Terrain, weist ein natürliches Spannungsverhältnis zum Einheitsund Solidaritätsgedanken auf, der die in den Präambeln des EUV ${ }^{137}$ und des AEUV $^{138}$ verankerte Programmatik der EU ebenso prägt wie deren Werte ${ }^{139}$ und

$134 \mathrm{Vgl}$. zum Ausgangspunkt der Bestrebungen um eine verstärkte Zusammenarbeit bereits Martenczuk, Die differenzierte Integration nach dem Vertrag von Amsterdam, ZEuS 1998, S. $447,448 \mathrm{f}$

135 Vgl. Blanke, in: Grabitz/Hilf/Nettesheim (Hrsg.), Das Recht der Europäischen Union, Stand 2019, Art. 20 EUV Rn. 1.

136 Vgl. Blanke, in: Grabitz/Hilf/Nettesheim (Hrsg.), Das Recht der Europäischen Union, Stand 2019, Art. 20 EUV Rn. 4; Pechstein, in: Streinz (Hrsg.), EUV/AEUV, 3. Aufl. 2018, Art. 20 EUV Rn. 6.

137 Vgl. den 3. Absatz („eingedenk der historischen Bedeutung der Überwindung der Teilung des europäischen Kontinents“), den 6. Absatz (,in dem Wunsch, die Solidarität zwischen ihren Völkern ... zu stärken“), den 7. Absatz („einheitlichen institutionellen Rahmen“), den 8. Absatz („eine einheitliche, stabile Währung“), den 9. Absatz („Stärkung des Zusammenhalts") der Präambel des EUV.

138 Vgl. den 2. Absatz („entschlossen, durch gemeinsames Handeln den wirtschaftlichen und sozialen Fortschritt ihrer Staaten zu sichern“), 4. Absatz (,in der Erkenntnis, dass zur Beseitigung der bestehenden Hindernisse ein einverständliches Vorgehen erforderlich ist“") und 5. Absatz („in dem Bestreben, ihre Volkswirtschaften zu einigen“) der Präambel des AEUV.

139 Vgl. zum Wert der Solidarität Art. 2 EUV. 
Aufgaben. ${ }^{140}$ Allerdings ist die Einheit der EU als Union des Rechts kein Ziel an sich, sondern hat dienende Funktion als Mittel zur Erreichung der Integration. ${ }^{141}$ Soweit eine geographisch begrenzte verstärkte Zusammenarbeit in einer Gesamtschau der erweiterungs- und vertiefungsbezogenen Dimensionen einer immer engeren Union integrationsfördernd wirkt, besteht daher keine unionsrechtliche Pflicht, sie als unionsrechtswidrige Ausnahme zum Grundsatz der Rechtseinheit zu bewerten. ${ }^{142}$

Aus der primärunionsrechtlichen Verankerung von Voraussetzungen und Mechanismen einer verstärkten Zusammenarbeit folgt nicht, dass im Anwendungsbereich der europäischen Verträge andere Formen einer verstärkten Zusammenarbeit, zu denen auch die durch den Vertrag von Aachen erweiterte deutsch-französische Zusammenarbeit zählt, verboten sind. ${ }^{143}$ Gegen ein solches Verbot sprechen insbesondere semantische und teleologische Erwägungen. Art. 20 Abs. 1 EUV begründet nach seinem klaren Wortlaut ein Recht („kann“), keine Pflicht zur Inanspruchnahme des EUvertraglichen Regelungsregimes verstärkter Zusammenarbeit unter Einbindung von EU-Organen. ${ }^{144}$ Auch als Herren der Verträge verfügen die Mitgliedstaaten zudem über die Befugnis, sich anderer, vertraglich nicht vorgesehener Mittel regional differenzierter Integration zu bedienen. ${ }^{145}$

Allerdings haben die Mitgliedstaaten in einem solchen Fall regional differenzierter Integration außerhalb des Rahmens der europäischen Verträge das Prinzip der Unionstreue $^{146}$ zu beachten. Dieses gebietet u.a., auch in einer solchen völkervertraglichen

140 Vgl. zur Förderung des „wirtschaftlichen, sozialen und territorialen Zusammenhalts... zwischen den Mitgliedstaaten" Art. 3 Abs. 3 UAbs. 3 EUV.

141 Vgl. Bender, Die Verstärkte Zusammenarbeit nach Nizza. Anwendungsfelder und Bewertung im Spiegel historischer Präzedenzfälle der differenzierten Integration, ZaöRV 2001/61, S. 730, $735 \mathrm{f}$

142 Vgl. Blanke, in: Grabitz/Hilf/Nettesheim (Hrsg.), Das Recht der Europäischen Union, Stand 2019, Art. 20 EUV, Rn. 5.

143 So aber Constantinesco, Les clauses de coopération renforcée, RTDE 1997/33, S. 751, 755; Martenczuk, Die differenzierte Integration nach dem Vertrag von Amsterdam, ZEuS 1998, S. 447, 464; wie hier Hetje, in: Schwarze (Hrsg.), EU-Kommentar, 4. Aufl. 2019, Art. 20 EUV, Rn. 36; Ruffert, in: Calliess/Ruffert (Hrsg.), EUV/AEUV, 5. Aufl. 2016, Art. 20 EUV, Rn. 22; von Buttlar, Rechtsprobleme der verstärkten Zusammenarbeit nach dem Vertrag von Nizza, ZEuS 2001/4, S. 649, $659 \mathrm{ff}$.

144 Vgl. Bender, Die Verstärkte Zusammenarbeit nach Nizza. Anwendungsfelder und Bewertung im Spiegel historischer Präzedenzfälle der differenzierten Integration, ZaöRV 2001/61, S. 730, 765; Blanke, in: Grabitz/Hilf/Nettesheim (Hrsg.), Das Recht der Europäischen Union, Stand 2019, Art. 20 EUV, Rn. 28.

145 Vgl. Ehlermann, Engere Zusammenarbeit nach dem Amsterdamer Vertrag: Ein neues Verfassungsprinzip?, EuR 1997, S. 362, 372; Hofmann, Wieviel Flexibilität für welches Europa?- Gedanken zur zukünftigen Entwicklung der europäischen Integration, EuR 1999, S. 713, 727 f.; von Arnauld, „Unions(ergänzungs)völkerrecht“. Zur unions- und verfassungsrechtlichen Einbindung völkerrechtlicher Instrumente differenzierter Integration, in: Breuer u.a. (Hrsg.), Der Staat im Recht. Festschrift für Eckart Klein, 2013, S. 509, 514.

146 Vgl. hierzu z.B. Schliesky, Souveränität und Legitimität von Herrschaftsgewalt, 2004, S. 551 ff.; Unruh, Die Unionstreue: Anmerkungen zu einem Rechtsgrundsatz der Europäischen Union, EuR 2002, S. $41 \mathrm{ff}$. 
Konstellation die supranationalen Normen sowie die Ziele der EU nicht zu verletzen. ${ }^{147}$

Dem trägt der Vertrag von Aachen Rechnung:

- Die Zusammenarbeitsthemen sind so offen formuliert, dass eine Kollision mit in Art. 20 Abs. 1 UA 1 EUV in Bezug genommenen Feldern der ausschließlichen Zuständigkeiten der EU nach Art. 3 Abs. 1 AEUV nicht vorprogrammiert ist: Aus dem Vertrag von Aachen folgt keine völkerrechtliche Verpflichtung, bilaterale Regelungen zu erlassen, die die rechtsetzenden und rechtsprechenden Zuständigkeiten der EU in Bezug auf die Zollunion, die Wettbewerbsregeln, die gemeinsame Fischereipolitik, die gemeinsame Handelspolitik und die Währungspolitik antasten. Die auch in diesen Feldern bestehenden Koordinierungserfordernisse bei der Schaffung und ggf. Umsetzung von EU-Recht lassen die Zuständigkeit der EU gerade unberührt.

- Auch die deutsch-französische Zusammenarbeit ist nach dem klaren Wortlaut einer Vielzahl von Regelungen des Vertrages von Aachen i.S. des Art. 20 Abs. 1 UA 2 EUV darauf ausgerichtet, die Verwirklichung der Ziele der Union zu fördern, ihre Interessen zu schützen und ihren Integrationsprozess zu stärken.

Dies erschließt sich insbesondere auch bei einem Vergleich der europapolitischen Grundnorm des Art. 1 des Vertrags mit Art. 3 EUV: Nach Satz 2 der Vertragsklausel setzen sich beide Vertragsstaaten für eine wirksame und starke Gemeinsame Außenund Sicherheitspolitik ein und stärken und vertiefen die Wirtschafts- und Währungsunion, wobei sich diese Vertiefung allerdings zumindest im Schwerpunkt auf die wirtschaftspolitische Dimension dieses Ziels beziehen dürfte. Die Vertragsstaaten bemühen sich zudem nach Satz 3 um die Vollendung des Binnenmarkts, ${ }^{148}$ wirken auf eine wettbewerbsfähige, sich auf eine starke industrielle Basis stützende Union als Grundlage für Wohlstand hin und fördern so die wirtschaftliche, steuerliche und soziale Konvergenz sowie die Nachhaltigkeit in allen ihren Dimensionen.

- Die deutsch-französische Zusammenarbeit ist schließlich auch nicht als „closed shop" vertraglich strukturiert, vielmehr sind die Vertragsstaaten - dem Prinzip der "offenen Tür"149 nach Art. 20 Abs. 1 UA 1 Satz 2 EUV entsprechend - nach dem 4. Absatz der Präambel des Vertrags von Aachen bestrebt, diese Zusammenarbeit „allen Mitgliedstaten der Europäischen Union offen zu halten“. Es liegt allerdings nicht zuletzt i.S. einer wertegebundenen Öffnung nahe, die deutsch-französische Zusammenarbeit nur solchen Mitgliedstaaten (oder sonstigen Drittstaaten) offen

147 Vgl. Becker, Differenzierungen der Rechtseinheit durch „abgestufte Integration“, EuR 1998, Beiheft 1, S. 29, 43; Blanke, in: Grabitz/Hilf/Nettesheim (Hrsg.), Das Recht der Europäischen Union, Stand 2019, Art. 20 EUV, Rn. 28; Schawer, Schengen - Maastricht Amsterdam. Auf dem Weg zu einer flexiblen Union, 2000, S. $150 \mathrm{f}$.

148 Hier knüpft der Vertrag auch an die gemeinsame Resolution von Deutschem Bundestag und Assemblée nationale zum 55. Jahrestag des Élysée-Vertrags 2018 an: Dort wurde schon hervorgehoben, dass Deutschland und Frankreich „eine vollständige und rasche Integration ihrer Märkte“ anstreben und „sich gemeinsam für einen vollständig integrierten europäischen Binnenmarkt einsetzen“ (BT-Drs. 19/440, 16.1.2018).

149 Vgl. Blanke, in: Grabitz/Hilf/Nettesheim (Hrsg.), Das Recht der Europäischen Union, Stand 2019, Art. 20 EUV Rn. 42. 
zu halten, die nach ihrem Bekenntnis zu den europäischen Grundwerten, ihrer Wahrung von Menschenrechten und völkerrechtlichem Gewaltverbot, ihrer wirtschaftlichen Leistungsfähigkeit, ihrem rechts- und sozialstaatlichen Besitzstand und ihrer Bereitschaft zur Solidarität nach innen wie nach außen beitrittsfähig und -willig sind. ${ }^{150}$

Ein rechtliches Dogma, Formen der verstärkten Zusammenarbeit nur bei einer Partnerzahl von mindestens neun Mitgliedstaaten ins Werk zu setzen, wie es in Art. 20 Abs. 2 Satz 1 EUV fixiert ist, besteht weder bei vertraglichen noch bei sonstigen Formen der Zusammenarbeit außerhalb des Rahmens dieses Artikels. ${ }^{151}$ Auch Art. 350 AEUV, wonach die Verträge dem Bestehen und der Durchführung der regionalen Zusammenschlüsse zwischen Belgien und Luxemburg ${ }^{152}$ sowie zwischen Belgien, Luxemburg und den Niederlanden ${ }^{153}$ nicht entgegenstehen, soweit die Ziele dieser Zusammenschlüsse durch Anwendung der Verträge nicht erreicht sind, steht weder regionalen Zusammenschlüssen außerhalb dieses Staatenkreises noch lediglich bilateralen Zusammenschlüssen unionsrechtlich entgegen.

\section{Der Vertrag von Aachen, die Rechtsetzung in der EU und die Umsetzung von EU-Recht}

Deutschland und Frankreich halten nach Art. 2 Satz 1 des Vertrages „vor großen europäischen Treffen“ regelmäßig Konsultationen auf allen Ebenen ab und bemühen sich so, gemeinsame Standpunkte herzustellen und gemeinsame Äußerungen der Ministerinnen und Minister herbeizuführen. In Bezug auf die Frage, was ein „großes europäisches Treffen“ ist, kommt den Vertragsstaaten zwar jeweils ein Beurteilungsspielraum zu; allerdings dürften zumindest Sitzungen des Europäischen Rates i.S.d. Art. 235 AEUV hierunter stets fallen. Für eine Einbeziehung auch der Ratssitzungen nach Art. 237 AEUV, namentlich der in Art. 236 AEUV angesprochenen Räte „Allgemeine Angelegenheiten“ und „Auswärtige Angelegenheiten“, spricht das Ziel der Vorbereitung gemeinsamer Äußerungen der Minister.

Ist eine Entscheidung nicht einer monokratisch strukturierten Behörde, sondern einem Kollegialorgan wie dem Europäischen Rat und dem Rat der EU übertragen, so impliziert dies zugleich, dass die Entscheidung durch das Gremium erst nach einem

150 Vgl. hierzu bereits Ukrow, Der Kern eines vereinten Europas. 10-Punkte-Plan für eine deutsch-französische Konföderation, EUROPA aktiv 2016/4, S. 3.

151 Vgl. auch Pechstein, in: Streinz (Hrsg.), EUV/AEUV, 3. Aufl. 2018, Art. 20 EUV, Rn. 13.

152 Vgl. hierzu zuletzt "Protocole portant modification de la Convention coordonnée instituant l'Union économique belgo-luxembourgeoise” v. 18.12.2002, Mém. A - 89 du 17 juin 2004, S. 1514, abrufbar unter: http://data.legilux.public.lu/file/eli-etat-leg-recueildouanes_accises-20181101-fr-pdf.pdf, S. 124 (05.03.2019); dazu z.B. Somers, BelgiumLuxembourg Economic Union (BLEU), in: Wolfrum (ed.), The Max Planck Encyclopedia of Public International Law, 2012/1, S. $869 \mathrm{ff}$.

153 Vgl. hierzu nunmehr „Traité portant révision du Traité instituant l'Union économique Benelux du 3 février 1958“ v. 17. Juni 2008, mit dem nach dessen Art. 1 eine „BeneluxUnion“ gegründet wird, abrufbar unter: http://www.benelux.int/files/3914/0067/7093/tr ait_Benelux_17.6.2008Ondertekend.pdf (05.03.2019). 
Austausch der Argumente als Meinungsbildungsprozess seiner Mitglieder getroffen wird. ${ }^{154}$ Der Meinungsbildungsprozess in einem Kollegialorgan ist bei Entscheidungen nicht allein auf eine Beratung als Austausch der Argumente und Standpunkte, auf eine Bündelung von Sachkunde oder von Sichtweisen ausgelegt. Er zielt vielmehr darüber hinaus notwendig in starkem Maße auf den Versuch der Mitglieder ab, sich gegenseitig zu überzeugen, wie auch auf deren Bereitschaft, eine eigentlich zunächst eingenommene Haltung im Interesse der Mehrheitsfindung nochmals zu überdenken und ggf. auch aufzugeben. ${ }^{155}$ Letzteres wird durch bilaterale Abstimmungs- und Koordinierungspflichten ggf. zwar erschwert. Dies spricht aber nicht gegen deren $\mathrm{Zu}-$ lässigkeit - auch nicht im Lichte der pacta tertiis-Klausel. ${ }^{156}$ Für die Zulässigkeit solcher bilateraler Vorabstimmungen sprechen nicht nur Praktiken auch dritter EUMitgliedstaaten, z.B. im Visegrad-Rahmen, ${ }^{157}$ sondern im Sinne eines a maiore ad minus nicht zuletzt die Regelungen in Art. 235 Abs. 1 UA 1 und Art. 239 AEUV: Danach kann sich jedes Mitglied des Europäischen Rates und des Rates das Stimmrecht höchstens eines anderen Mitglieds übertragen lassen. Wenn eine solche Stimmrechtsübertragung unionsrechtskonform ist, so muss dies erst recht eine vorherige Abstimmung des Abstimmungsverhaltens zwischen zwei Staaten in Vorbereitung von Ratstreffen sein. Denn Stimmrechtsübertragungen ohne Kenntnis des voraussichtlichen Abstimmungsverhaltens des Staatenvertreters, dem die Stimme übertragen wird, lassen sich mit staatlichem Selbstverständnis aus der souveränen Gleichheit der Staaten heraus nicht in Einklang bringen.

Nach Art. 2 Satz 2 des Vertrages stimmen sich die beiden Vertragsstaaten zudem auch bei der Umsetzung von europäischem Recht in ihr nationales Recht ab. Diese Abstimmungspflicht bezieht sich im Schwerpunkt, aber nicht ausschließlich auf die Umsetzung von Richtlinien der EU nach Art. 288 Abs. 3 AEUV: So ist z.B. auch die Umsetzung von Übereinkommen des Europarates in nationales Recht von der Verpflichtung erfasst. Diese Verpflichtung trägt dazu bei, das in Art. 20 Abs. 1 Satz 1 des Vertrages enthaltene Ziel eines deutsch-französischen Wirtschaftsraums mit gemeinsamen Regeln zu erreichen. Eine Ausdehnung von Umsetzungsfristen des EU-Rechts oder sonstiger terminlicher Vorgaben geht mit Art. 2 Satz 2 nicht einher. Allerdings bietet es sich in Auswertung praktischer Erfahrungen mit dieser Vertragsklausel ggf. für die Zukunft an, mit Blick auf den zusätzlichen Koordinierungsaufwand durch diese Verpflichtung Umsetzungsfristen zur Synchronisierung von Pflichten aus dem

154 Vgl. für den nationalen Rechtskreis BVerwG, 7 C 21/92, juris, Rn. 15.

155 Vgl. für letzteres im nationalen Rechtsrahmen jüngst Sächsisches OVG, Az. 5 B 229/18, Rn. 39.

156 Nach Art. 34 WVRK, dessen Inhalt auch gewohnheitsrechtlich gilt, ist es Staaten nicht gestattet, völkerrechtliche Verträge zu schließen, die Verpflichtungen für dritte Staaten beinhalten. Zudem dürfen nach dieser sog.pacta tertiis-Regel die Rechte eines Drittstaates aus einem früheren Vertrag vom Vertragspartner in einem späteren Abkommen mit einem anderen Staat nicht verletzt werden; vgl. hierzu Doehring, Völkerrecht, 1999, 347 ff.; Stein/ von Buttlar, Völkerrecht, 14. Aufl. 2017, Rn. $113 \mathrm{ff}$.

157 Vgl. http://www.visegradgroup.eu/cooperation/guidelines-on-the-future-110412 (05.03.2019). 
EU-Recht und dem deutsch-französischem Völkervertragsrecht moderat zu erweitern.

\section{Der Vertrag von Aachen und das Europa der Bürger}

\section{Fehlende Direktwirkung und Staatshaftungsrelevanz}

Im Unterschied zu einzelnen Regelungen des primären wie des sekundären Unionsrechts ${ }^{158}$ begründet der Vertrag von Aachen an keiner Stelle unmittelbar Einzelpersonen berechtigende bzw. Behörden und Gerichte zu unmittelbarem Agieren befähigende Rechtspositionen. Die Direktwirkung von EU-Recht wie auch das unionsrechtliche Staatshaftungsrecht ${ }^{159}$ haben sich in der Vergangenheit als wichtige Instrumente dezentraler Kontrolle der Einhaltung von Unionsrecht erwiesen. ${ }^{160} \mathrm{Un}$ geachtet des Integrationsziels des Vertrages von Aachen fehlt es an solchen Instrumenten im deutsch-französischen Vertragsverhältnis auch weiterhin. Die Zusammenarbeit zwischen Deutschland und Frankreich als Bürger-Gemeinschaft des Rechts ist damit weiterhin ausbaufähig.

\section{Grundrechtliche Kontrollmöglichkeit über Rechtsprechung des BVerfG zu Integrationsverdichtungen}

Wie das Bundesverfassungsgericht erstmals in seinem Maastricht-Urteil ${ }^{161}$ entwickelt hat, wird das Demokratieprinzip - soweit es um die demokratische Legitimation im Prozess der europäischen Integration geht - durch Art. 38 GG subjektiviert: Jeder wahlberechtigte Staatsbürger hat nach Auffassung des Bundesverfassungsgerichts das Recht, durch Teilnahme an Bundestagswahlen an der Legitimation der Staatsgewalt durch das Volk auf Bundesebene mitzuwirken und auf ihre Ausübung Einfluss zu nehmen. Werde durch Verlagerung von Aufgaben und Befugnissen auf die europäische Ebene die durch die Wahl bewirkte Legitimation von Staatsgewalt und Einflussnahme auf deren Ausübung so entleert, dass das demokratische Prinzip, so wie es Art. 79 Abs. 3 i.V.m. Art. 20 Abs. 1 und 2 GG für unantastbar erklärt, verletzt wird, dann werde damit auch das Grundrecht aus Art. 38 GG verletzt.

Eine parallele Integrationsverdichtung wie diejenige durch die europäischen Verträge ist durch den Vertrag von Aachen selbst noch nicht erfolgt. Eine unmittelbare Verlagerung von Aufgaben und Befugnissen, die bislang nationalstaatlich bestehen

158 Vgl. Klein, Unmittelbare Geltung, Anwendbarkeit und Wirkung von Europäischem Gemeinschaftsrecht, 1988; Wohlfahrt, Veränderungen des Lissabon-Vertrages im Hinblick auf die Doktrin der unmittelbaren Wirkung, ZaöRV 2010/70, S. 523, $524 \mathrm{f}$.

159 Vgl. hierzu z.B. Ukrow, Richterliche Rechtsfortbildung durch den EuGH, 1995, S. 273 ff.

160 Vgl. z.B. Langenfeld, Die dezentrale Kontrolle der Anwendung des Europäischen Gemeinschaftsrechts im innerstaatlichen Rechtsraum, in: Siedentopf (Hrsg.), Europäische Integration und nationalstaatliche Verwaltung - Deutsche Vereinigung und institutionelle Weiterentwicklung der Europäischen Gemeinschaft 1991, S. 173.

161 BVerfGE 89, 155, $171 \mathrm{ff}$. 
oder wahrgenommen werden, auf Einrichtungen des deutsch-französischen Integrationsgefüges ist im Vertrag nicht angelegt. Vor diesem Hintergrund ist der Vertrag von Aachen kein tauglicher Gegenstand eines Verfassungsbeschwerde-Verfahrens. Anderes kann allerdings für Rechtsakte gelten, die in Ausfüllung völkerrechtlicher Impulse des Vertrags von Aachen erlassen werden. Dies gilt ggf. auch für Formen interregionaler Zusammenarbeit auf der Grundlage des Vertrags von Aachen, bei denen Verlagerungen landesbezogener Kompetenzen auf interregionale Organisationseinheiten erfolgen.

\section{Regionale und grenzüberschreitende Zusammenarbeit}

Beide Staaten erkennen in Art. 13 Abs. 1 des Vertrags zunächst an, wie bedeutend die grenzüberschreitende Zusammenarbeit zwischen den Vertragsparteien zur Förderung engerer Beziehungen zwischen den Bürgerinnen und Bürgern sowie zwischen Unternehmen auf beiden Seiten der Grenze ist. ${ }^{162}$ Sie beabsichtigen, in Grenzregionen die Beseitigung von Hindernissen zu erleichtern, um grenzüberschreitende Vorhaben umzusetzen und den Alltag der Menschen, die in Grenzregionen leben, zu erleichtern. $\mathrm{Zu}$ diesem Zweck statten beide Staaten unter Achtung der jeweiligen verfassungsrechtlichen Regeln der beiden Staaten sowie im Rahmen des Rechts der Europäischen Union die Gebietskörperschaften der Grenzregionen sowie grenzüberschreitende Einheiten wie Eurodistrikte nach Art. 13 Abs. 2 des Vertrags mit „angemessenen Kompetenzen, zweckgerichteten Mitteln und beschleunigten Verfahren“ aus, um Hindernisse bei der Umsetzung grenzüberschreitender Vorhaben, insbesondere in den Bereichen Wirtschaft, Soziales, Umwelt, Gesundheit, Energie und Transport zu überwinden. Sofern kein anderes Instrument es ihnen ermöglicht, Hindernisse dieser Art zu überwinden, können auch angepasste Rechts- und Verwaltungsvorschriften einschließlich Ausnahmeregelungen vorgesehen werden. In diesem Fall kommt es beiden Staaten zu, einschlägige Rechtsvorschriften einzubringen.

Ein justitiabler Anspruch der Gebietskörperschaften, der Grenzregionen sowie grenzüberschreitenden Einheiten auf ein bestimmtes Vorgehen der Regierungen und Parlamente der Vertragsparteien wird durch diese vertragliche Verpflichtung nicht begründet.

Dem Umstand, dass die Verpflichtung beider Staaten auf den „Erhalt hoher Standards in den Bereichen des Arbeitsrechts, der sozialen Sicherung, der Gesundheit und der Sicherheit sowie des Umweltschutzes“ in Art. 13 Abs. 3 des Vertrages verankert ist, spricht systematisch dafür, dass sich diese Verpflichtung zunächst nur auf die mit der Öffnungsklausel des Absatzes 2 verbundenen Risiken für eine Absenkung von Standards im Interesse verbesserter Wettbewerbschancen im jeweiligen nationalen, europäischen und globalen Wettbewerb bezieht.

162 Diese Anerkennung umfasst die in dieser Hinsicht wesentliche Rolle der Gebietskörperschaften und „anderer lokaler Akteure“. Damit knüpft der Artikel an den 12. Absatz der Präambel des Vertrags an, in dem u.a. die wichtige Rolle gewürdigt wird, welche die dezentralisierte Zusammenarbeit der Gemeinden, der französischen Departements, der französischen Regionen, der Länder, des Bundesrats und des französischen Senats spielen. 
Nach Art. 15 des Vertrages sind Deutschland wie Frankeich dem Ziel der Zweisprachigkeit in den Grenzregionen verpflichtet und unterstützen die dortigen Stellen dabei, geeignete Strategien zu entwickeln und umzusetzen. Damit erfahren nicht zuletzt die Frankreich-Strategie des Saarlandes, das sich bereits 2015 zum Ziel gesetzt hat, sich innerhalb einer Generation zu einer multilingualen Region deutsch-französischer Prägung und somit zum ersten mehrsprachigen Bundesland der Bundesrepublik Deutschland zu entwickeln, ${ }^{163}$ sowie parallele Ansätze in der Region Grand Est ${ }^{164}$ eine völkervertragsrechtliche Unterstützung.

Beide Vertragsstaaten verpflichten sich zudem nach Art. 16 des Vertrages, die grenzüberschreitende Mobilität zu erleichtern, indem sie die zwischen ihnen bestehenden digitalen und physischen Netze, unter anderem die Eisenbahn- und Straßenverbindungen, besser miteinander verknüpfen. ${ }^{165}$ Sie werden im Bereich der innovativen, nachhaltigen und allen zugänglichen Mobilität eng zusammenarbeiten, um gemeinsame Ansätze oder Standards zwischen beiden Staaten zu entwickeln.

Jenseits der unmittelbar grenzüberschreitenden Zusammenarbeit regen beide Staaten in Art. 17 des Vertrags zur dezentralisierten Zusammenarbeit zwischen Gebietskörperschaften an, die nicht an der Grenze liegen. Sie setzen sich dafür ein, Initiativen dieser Gebietskörperschaften, die in diesen Regionen umgesetzt werden, zu unterstützen. Dies kann z.B. zu zusätzlichen Städtepartnerschaften zwischen Kommunen ohne Grenze zum jeweiligen Vertragspartner führen, was die bürgerschaftliche Dimension der Zusammenarbeit verstärken kann.

Beide Staaten richten nach Art. 12 einen gemeinsamen Bürgerfonds ein, der Bürgerinitiativen und Städtepartnerschaften fördern und unterstützen soll, um ihre beiden Völker einander noch näher zu bringen.

163 Französisch soll dabei als Verkehrssprache neben die Mutter- und Amtssprache Deutsch treten und durch Englisch und/oder weitere Fremdsprachen ergänzt werden; vgl. Eckpunkte einer Frankreichstrategie für das Saarland, S. 9 ff., abrufbar unter: https://www.sa arland.de/dokumente/thema_europa/01_D_Eckpunkte_Frankreich-Strategie_210114.pd $f(05.03 .2019)$.

164 Auf ihrer Plenartagung am 14. Dezember 2018 billigte die Region Grand Est, die die früheren Departements Elsass, Lothringen und Champagne-Ardennes umfasst, die neuen strategischen Orientierungen für die grenzüberschreitende Zusammenarbeit, die in $\mathrm{Zu}-$ sammenarbeit mit Belgien, Luxemburg, Deutschland und der Schweiz durchgeführt werden sollen und zu denen die Beseitigung von Sprachbarrieren für das Verständnis von Partnern durch das Erlernen von Sprachen zählt; vgl. https://www.grandest.fr/blog/2018/ 12/14/une-region-au-coeur-de-leurope/ (05.03.2019).

165 In Bezug auf die physischen Netze werden insoweit in Ziffer 8 der Deutsch-Französischen Agenda die „Verbesserung grenzüberschreitender Bahnverbindungen, zum Beispiel Colmar - Freiburg durch den Wiederaufbau der Rheinbrücke in Abhängigkeit der Ergebnisse der laufenden Machbarkeitsstudie, Verbindung zwischen Straßburg und Flughafen Frankfurt sowie Straßburg und der Pfalz, Verbindung zwischen Saarbrücken und Paris“ benannt. 


\section{F. Gemeinsame Außen- und Sicherheitspolitik nach dem Vertrag von Aachen}

\section{Militärische Kooperation}

Es liegt in der Tradition des Élysée-Vertrages, dass militärischen Fragen auch im Vertrag von Aachen ein besonderes Gewicht beigemessen wird. Und es mag Ausdruck des Scheiterns der Hoffnung auf ein „Ende der Geschichte“ (Fukuyama), nicht zuletzt auf ein Ende der Geschichte den europäischen Kontinent unmittelbar betreffender Bedrohungen von Frieden und Sicherheit sein, dass kaum ein politischer Bereich eine solch umfangreiche vertragliche Aufmerksamkeit gefunden hat wie derjenige der sicherheits- und verteidigungspolitischen Zusammenarbeit. Die Zweifel an der fortdauernden transatlantischen Bündnistreue der USA mögen die nachfolgend skizzierten völkervertraglichen Regelungen ebenso motiviert haben wie die Ungewissheit über die außen- und sicherheitspolitischen Folgen des Brexit, der Zerrüttung des Verhältnisses zu Russland - einschließlich der andauernden Ukraine-Krise, der fortdauernden Syrien-Krise, der fragilen Zukunft des Iran-Atom-Abkommens, des Kollaps bestehender Rüstungskontroll- und Abrüstungsverträge und der Hinwendung des NATO-Mitglieds Türkei zu aus Sicht einer Vielzahl der NATO-Partner kritischen Partnerschaften mit Russland und dem Iran und der Spannungen im Verhältnis zu China und Nordkorea. ${ }^{166}$ Neue Herausforderungen hybrider Kriegsführung ${ }^{167}$ und durch Cyberwar-Gefahren ${ }^{168}$ ergänzen dieses Risikopotential, dem Deutschland und Frankreich gemeinsam begegnen wollen:

- Nach Art. 4 Abs. 1 des Vertrages von Aachen verpflichten sich Deutschland und Frankeich, in Anbetracht ihrer Beistandsverpflichtungen nach Art. 5 des Nordatlantikvertrags und nach Art. 42 Abs. 7 EUV, überzeugt davon, dass ihre Sicherheitsinteressen „untrennbar“ miteinander verbunden sind, ihre sicherheits- und verteidigungspolitischen „Zielsetzungen und Strategien“ einander zunehmend anzunähern und so auch die Systeme kollektiver Sicherheit, denen sie angehören, wozu unzweifelhaft die UN zählt, ${ }^{169}$ zu stärken. Dass die Vertragsstaaten von „Systemen“ sprechen, verdeutlicht, dass sie nicht nur die UN als solches System verstehen. Die gemeinsame Einordnung der NATO als solches System durch die Vertragsstaaten ist damit offenkundig. Zugleich macht der Vertragswortlaut klar,

166 Vgl. zum Ganzen z.B. Ischinger, Welt in Gefahr, 2018.

167 Vgl. hierzu z.B. Hector, Hybride Kriegsführung: Eine neue Herausforderung?, ZaöRV 76 (2016), 513 ff.; Herdegen, Der Kampf um die Weltordnung, 2019, S. 219 ff.; Tamminga, Hybride Kriegsführung. Zur Einordnung einer aktuellen Erscheinungsform des Krieges, SWP-Aktuell 27 (März 2015).

168 Vgl. hierzu z.B. Bens, Cyberwar und völkerrechtliches Selbstverteidigungsrecht, BRJ 2011/2 S. 149 ff.; Schulze, Cyber-"War" - Testfall der Staatenverantwortlichkeit, 2015.

169 Vgl. zu solchen Systemen z.B. Herdegen, Der Kampf um die Weltordnung, 2019, S. 169 ff.; Röben, Außenverfassungsrecht, 2007, S. $239 \mathrm{ff}$. 
dass die Vertragsstaaten ihre durch den Vertrag von Aachen intensivierte Zusammenarbeit nicht als ein solches System einstufen. ${ }^{170}$

- Nach Art. 4 Abs. 2 des Vertrages von Aachen handeln Deutschland und Frankreich „im Einklang mit ihren jeweiligen innerstaatlichen Vorschriften“ - wozu in Deutschland nicht zuletzt der Parlamentsvorbehalt für Bundeswehreinsätze zählt -, „wann immer möglich“ - was ein politisches Ermessen jedes Staates belässt -, gemeinsam, um Frieden und Sicherheit zu wahren. Sie entwickeln hierzu nach Satz 2 der Regelung Europas „Leistungsfähigkeit, Kohärenz und Glaubwürdigkeit im militärischen Bereich“ weiter. ${ }^{171}$ Hierdurch verpflichten sie sich gemäß Satz 3 der Regelung, die Handlungsfähigkeit Europas zu stärken und „gemeinsam zu investieren, um Lücken bei europäischen Fähigkeiten zu schließen“ und damit die Europäische Union und die Nordatlantische Allianz zu stärken. Damit wird nicht nur eine „strategische Autonomie Europas“ gegenüber Amerika in Sicherheits- und Verteidigungsfragen, die Präsident Macron als geopolitische Notwendigkeit eingestuft hat, ${ }^{172}$ befördert, ${ }^{173}$ sondern zugleich inzident das Testat „,bedingt abwehrbereit“ in Bezug auf die aktuelle militärische Substanz Europas ausgestellt.

Eine Grenze dieser Weiterentwicklung der militärischen Leistungsfähigkeit besteht für Deutschland fortdauernd aus Art. 3 Abs. 2 des sog. Zwei-plus-Vier-Vertrages: ${ }^{174}$ Dort ist die Erklärung Deutschlands während der KSE-Konferenz in Bezug genommen, dass es sich verpflichtet, die Streitkräfte des vereinten Deutschland innerhalb von drei bis vier Jahren auf eine Personalstärke von 370.000 Mann (Land-, Luft- und Seestreitkräfte) zu reduzieren. Im Rahmen dieser Gesamtobergrenze werden nicht mehr als 345.000 Mann den Land- und Luftstreitkräften angehören. Die Bundesregierung sieht in ihrer Verpflichtung zur Reduzierung von Land- und Luftstreitkräften einen bedeutsamen deutschen Beitrag zur Reduzierung der konventionellen Streitkräfte in Europa. Sie geht davon aus, dass in Folgeverhandlungen auch die anderen Verhandlungsteilnehmer ihren Beitrag zur Festigung von Sicherheit und Stabilität in Europa, einschließlich Maßnahmen zur Begrenzung der Per-

170 Zum verfassungsrechtlichen Verständnis eines Systems kollektiver Sicherheit i.S. des Art. 24 Abs. 2 GG vgl. BVerfGE 90, 286, 344 ff. sowie z.B. Nolte, Bundeswehreinsätze in kollektiven Sicherheitssystemen, ZaöRV 1994/54, S. $652 \mathrm{ff}$.

171 Dies würde im Zweifel eine Annäherung an die 2002 in der NATO vereinbarte Zielvorgabe, dass die Partner ihre Verteidigungsausgaben auf $2 \%$ des Bruttoinlandsprodukts (BIP) erhöhen, mit sich bringen; zur Kritik an dieser Zielvorgabe vgl. z.B. Mölling, Die ZweiProzent-Illusion der Nato, SWP-Aktuell 54 (August 2014).

$172 \mathrm{https} / /$ www.elysee.fr/emmanuel-macron/2018/01/19/voeux-du-president-emmanuel-m acron-aux-armees (05.03.2019).

173 Schon am 13. Juli 2018 kündigten Macron und Merkel den Bau eines gemeinsamen Kampfflugzeugs an, das die bestehenden Flotten beider Länder ersetzen soll. Verteidigungsministerin Ursula von der Leyen und ihre französische Kollegin Florence Parly haben im Nachgang zur Unterzeichnung des Vertrages von Aachen vereinbart, dass bis Mitte 2019 Dassault und Airbus ein Konzept für ein gemeinsames Luftkampfsystem (FCAS), KraussMaffei Wegmann und Nexter einen Vorschlag für ein neues gemeinsames Kampfpanzersystem vorlegen sollen. Für Ersteres erhält Frankreich, für Letzteres Deutschland die Führung; vgl. Wallraff, Kampf um den Konsens, Süddeutsche Zeitung v. 08.02.2019, S. 2.

174 Vertrag über die abschließende Regelung in Bezug auf Deutschland (Zwei-plus-Vier-Vertrag), BGBl. II, 1990, S. 1317. 
sonalstärken, leisten werden. Dies betrifft auch Frankreich als Verhandlungsteilnehmer des KSE-Prozesses wie als Vertragspartei des 2 plus 4-Vertrages. Allerdings bewegt sich die Personalstärke der Bundeswehr mit weniger als 182.000 Soldaten nicht nur aktuell deutlich unter den im 2 plus 4-Vertrag angesprochenen Obergrenzen, sondern dürfte schon mit Blick auf die Abkehr von der allgemeinen Wehrpflicht dauerhaft deutlich unter beiden Grenzwerten bleiben. Eine Pflicht zur Rückkehr zur allgemeinen Wehrpflicht wird durch den Vertrag von Aachen im Übrigen nicht begründet.

- Entsprechend dem selbstkritischen Befund verpflichten sich die Vertragstaaten nach Art. 4 Abs. 3 Satz 1 des Vertrages von Aachen, die Zusammenarbeit zwischen ihren Streitkräften mit Blick auf eine „gemeinsame Kultur und gemeinsame Einsätze“ weiter zu verstärken. Sie intensivieren die Erarbeitung „gemeinsamer Verteidigungsprogramme“ und deren Ausweitung auf Partner.

\section{Insbesondere: Die Beistandsklausel des Vertrags von Aachen}

Nach Art. 4 Abs. 1 Satz 2 des Vertrages von Aachen „leisten“ Deutschland und Frankreich „einander im Falle eines bewaffneten Angriffs auf ihre Hoheitsgebiete jede in ihrer Macht stehende Hilfe und Unterstützung; dies schließt militärische Mittel ein“.

Die territoriale Reichweite dieser Hilfeleistungs- und Unterstützungsverpflichtung, bei der es sich um eine echte Rechtspflicht handelt, entspricht gemäß Art. 4 Abs. 1 Satz 3 des Vertrages derjenigen nach Art. 42 Abs. 7 EUV. Fraglich erscheint vor diesem Hintergrund, ob mit dem Begriff „ihre Hoheitsgebiete“ auch „La France d'òutre-mer" eingeschlossen ist. Hierfür könnte eine semantische und systematische Auslegung des EUV sprechen. Denn Art. 42 Abs. 7 Satz 1 EUV enthält keine ausdrückliche Regelung zur territorialen Reichweite der Norm, so dass insoweit auf die allgemeinen Bestimmungen zu dieser Thematik abgestellt werden muss. Im EU-Vertrag selbst wird insoweit in Art. 52 Abs. 1 EUV zunächst darauf abgestellt, dass die Verträge für die einzelnen Mitgliedstaaten gelten und sodann in Absatz 2 dieses Artikels bestimmt, dass der räumliche Geltungsbereich der Verträge in Art. 355 AEUV im Einzelnen angegeben werde. In Art. 355 Abs. 1 AEUV wiederum wird bestimmt, dass EUV und AEUV nach Art. 349 AEUV u.a. auch für Guadeloupe, FranzösischGuayana, Martinique, Réunion, Saint Barthélemy und Saint Martin gelten. Eine partielle Einschränkung des Anwendungsbereichs der Vertragsbestimmungen, wie sie Art. 355 Abs. 5 AEUV für Hoheitsgebiete dritter EU-Mitgliedstaaten enthält, fehlt für diese französischen Überseegebiete. Zwar bleiben nach Art. 42 Abs. 7 Satz 2 EUV die Verpflichtungen und die Zusammenarbeit in diesem Bereich „im Einklang mit den im Rahmen der Nordatlantikvertrags-Organisation eingegangenen Verpflichtungen, die für die ihr angehörenden Staaten weiterhin das Fundament ihrer kollektiven Verteidigung und das Instrument für deren Verwirklichung ist." Dies könnte bei der Frage der territorialen Reichweite der Bündnispflicht für eine Synchronisierung der unions- 
und der NATO-rechtlichen Verpflichtung i.S. eines Anwendungsvorrangs ${ }^{175}$ bzw. einer auslegungsleitenden Funktion der NATO-Verpflichtungen und damit dafür sprechen, dass der territoriale Anwendungsbereich der Beistandspflicht die überseeischen Gebiete Frankreichs nicht erfasst. Der „Einklang“ der Verpflichtungen steht indessen einem territorial umfangreicheren Verständnis materieller Verpflichtungen vom Wortlaut her nicht entgegen: Auch wenn von der Verpflichtung nach Art. 5, 6 NATO-Vertrag die überseeischen Gebiete Frankreichs noch nie umfasst waren, spricht dies im Hinblick auf die stärkere integrative Verdichtung im Rechtsraum EU nicht gegen ein umfassenderes Verständnis unionsrechtlicher Pflichten. ${ }^{176}$ Im Blick auf eine teleologische Auslegung, auch vor dem Hintergrund der pacta tertiis-Klausel des Völkerrechts, sind allerdings auch die Zielsetzung einer Stärkung des europäischen Pfeilers innerhalb der NATO, das Bemühen um die Vermeidung von Inkompatibilitäten zwischen den beiden Schutzsystemen und die Verhinderung einer territorialen Entgrenzung von Abschreckungs- und Eskalationslogiken interpretationsrelevant: Sie sprechen im Ergebnis gegen eine Ausdehnung der territorialen Reichweite der Bündnisverpflichtung, da hierdurch ggf. NATO-Staaten, die nicht der EU angehören, $\mathrm{zu}$ solidarischem Verhalten mit Blick auf Sachverhalte außerhalb des territorialen Rahmens des Art. 6 NATO-Vertrag gedrängt werden können, u.a. wenn ein militärisches Engagement zur Verteidigung überseeischer Gebiete zu Angriffshandlungen auf das NATO-geschützte Gebiet eines EU-Mitglieds führt. Die Sorge vor bündnispolitischen Folgerungen aus fortdauerndem kolonialem Engagement, die bereits die Fassung des Art. 6 NATO-Vertrag prägte, ${ }^{177}$ wirkt insoweit auslegungsrelevant fort.

Nach alledem ist zwar der territoriale Anwendungsbereich der Beistandsklausel zwischen beiden Vertragsstaaten identisch zu demjenigen im Rahmen der Gemeinsamen Außen- und Sicherheitspolitik der EU. Materiell geht der Verpflichtungsgrad, der im Vertrag von Aachen begründet wird, allerdings erkennbar über die Verpflichtung durch Art. 42 Abs. 7 EUV hinaus: Während der Auslöser der Beistandspflicht „ein bewaffneter Angriff auf das Hoheitsgebiet“ eines Mitgliedstaats rsp. einer der Vertragsparteien - identisch ist und auch die materielle Reichweite der Beistandspflicht auf den ersten Blick identisch zu sein scheint - die anderen Mitgliedstaaten „schulden“ dem angegriffenen Mitgliedstaat nach Art. 42 Abs. 7 Satz 1 EUV „alle in ihrer Macht stehende Hilfe und Unterstützung" im Einklang mit Art. 51 der UNCharta -, wird der Grad der vertraglichen Bindung durch Art. 42 Abs. 7 Satz 2 EUV deutlich eingegrenzt: Danach „,[bleiben] (d)ie Verpflichtungen und die Zusammenarbeit in diesem Bereich ... im Einklang mit den im Rahmen der NordatlantikvertragsOrganisation eingegangenen Verpflichtungen, die für die ihr angehörenden Staaten

175 In diesem Sinne Geiger, in: ders./Khan/Kotzur, EUV/AEUV, 6. Aufl. 2016, Art. 42 EUV, Rn. 11.

176 Für eine solche weitere Reichweite der Beistandspflicht nach dem EUV unter Einbeziehung der überseeische Gebiete Schmidt-Radefeldt, Die Aktivierung der EU-Beistandsklausel im Nachgang zu den Terroranschlägen von Paris im November 2015: Rechtlicher Rahmen und politische Praxis, in: Kadelbach (Hrsg.), Die Welt und wir, 2017, S. 243, 245.

177 Vgl. hierzu Grady, Article 5 of the NATO Treaty: Past, Present, and Uncertain Future, Georgia Journal of International and Comparative Law 2002/31, S. 167, 181. 
weiterhin das Fundament ihrer kollektiven Verteidigung und das Instrument für deren Verwirklichung ist". Auch im Rahmen der Beistandspflicht nach dem EUV gilt mithin Art. 5 Abs. 1 NATO-Vertrag, wonach die Beistandspflicht dahingehend konditioniert ist, dass jeder NATO-Partner im Falle eines bewaffneten Angriffs auf einen Partner „unverzüglich für sich und im Zusammenwirken mit den anderen Parteien die Maßnahmen, einschließlich der Anwendung von Waffengewalt, trifft, die sie für erforderlich erachtet, um die Sicherheit des nordatlantischen Gebiets wiederherzustellen und zu erhalten". Eine völkerrechtliche Pflicht zur Beteiligung an Militäreinsätzen zur Verteidigung kennt mithin das NATO-Recht ebenso wenig ${ }^{178}$ wie das EURecht bislang eine entsprechende europarechtliche Verpflichtung kennt. ${ }^{179}$

Dieses weite Entschließungsermessen nach dem NATO-Vertrag wird in der Beistandsklausel des Vertrages von Aachen nicht in Bezug genommen. Vielmehr wird die Reichweite der auch militärischen Kooperationspflicht im Falle eines Angriffs auf eine der Parteien des Vertrages von Aachen rechtshistorisch nochmals erhellt, wenn man die Passage mit Art. 2 des Vertrages zur Gründung einer Europäischen Verteidigungsgemeinschaft ${ }^{180}$ vergleicht, der in den 1950er Jahren nicht in Kraft trat: Nach dessen $\$ 3$ Abs. 2 sollten die Mitgliedstaaten der EVG und die Europäischen Verteidigungsstreitkräfte einem bewaffnet angegriffenen Mitgliedstaat „mit allen ihnen zu Gebote stehenden militärischen und sonstigen Mitteln Hilfe und Beistand [leisten]" - auch dieses ohne verbleibendes Ermessen in Bezug auf das „ob“ des Beistandes.

Bei der Frage, was „in der Macht“ einer der beiden Vertragsparteien in Sachen militärische Mittel steht, verfügt zwar jede zum Beistand verpflichtete Vertragspartei über einen gewissen eigenen Beurteilungsspielraum. Dieser ist indessen nicht grenzenlos; eine Vertragspartei darf sich weder in Widerspruch zu vorangegangenem Verhalten setzen noch die Leistungsfähigkeit der eigenen Streitkräfte so faktisch reduzieren, dass die Beistandspflicht im Ernstfall leerlaufen muss.

Zur Frage, wann ein „bewaffneter Angriff auf das Hoheitsgebiet einer Vertragspartei i.S.d. Art. 4 Abs. 1 Satz 2 des Vertrages von Aachen vorliegt, können zunächst die definitorischen Ansätze des Art. 6 des NATO-Vertrages fruchtbar gemacht werden: Als solcher bewaffneter Angriff muss danach jeder bewaffnete Angriff auf das Gebiet eines dieser Staaten in Europa sowie auf die Streitkräfte, Schiffe oder Flugzeuge einer der Parteien, wenn sie sich in oder über diesem Gebiete befinden, gelten.

Aber auch die im Nachgang zur Verabschiedung des NATO-Vertrages eingetretenen Entwicklungen sind für die Begriffsbestimmung bedeutsam. Dies ist insbeson-

178 Vgl. Maraubn, North Atlantic Treaty Organization, in: Wolfrum (ed.), The Max Planck Encyclopedia of Public International Law, Vol. VII, 2012, S. 793 ff., Tz. 15 f.; Sauer, Die NATO und das Verfassungsrecht: neues Konzept - alte Fragen, ZaöRV 2002/62, S. 317, 318.

179 Vgl. zur europarechtlichen Einordnung auch Geiger, in: ders./Khan/Kotzur, EUV/ AEUV, 6. Aufl. 2017, Art. 42 EUV, Rn. 11; Regelsberger/Kugelmann, in: Streinz (Hrsg.), EUV/AEUV, 3. Aufl. 2018, Art. 42 EUV, Rn. 11; Terhechte, in: Schwarze (Hrsg.), EUKommentar, 4. Aufl. 2019, Art. 42 EUV, Rn. 19; a.A. (kein Ermessen) Cremer, in: Calliess/ Ruffert (Hrsg.), EUV/AEUV, 5. Aufl. 2016, Art. 42 EUV, Rn. 16 f.

180 Vertrag über die Europäische Verteidigungsgemeinschaft (EVG-Vertrag), BGBl. 1954 II, S. $343 \mathrm{ff}$. 
dere für die Frage relevant, ob auch terroristische Attacken vom Begriff erfasst sind. Hierfür spricht die Praxis im NATO- wie im EU-Rahmen:

- So wurde im Nachgang zu den Angriffen vom 11. September 2001 am 12. September zum ersten und bislang einzigen Mal der Bündnisfall des Art. 5 NATOVertrag ausgerufen - allerdings mit der Einschränkung „falls festgestellt wird, dass [...] [der Terroranschlag] [...] vom Ausland aus gegen die Vereinigten Staaten verübt wurde“. ${ }^{181}$ Beschlossen wurde der Bündnisfall durch den NATO-Rat dann am 2. Oktober 2001, nachdem die US-Regierung entsprechende Beweise vorgelegt hatte. ${ }^{182}$

- Frankreich hat anlässlich der Terrorakte in Paris vom 13. November 2015 am 16. November 2015 im EU-Rat der Verteidigungsminister zum ersten Mal überhaupt von Art. 42 Abs. 7 EUV Gebrauch gemacht und den Beistand der EU-Partner angefordert. Die Verteidigungsminister der EU-Mitgliedstaaten haben am selben Tag einstimmig ihre volle Unterstützung und Bereitschaft erklärt, jede erforderliche und benötigte Hilfe bereitzustellen. ${ }^{183}$

Diese Praxis dürfte auch im Einklang mit der Praxis des UN-Sicherheitsrates stehen. Dieser hatte, wenn auch nicht im operativen Teil der betreffenden Resolutionen, nach den Anschlägen des 11. September 2001 das individuelle und kollektive Selbstverteidigungsrecht in Reaktion auf die Terrorattacken betont. ${ }^{184}$ Das Fehlen einer Art. 222 AEUV vergleichbaren Regelung im Vertrag von Aachen, die eine spezielle ${ }^{185}$ mitgliedstaatliche Solidaritätspflicht im Nachgang u.a. zu Terrorakten regelt, spricht im Lichte dieser völker- und europarechtlichen Praxis dafür, dass auch terroristische Angriffe unter Berücksichtigung der Judikatur des IGH ${ }^{186}$ zumindest dann die Beistandspflicht nach Art. 4 Abs. 1 Satz 2 des Vertrages von Aachen auslösen, wenn sich ein Drittstaat das Handeln des nicht-staatlichen terroristischen Akteurs zurechnen lassen muss. Ob dies eine effektive Kontrolle des Drittstaates über den terroristischen

181 https://www.nato.int/docu/pr/2001/p01-124e.htm (05.03.2019).

182 https://www.nato.int/cps/en/natohq/topics_77646.htm\# (05.03.2019).

183 https://eeas.europa.eu/headquarters/headquarters-homepage/5553_fr (05.03.2019).

184 S/RES/1368 (2001) - „Recognizing the inherent right of individual or collective self-defence in accordance with the Charter", abrufbar unter: https://documents-dds-ny.un.org/ doc/UNDOC/GEN/N01/533/82/PDF/N0153382.pdf?OpenElement (05.03.2019); S/ RES/1373 (2001) - „Reaffirming the inherent right of individual or collective self-defence as recognized by the Charter of the United Nations as reiterated in resolution 1368 (2001), abrufbar unter: https://documents-dds-ny.un.org/doc/UNDOC/GEN/N01/557/43/PD F/N0155743.pdf?OpenElement (05.03.2019).

185 Zum Verhältnis von Art. 42 Abs. 7 EUV zu Art. 222 AUV vgl. Calliess, in: ders./Ruffert (Hrsg.), EUV/AEUV, 5. Aufl. 2016, Art. 222 AEUV, Rn. 19; Ohler, in: Streinz (Hrsg.), EUV/AEUV, 3. Aufl. 2018, Art. 222 AEUV, Rn. 7; Rathke, Kollektiver Beistand in der EU gemäß Art. 42 Abs. 7 EUV und die Mitwirkungsrechte des Bundestages, 2015, S. 1 f.; Terbechte, in: Schwarze (Hrsg.), EU-Kommentar, 4. Aufl. 2019, Art. 42 EUV, Rn. 19; Zeitzmann, Die Terrorakte von Paris: Anwendung des Art. 42 Abs. 7 EUV gerechtfertigt?, 2016.

186 Vgl. die IGH-Gutachten in Sachen Legal Consequences of the Construction of a Wall in the Occupied Palestinian Territory v. 9.7.2004, http://www.icj-cij.org/docket/files/ 131/1671.pdf, Rn. 139 (05.03.2019) sowie Armed Activities on the Territory of the Congo v. 19.12.2005, http://www.icj-cij.org/docket/files/116/10455.pdf, Rz. $146 \mathrm{f}$ (05.03.2019). 
Akteur voraussetzt oder ob das Gewähren eines „sicheren Hafens“ für diesen Akteur genügt, ${ }^{187}$ ist bislang eben so wenig eindeutig juristisch geklärt wie die Frage, ob ein Staat militärische Maßnahmen gegen terroristische Gruppen, die von seinem Territorium aus agieren, dulden muss, wenn er sich weder als „bereit noch fähig“ („unwilling or unable“) erweist, diese zu bekämpfen und Übergriffe auf das Gebiet eines dritten Staates (hier Deutschland und/oder Frankeich) zu verhindern. ${ }^{188}$

Die Beteiligungsrechte der jeweiligen nationalen Parlamente im Rahmen eines über Art. 4 Abs. 1 Satz 2 des Vertrages von Aachen aktivierten Beistandsfalles richten sich nach dem jeweiligen innerstaatlichen Verfassungsrecht. Der Deutsche Bundestag hätte mithin auch in einer solchen Konstellation ein Frage-, Debatten- und Entschließungsrecht; auch seine Kontroll- und Haushaltsbefugnisse bleiben durch den Vertrag von Aachen unberührt. ${ }^{189}$ Wäre der von Seiten Deutschlands zu leistende Beitrag militärischer Art, so würde dies zudem den wehrverfassungsrechtlichen Parlamentsvorbehalt als ein Mitentscheidungsrecht des Bundestages in Angelegenheiten der auswärtigen Gewalt auslösen, nach dem jeder verfassungskonforme Einsatz bewaffneter Streitkräfte eine konstitutive, im Prinzip vorherige Zustimmung des Bundestages voraussetzt. ${ }^{190}$ Der Vertrag von Aachen schafft mithin kein außerparlamentarisches, rein exekutiv organisiertes Hilfe- und Unterstützungsregime.

\section{Rüstungsindustrie- und -exportpolitik nach dem Vertrag von Aachen}

Dem selbstkritischen Befund in Bezug auf eigene militärische Kapazitäten tragen die Vertragsstaaten im Vertrag von Aachen nicht nur in militärstrategischer und planerischer Hinsicht Rechnung; er ist auch Anknüpfungspunkt für die Verpflichtung zu einer aktiven Industrie- und Exportpolitik im Bereich von Rüstungsgütern. Die Vertragspartner beabsichtigen nach Art. 4 Abs. 3 Satz 3 des Vertrages, die Wettbewerbsfähigkeit und Konsolidierung der europäischen verteidigungstechnologischen und -industriellen Basis zu fördern - was mit Zielen einer restriktiven Rüstungsexportpolitik nur schwer in Deckung zu bringen ist. Diese völkervertraglichen Schranken für eine ggf. innerstaatlich gewünschte Politik der Rückführung von Rüstungsexporten werden durch die folgenden Bestimmungen noch ergänzt: Danach unterstützen

187 Vgl. hierzu Deutscher Bundestag - Wissenschaftliche Dienste, Staatliche Selbstverteidigung gegen Terroristen. Völkerrechtliche Bewertung der Terroranschläge von Paris vom 13. November 2015, WD 2 - 3000 - 203/15, 9; Thiele, Auslandseinsätze der Bundeswehr zur Bekämpfung des internationalen Terrorismus, 2011, S. $159 \mathrm{ff}$.

188 Vgl. hierzu z.B. Corten, The 'Unwilling or Unable' Test: Has it Been, and Could it be, Accepted Leiden Journal of International Law 2016/29, S. 777 ff.; Skantz, The Unwilling or Unable Doctrine - The Right to Use Extraterritorial Self-Defense Against Non-State Actors, 2017; Starski, Right to Self-Defense, Attribution and the Non-State Actor - Birth of the "Unable or Unwilling" Standard? -, ZaöRV 2015/75, S. 455 ff.; Stein/v.Buttlar, Völkerrecht, \$6, Rn. 845.

189 Vgl. BVerfGE 131, S. 152, 196.

190 Vgl. BVerfGE 90, S. 286, 381 ff.; vgl. hierzu mit Blick auf die Beistandsklausel in Art. 42 EUV Thym, GASP und äußere Sicherheit, in: von Arnauld (Hrsg.), Europäische Außenbeziehungen (EnzEuR Bd. 10), 2014, $\$ 16$, Rn. 42, $45 \mathrm{ff}$. 
Deutschland und Frankreich die „engstmögliche Zusammenarbeit zwischen ihren Verteidigungsindustrien" auf der Grundlage gegenseitigen Vertrauens. Beide Staaten werden zudem bei gemeinsamen Projekten einen „gemeinsamen Ansatz für Rüstungsexporte" entwickeln.

Primärunionsrechtlich begegnet dieser deutsch-französische Ansatz keinen durchgreifenden Bedenken: Er bewegt sich ebenso im Rahmen anerkannter warenverkehrsfreiheitlicher Ausnahmen vom Verbot mengenmäßiger Beschränkungen, das durch spezifische bilaterale Förderaktivitäten belastet werden kann, wie im Rahmen kartellrechtlicher Ausnahmeklauseln nach Art. 101 Abs. 3 AEUV. Bei der Ausformung der rüstungsindustriellen und rüstungsexportbezogenen Zusammenarbeit der Vertragsstaaten sind aus dem unionsrechtlichen Loyalitätsgebot heraus die Kriterien zu beachten, die im Gemeinsamen Standpunkt 2008/944/GASP des Rates vom 8. Dezember 2008 betreffend gemeinsame Regeln für die Kontrolle der Ausfuhr von Militärtechnologie und Militärgütern ${ }^{191}$ festgehalten sind. Im Übrigen bewegt sich die vereinbarte Zusammenarbeit auch auf der Linie der Verordnung (EU) 2018/1092 des Europäischen Parlaments und des Rates vom 18. Juli 2018 zur Einrichtung des Europäischen Programms zur industriellen Entwicklung im Verteidigungsbereich zwecks Förderung der Wettbewerbsfähigkeit und der Innovation in der Verteidigungsindustrie der Union ${ }^{192}$ sowie des von der Europäischen Kommission initiierten Europäischen Verteidigungsfonds. ${ }^{193}$

Bemühungen um eine Begrenzung von Rüstungsexporten auf völkerrechtlicher Ebene ${ }^{194}$ werden durch die genannten Klauseln des Vertrages von Aachen nicht befördert. Sie begründen allerdings auch keine Abweichungskompetenz zu für einen Vertragsstaat bestehenden völkerrechtlichen Bindungen, wie z.B. dem in Art.3 Abs. 1 des sog. Zwei-plus-Vier-Vertrages für Deutschland verankerten Verzicht Deutschlands auf Herstellung und Besitz von und auf Verfügungsgewalt über atomare, biologische und chemische Waffen sowie den Rechten und Verpflichtungen Deutschlands aus dem Vertrag über die Nichtverbreitung von Kernwaffen vom 1. Juli 1968 für das vereinte Deutschland. ${ }^{195}$ Zudem begründen die Klauseln namentlich keine justitiablen subjektiven Ansprüche, z.B. auf Genehmigung von Rüstungsexporten

191 ABl. L 335 v. 28.12.2008, S. 99.

192 ABl. L 200 v. 7.8.2018, S. 30.

193 Vgl. European Commission, Launching the European Defence Fund, COM(2017) 295 final; vgl. nunmehr auch den Vorschlag für eine Verordnung zur Einrichtung des Europäischen Verteidigungsfonds, COM(2018) 476 final.

194 Vgl. Vertrag vom 2. April 2013 über den Waffenhandel, BGBl. 2013, II, S. 1426.

$195 \mathrm{Ob}$ der anlässlich der Hinterlegung der Ratifikationsurkunde zu diesem Vertrag erfolgte Erklärung der Bundesrepublik Deutschland, dass „keine Bestimmung des Vertrages so ausgelegt werden kann, als behindere sie die weitere Entwicklung der europäischen Einigung, insbesondere die Schaffung einer Europäischen Union mit entsprechenden Kompetenzen”, (BGBl. 1976, II, S. 555) in Anbetracht der eigenständigen Verpflichtung im Zweiplus-Vier-Vertrag eine fortdauernde Berechtigung Deutschlands entnommen werden kann, an der Entwicklung einer europäischen Nuklearstreitkraft mitzuwirken (hierzu Abg. Mischnick Deutscher Bundestag - 7. Wahlperiode - 81. Sitzung. Bonn, Mittwoch, den 20. Februar 1974, S. 5275), erscheint zweifelhaft. 
nach den $\int \mathbb{S} 2 \mathrm{ff}$. Kriegswaffenkontrollgesetz. ${ }^{196}$ Allerdings hat die Genehmigungspraxis zukünftig mit Blick auf das Gebot einer völkerrechtskonformen, hier einer völkervertragskonformen Auslegung nationalen Rüstungsexportrechts in einer Weise zu erfolgen, die nicht mit dem Sinn und Zweck des Vertrages von Aachen kollidiert. ${ }^{197}$

\section{Ansätze zu einem umfassenden Sicherheitsbegriff im Vertrag von Aachen}

Die Internationalisierung und Europäisierung ${ }^{198}$ des Staatszwecks Sicherheit als historisch primärem Staatszweck ${ }^{199}$ erfährt durch den Vertrag von Aachen nicht nur in Bezug auf die äußere, sondern auch in Bezug auf die innere Sicherheit eine zusätzliche Konturierung. Schon systematisch ist die Verortung von Fragen der inneren Sicherheit im Kapitel „Frieden, Sicherheit und Entwicklung“ und dort zwischen zwei Artikeln, die sich der Zusammenarbeit der beiden Außenministerien und der Partnerschaft mit Afrika widmen, ein deutliches Signal für die Untrennbarkeit innerer und äußerer Aspekte der Sicherheit in Bezug auf Gefährdungslagen des 21. Jahrhunderts und damit für die „hohe Elastizität“ von Sicherheit als Rechtsbegriff ${ }^{200}$ - unbeschadet fortdauernder verfassungsrechtlicher Einhegungen beim Einsatz von Mitteln, die für die Wahrung der äußeren Sicherheit konzipiert sind (Bundeswehr), als Instrument der (Wieder-) Herstellung innerer Sicherheit. ${ }^{201}$

Bereits in Art. 3 Satz 1 des Vertrages erfolgt eine Verkopplung von Fragen der inneren und äußeren Sicherheit: Beide Staaten vertiefen danach ihre Zusammenarbeit in Angelegenheiten der Außenpolitik, der Verteidigung, „der äußeren und inneren Sicherheit" und der Entwicklung. Die Konsultationspflicht Deutschlands und Frankreichs nach Satz 2 der Regelung, die auf das Ziel gerichtet ist, „gemeinsame Standpunkte bei allen wichtigen Entscheidungen festzulegen, die ihre gemeinsamen

196 Ausführungsgesetz zu Artikel 26 Abs. 2 des Grundgesetzes (Gesetz über die Kontrolle von Kriegswaffen) in der Fassung der Bekanntmachung vom 22. November 1990 (BGBl. I, S. 2506), das zuletzt durch Artikel 6 Absatz 2 des Gesetzes vom 13. April 2017 (BGBl. I, S. 872) geändert worden ist.

197 Eine solche völkervertragskonforme Anwendung und Auslegung könnte z.B. über sog. de-minimis-Klauseln erfolgen, nach denen bis zu bestimmten Wert- oder Mengengrenzen keine vertiefte Exportkontrolle von Seiten des zuliefernden Landes stattfindet. Zudem könnte man sich auch auf Listen mit unterschiedlich einzustufenden Ländern verständigen. In Anlehnung an das sog. Schmidt-Debré-Abkommen aus 1972 wird auch darüber diskutiert, dass die Regierungen sich wechselseitig nicht daran hindern werden, Kriegswaffen oder sonstiges Rüstungsmaterial aus einer gemeinsam durchgeführten Entwicklung oder Fertigung in Drittländer auszuführen; vgl. Wallraff, Kampf um den Konsens, Süddeutsche Zeitung v. 08.02.2019, S. 2.

198 Vgl. zur Internationalisierung und Europäisierung bereits Ress, Staatszwecke im Verfassungsstaat - nach 40 Jahren Grundgesetz, VVDStRL 1990/48, S. 56, 79.

199 Vgl. hierzu Clausen, Das Verhältnis von Achtungs- und Schutzpflichten in Ausnahmesituationen, 2018, S. 54 f.; Herzog, Staaten der Frühzeit, 1988, S. 75 f.

200 Herdegen, Der Kampf um die Weltordnung, 2019, S. 146.

201 Vgl. hierzu auch Götz, Innere Sicherheit, in: Isensee/Kirchhof (Hrsg.), Handbuch des Staatsrechts, Bd. IV - Aufgaben des Staates, 3. Aufl. 2006, \85, Rn. 17; Schlögel, Das Bundesverfassungsgericht im Politikfeld Innere Sicherheit, 2010, S. 18 ff. 
Interessen berühren, und, wann immer möglich, gemeinsam zu handeln“, ist auf beide genannten Sicherheitsdimensionen hin ausgerichtet.

Im Bereich der inneren Sicherheit verstärken die Regierungen beider Staaten nach Art. 6 des Vertrages weiter ihre bilaterale Zusammenarbeit bei der Bekämpfung des Terrorismus und der organisierten Kriminalität sowie im Bereich der Justiz, der Nachrichtendienste und der Polizei. Sie führen gemeinsame Maßnahmen im Hinblick auf Aus- und Fortbildung und Einsätze durch und richten eine gemeinsame Einheit für Stabilisierungsoperationen in Drittstaaten, wozu nicht nur Staaten des in Art. 7 des Vertrages erwähnten afrikanischen Kontinents zählen, ein.

Die Zusammenarbeit auf der Grundlage des Vertrags von Aachen reicht damit gerade in Bezug auf nachrichtendienstliche Tätigkeiten weiter als dies im Rahmen der europäischen Verträge möglich ist: Die einschlägigen Regelungsbereiche des Titels V des EU-Vertrages zur GASP sowie des Titels V des AEUV zum „Raum der Freiheit, der Sicherheit und des Rechts" nehmen keinen Bezug auf die nachrichtendienstliche Kooperation. Art. 72 AEUV betont nicht Kompetenzen der EU, sondern die fortdauernde Wahrung nachrichtendienstlicher Souveränität der Mitgliedstaaten, wenn er ausdrücklich darauf hinweist, dass der genannte Titel V des AEUV nicht „die Wahrnehmung der Zuständigkeiten der Mitgliedstaaten für die Aufrechterhaltung der öffentlichen Ordnung und den Schutz der inneren Sicherheit" berührt. Artikel 73 des AEUV ergänzt diese souveränitätsschonende Ausrichtung, indem er die freie Entscheidung der Mitgliedstaaten unterstreicht, „untereinander und in eigener Verantwortung Formen der Zusammenarbeit und Koordinierung zwischen den zuständigen Dienststellen ihrer für den Schutz der nationalen Sicherheit verantwortlichen Verwaltungen einzurichten, die sie für geeignet halten." Eine Zusammenarbeit auf nachrichtendienstlicher Ebene, auch in regional differenzierter Form, wird den Mitgliedstaaten also zwar nicht eingeräumt, ihre Vereinbarkeit mit Unionsrecht aber bestätigt. ${ }^{202}$

Eine deutliche Verbindung zu einem umfassenden Sicherheits- und Vorsorgekonzept weist auch Art. 7 des Vertrags von Aachen auf. Die besondere Bedeutung Afrikas als europäischem Nachbarkontinent hat zwar in Frankreich nicht zuletzt auch koloniale Gründe sowie Gründe der Frankophonie. Das gemeinsame deutsch-französische vertragliche Interesse dürfte aber nicht zuletzt auch dem Ziel einer Bekämpfung von Flucht- und Migrationsursachen geschuldet sein.

Nach dem Vertrag von Aachen setzen sich Deutschland und Frankeich dafür ein, eine immer engere Partnerschaft zwischen Europa und Afrika zu errichten, indem sie ihre Zusammenarbeit in den Bereichen der Entwicklung des privaten Sektors, der regionalen Integration, der Bildung und Berufsbildung sowie der Gleichstellung der Geschlechter und der Stärkung und Selbstbestimmung von Frauen mit dem Ziel stärken, soziale und wirtschaftliche Perspektiven, Nachhaltigkeit, gute Regierungsführung sowie Krisenprävention, Konfliktbewältigung und -nachsorge zu verbessern.

202 Vgl. hierzu und bestehenden Formen zwischenstaatlicher nachrichtendienstlicher Zusammenarbeit (jeweils unter Einschluss Deutschlands und Frankreichs) Seyfried, Ein europäischer Nachrichtendienst? Möglichkeiten und Grenzen nachrichtendienstlicher Kooperation auf EU-Ebene, Arbeitspapier Sicherheitspolitik, 2017/20, S. 2 f. 
Diese Partnerschaft kann auch in der Fortentwicklung des Vertrags von Cotounou $^{203}$ entwickelt werden.

Der sicherheitsbezogene Teil des Vertrags von Aachen fördert in einer Zusammenschau die Weiterentwicklung des Staatsverständnisses in beiden Vertragsstaaten hin zu einem Risikovorsorgestaat, ${ }^{204}$ wobei allerdings die fehlende Einbindung der sozialen Dimension von Sicherheit in den Sicherheitsbegriff des Vertrages einer Anreicherung dieser Entwicklungstendenz um Elemente eines Staatszwecks Zukunftsvorsorge, ${ }^{205}$ dem neben ökologischen unter grundrechtlichem Blickwinkel auch soziale Elemente eigen sind, Grenzen setzt.

Die Ableitung der Pflicht des Staates zum ausreichenden Rechtsgüterschutz als Kern einer umfassenden Sicherheits-Zweckrichtung des Staates aus den - bei rechtsvergleichender und europäischer Betrachtung zunehmend um eine soziale Dimension erweiterten - Grundrechten ist im Begriff, zum Bestandteil der gemeineuropäischen Rechtskultur zu werden ${ }^{206}$ - ein Prozess, zu dem sich der Vertrag von Aachen allerdings mangels originärer grundrechtlicher Dimension des Vertragstextes indifferent verhält. Auch Diskussionen über ein Grund- oder Menschenrecht auf Sicherheit ${ }^{207}$ werden vor diesem Hintergrund durch den Vertrag von Aachen nicht zusätzlich befördert.

\section{UN}

Nach Art. 8 Satz 1 des Vertrags von Aachen werden Deutschland und Frankreich im Rahmen der Charta der Vereinten Nationen in allen Organen der Vereinten Nationen eng zusammenarbeiten. Sie werden dabei nach Satz 2 ihre Positionen eng abstimmen, auch als Teil breiter angelegter Bemühungen einer Abstimmung der dem Sicherheits-

203 Partnerschaftsabkommen zwischen den Mitgliedern der Gruppe der Staaten in Afrika, im Karibischen Raum und im Pazifischen Ozean einerseits und der Europäischen Gemeinschaft und ihren Mitgliedstaaten andererseits, unterzeichnet in Cotonou am 23. Juni 2000, ABl. L 317 v. 1.12.2017, S. 3; dazu z.B. Friesen, Das Abkommen von Cotonou unter besonderer Berücksichtigung des neuen Handelsregimes, ZEuS 2009/12, S. $419 \mathrm{ff}$.

204 Vgl. hierzu Marques, Der Rechtsstaat der Risikovorsorge, 2018, S. 114 ff.; Stoll, Sicherheit als Aufgabe von Staat und Gesellschaft, 2003, S. $322 \mathrm{ff}$.

205 Vgl. hierzu Appel, Staatliche Zukunfts- und Entwicklungsvorsorge, 2005, S. 42 ff.; Theisen, Zukunftsvorsorge als Staatsaufgabe, Staatswissenschaften und Staatspraxis 1995/6, S. $111 \mathrm{ff}$.

206 Vgl. Classen, Die Ableitung von Schutzpflichten des Gesetzgebers aus Freiheitsrechten ein Vergleich von deutschem und französischem Verfassungsrecht sowie der Europäischen Menschenrechtskonvention, JöR 1987/36, S. 29 ff.; Ress, Staatszwecke im Verfassungsstaat - nach 40 Jahren Grundgesetz, VVDStRL 1990/48, S. 56, $91 \mathrm{f}$.

207 Vgl. hierzu Eichenhofer, Menschenrecht auf soziale Sicherheit, VSSR 2007, S. 87 ff.; Gusy, Gewährleistung von Freiheit und Sicherheit im Lichte unterschiedlicher Staats- und Verfassungsverständnisse, VVDStRL 2004/63, S. 151, 168 ff.; Isensee, Das Grundrecht auf Sicherheit, 1983, S. 33 f.; Robbers, Sicherheit als Menschenrecht, 1987, S. 13 ff. 
rat der Vereinten Nationen angehörenden EU-Mitgliedstaaten ${ }^{208}$ sowie im Einklang mit den Positionen und Interessen der EU. Sie werden zusammenarbeiten, um innerhalb der Vereinten Nationen die Positionen und Zusagen der EU in Bezug auf globale Herausforderungen und Bedrohungen voranzubringen. Sie werden alles daran setzen, eine einheitliche Position der EU in den einschlägigen UN-Organen herbeizuführen. Alle diese Verpflichtungen bewegen sich im Rahmen der in der Gemeinsamen Außenund Sicherheitspolitik der EU vereinbarten UN-bezogenen Verfahren auf der Grundlage von Art. 34 EUV. 209

Beide Staaten verpflichten sich nach Art. 8 Abs. 2 des Vertrags von Aachen zur Fortsetzung ihrer Anstrengungen, zwischenstaatliche Verhandlungen über die Reform des Sicherheitsrats der Vereinten Nationen abzuschließen. Die Aufnahme der Bundesrepublik Deutschland als ständiges Mitglied des Sicherheitsrats der Vereinten Nationen ist nach Satz 2 der Regelung „eine Priorität der deutsch- französischen Diplomatie“. Die Erfolgschancen dieser sich seit bereits über zwei Jahrzehnten hinziehenden Bemühungen ${ }^{210}$ dürfen auch weiterhin im Hinblick auf die relativ sinkende Bedeutung Europas im Allgemeinen und Deutschlands im Besonderen im globalen Wettbewerb als gering eingestuft werden.

\section{G. Der Beitrag des Vertrages von Aachen zur Verankerung der Nachhaltigkeit als Grundsatz des Völkerrechts}

Nach Art. 18 Satz 1 des Vertrags arbeiten beide Vertragsstaaten darauf hin, den Prozess der Durchführung mehrseitiger Übereinkünfte in den Bereichen der nachhaltigen Entwicklung, der globalen Gesundheit sowie des Umwelt- und Klimaschutzes, insbesondere das Übereinkommen von Paris vom 12. Dezember $2015^{211}$ und die Agenda 2030 für nachhaltige Entwicklung der Vereinten Nationen, ${ }^{212}$ zu stärken. Diese Verpflichtung greift den vorletzten Absatz der Präambel des Vertrags auf, wonach die Vertragsstaaten in der Überzeugung handeln, dass Wohlstand und Sicherheit nur ge-

208 Ausdruck dieses Willens ist Ziffer 1 der Deutsch-Französischen Agenda, wonach eine Stärkung der Zusammenarbeit im UN-Sicherheitsrat anlässlich der zweijährigen Mitgliedschaft Deutschlands, unter anderem im Rahmen der „Zwillingspräsidentschaft" der beiden Vorsitze im Sicherheitsrat (Frankreich im März und Deutschland im April 2019; 2020 entweder Mai/Juni oder Juni/Juli) vorgesehen ist.

209 Danach koordinieren die Mitgliedstaaten ihr Handeln in internationalen Organisationen und auf internationalen Konferenzen. Sie treten dort für die Standpunkte der Union ein. Die Mitgliedstaaten, die auch Mitglieder des Sicherheitsrats der Vereinten Nationen sind, stimmen sich ab und unterrichten die übrigen Mitgliedstaaten sowie den Hohen Vertreter in vollem Umfang. Die Mitgliedstaaten, die Mitglieder des Sicherheitsrats sind, setzen sich bei der Wahrnehmung ihrer Aufgaben unbeschadet ihrer Verantwortlichkeiten aufgrund der Charta der Vereinten Nationen für die Standpunkte und Interessen der Union ein.

$210 \mathrm{Vgl}$. Andrae, Reform in der Warteschleife: Ein deutscher Sitz im UN-Sicherheitsrat?, 2002, S. 40 ff.; Siegert, Reform des UN-Sicherheitsrats - Die Errungenschaft der Vergangenheit zukunftsfähig machen, 2015, S. $11 \mathrm{f}$.

211 ABl. L 282 v. 19.10.2016, S. 4.

212 „Transformation unserer Welt: die Agenda 2030 für nachhaltige Entwicklung“ - Resolution der UN-Generalversammlung, verabschiedet am 25. September 2015, abrufbar unter: http://www.un.org/Depts/german/gv-70/band1/ar70001.pdf (05.03.2019). 
währleistet werden können, wenn umgehend Maßnahmen zum Schutz des Klimas und zum Erhalt der biologischen Vielfalt und der Ökosysteme ergriffen werden. Die besondere Erwähnung des Pariser Klima-Übereinkommens wie der UN-Agenda 2030 ist zugleich Ausfluss des in der Präambel dokumentierten Bekenntnisses zur multilateralen Regulierungsmethode sowie zur Bedeutung der UN als völkerrechtlichem Ordnungsrahmen.

$\mathrm{Zu}$ diesem Zweck arbeiten die Vertragsstaaten nach Art. 18 Abs. 2 des Vertrages eng zusammen, um gemeinsame Ansätze und politische Strategien zu erarbeiten. Hierzu zählen auch die Schaffung von Anreizen für den Umbau ihrer Volkswirtschaften und die Förderung ehrgeiziger Maßnahmen zum Kampf gegen den Klimawandel, ohne dass hierdurch allerdings im jeweiligen nationalen Rahmen oder in der wechselseitigen Beziehung konkrete justitiable Rechtspflichten erwachsen würden. Der Vertrag von Aachen reiht sich damit ein in eine Vielzahl internationaler, europäischer und nationaler Regelungswerke, die den Nachhaltigkeitsbegriff verwenden. Erkennbar ist, dass er aus Sicht der Vertragsstaaten nicht ausschließlich in Richtung auf ein umweltrechtliches Prinzip wirkt. Die Dimension eines Ausgleichs zwischen ökologischen und ökonomischen Belangen wird im Begriffsverständnis des Vertrages von Aachen deutlich. ${ }^{213}$

Trotz der Betonung der Bedeutung des Umwelt- und Klimaschutzes findet eine Gleichbehandlung von Ökonomie und Ökologie im Vertrag von Aachen allerdings nicht statt: Eine völkervertragliche Verankerung des Deutsch-Französischen Umweltrates, der 1989 durch einen Notenwechsel zwischen den Außenministern der Bundesrepublik Deutschland und der Französischen Republik eingerichtet wurde, ${ }^{214}$ findet, obwohl sie der Zusammenarbeit im Umweltbereich institutionell zusätzliches Gewicht hätte geben können, im Unterschied zum Deutsch-Französischen Verteidigungs- und Sicherheitsrat (Art. 4 Abs.4) und zum Deutsch-Französischen Finanz- und Wirtschaftsrat (Art. 20 Abs. 1 Satz 2) nicht statt.

Nach Art. 18 Satz 3 des Vertrages stellen die Vertragsstaaten die Berücksichtigung des Klimaschutzes in allen Politikbereichen sicher, unter anderem durch regelmäßigen, sektorübergreifenden Austausch zwischen den Regierungen in Schlüsselbereichen. Diese Verpflichtung greift die umweltschutzpolitische Querschnittsklausel des Art. 11 AEUV auf; ${ }^{215}$ die spezifisch klimaschutzpolitische Zielsetzung kann an die Änderungen des Umweltverfassungsrechts der EU durch die Einführung des Ziels der „Bekämpfung des Klimawandels“ in Art. 191 Abs. 1 4. Spiegelstrich AEUV²16 über den Vertrag von Lissabon anknüpfen.

213 Vgl. zur Einordnung des Nachhaltigkeitsbegriffs auch Gebne, Nachhaltige Entwicklung als Rechtsprinzip: Normativer Aussagegehalt, rechtstheoretische Einordnung, Funktionen im Recht, 2011.

214 Vgl. http://www.france-allemagne.fr/IMG/pdf/Notenwechsel_uber_die_Grundung_des _Deutsch-Franzosischen_Umweltrates_2-11-1989_-2.pdf (05.03.2019).

215 Vgl. z.B. Meßerschmidt, Europäisches Umweltrecht, 2011, \$2 A. IV. 3.

216 Vgl. z.B. Nettesheim, in: Grabitz/Hilf/Nettesheim (Hrsg.), Das Recht der Europäischen Union, 2019, Art. 191 AEUV, Rn. 78 f. 
Nach Art. 19 des Vertrags werden beide Staaten die Energiewende in allen einschlägigen Bereichen weiter vorantreiben; zu diesem Zweck bauen sie ihre Zusammenarbeit aus ${ }^{217}$ und „stärken den institutionellen Rahmen zur Finanzierung, Vorbereitung und Umsetzung gemeinsamer Vorhaben, insbesondere in den Bereichen Infrastruktur, erneuerbare Energien und Energieeffizienz".

\section{H. Auf dem Weg zur deutsch-französischen Kultur-, Bildungs- und Forschungsgemeinschaft}

Nach Art. 9 erkennen beide Staaten die entscheidende Rolle an, die die Kultur und die Medien für die Stärkung der deutsch-französischen Freundschaft spielen. Daher sind sie entschlossen, für ihre Völker einen gemeinsamen Raum der Freiheit und der Chancen sowie einen gemeinsamen Kultur- und Medienraum zu schaffen. Mit einem solchen Raum könnte ein Beitrag zur Entwicklung einer europäischen (Teil-) Öffentlichkeit geschaffen werden, die für die Weiterentwicklung der EU aus Sicht des Bundesverfassungsgerichts zu deren demokratischer Legitimationsfähigkeit unverzichtbar ist. In seinem Urteil zum Rundfunkbeitrag hat das BVerfG 2018 im Blick auf die Entwicklung der Kommunikationstechnologie und insbesondere die Informationsverbreitung über das Internet u.a. betont, dass die Digitalisierung der Medien und insbesondere die Netz- und Plattformökonomie des Internet einschließlich der sozialen Netzwerke Konzentrations- und Monopolisierungstendenzen bei Anbietern, Verbreitern und Vermittlern von Inhalten begünstigen und zudem auf die Gefahr verwiesen, dass - auch mit Hilfe von Algorithmen - Inhalte gezielt auf Interessen und Neigungen der Nutzerinnen und Nutzer zugeschnitten werden, was wiederum zur Verstärkung gleichgerichteter Meinungen führt. Dies alles führe zu einer schwereren Trennbarkeit zwischen Fakten und Meinung, Inhalt und Werbung sowie zu neuen Unsicherheiten hinsichtlich der Glaubwürdigkeit von Quellen und Wertungen. ${ }^{218}$ Diese Unsicherheit berührt nicht zuletzt auch die fortdauernde Legitimität der Zielperspektive einer immer engeren Union. Dem auch durch einen gemeinsamen deutsch-französischen Medienraum entgegenzuwirken, stellt einen kulturellen Beitrag zur Selbstbehauptung eines wertegebundenen Europas dar. Authentischer, sorgfältig recherchierter Informationen, die Fakten und Meinungen auseinanderhalten, die Wirklichkeit nicht verzerrt darzustellen und das Sensationelle nicht in den Vorder-

217 In Ziffer 7 der Deutsch-Französischen Agenda sind insoweit die gemeinsame Entwicklung eines Projekts zur Nachnutzung des Gebiets rund um das AKW Fessenheim nach dessen Stilllegung, im Rahmen eines deutsch-französischen Wirtschafts- und Innovationsparks sowie Projekte im Bereich der grenzüberschreitenden Mobilität, Energiewende sowie Innovation vorgesehen. Ziffer 9 dieser Agenda sieht zudem eine Stärkung der Zusammenarbeit im Rahmen der bestehenden bilateralen hochrangigen Formate zu Energie und Klima, insbesondere zu den jeweiligen nationalen Energie- und Klimaplänen, mit dem Ziel vor, sich über die mögliche Entwicklung des Energiemixes auszutauschen, die Möglichkeit für ein gemeinsames deutsch-französisches Kapitel in diesen Plänen zu erörtern und Entwicklungsanreize für die Erreichung nationaler Ziele im Hinblick auf die Energiewende auszuloten.

218 BVerfG, 1 BvR 1675/16 - Rn. 79 f. 
grund zu rücken, ${ }^{219}$ bedarf es nicht nur im Kontext der innerstaatlichen Meinungsund Willensbildung, sondern auch im Blick auf die sich entwickelnden und von Deutschland wie Frankreich gewollten transnationalen Debatten zur Zukunft des europäischen Projekts.

Die Vertragsstaaten wollen zudem Mobilität und Austauschprogramme zwischen ihren Staaten ausbauen, vor allem für junge Menschen im Rahmen des Deutsch-Französischen Jugendwerks, und geben messbare Ziele in diesen Bereichen vor. Um immer engere Beziehungen in allen Bereichen des kulturellen Wirkens, auch durch integrierte Kulturinstitute, ${ }^{220} \mathrm{zu}$ fördern, richten sie spezielle Programme und eine digitale Plattform ein, die sich insbesondere an junge Menschen richten.

In Bezug auf die genannte digitale Plattform verdeutlicht Ziffer 3 der DeutschFranzösischen Agenda, dass hier die Schaffung einer „deutsch-französischen digitalen Plattform für audiovisuelle Inhalte und Informationsangebote" vorgesehen ist. Sofern es hierzu ergänzender völkervertraglicher Regelungen bedarf, sind hierzu als Vertragspartner in Deutschland - in Anlehnung an den am 2. Oktober 1990 geschlossenen Staatsvertrag zwischen Frankreich und den deutschen Ländern, ${ }^{221}$ mit dem der europäische Fernsehkulturkanal ARTE gegründet wurde, - die Länder im Hinblick auf deren innerstaatliche Gesetzgebungskompetenz zur Medienregulierung berufen. Ihre Regelungskompetenz in Ausformung des Art. 9 des Vertrages könnte auch ein Hörfunk-ARTE, eine deutsch-französische Suchmaschine sowie ein deutsch-französisches Facebook- oder WhatsApp-Pendant umfassen.

Gemäß Art. 10 des Vertrags führen beide Staaten ihre Bildungssysteme durch die Förderung des Erwerbs der Partnersprache, durch die Entwicklung von mit ihrer verfassungsmäßigen Ordnung in Einklang stehenden Strategien zur Erhöhung der Zahl der Schülerinnen, Schüler und Studierenden, die die Partnersprache erlernen, durch die Förderung der gegenseitigen Anerkennung von Schulabschlüssen sowie durch die Schaffung deutsch-französischer Exzellenzinstrumente für Forschung, Ausbildung und Berufsbildung sowie integrierter deutsch-französischer dualer Studiengänge enger zusammen. Der Grad völkervertraglicher Bindungen und Bindungsmöglichkeiten reicht damit über die europarechtlichen Handlungsmöglichkeiten im Hinblick auf deren Begrenzung in Art. 165 Abs. 1 AEUV („strikte Beachtung der Verantwortung der Mitgliedstaaten für die Lehrinhalte und die Gestaltung des Bildungssystems“) und Art. 166 Abs. 1 AEUV (,strikte Beachtung der Verantwortung der Mitgliedstaaten für Inhalt und Gestaltung der beruflichen Bildung“) hinaus.

Beide Staaten setzen sich zudem nach Art. 11 dafür ein, dass ihre Bildungs- und Forschungssysteme sowie deren Finanzierungsstrukturen miteinander vernetzt wer-

219 Zu deren Bedeutung BVerfG, 1 BvR 1675/16 - Rn 80.

220 Ziffer 2 der Deutsch-Französischen Agenda sieht die Schaffung von vier integrierten Deutsch-Französischen Kulturinstituten (in Rio, Palermo, Erbil, Bischkek) und die räumliche Zusammenlegung von fünf französischen und deutschen Instituten (in Cordoba, Atlanta, Glasgow, Minsk, Ramallah) vor.

221 Vgl. z.B. Gesetz über die Zustimmung zum Staatsvertrag zum Europäischen Fernsehkulturkanal (EKK) vom 17. April 1991, Abl. des Saarlandes vom 27. Juni 1991, S. 698 sowie hierzu z.B. Vollberg, Kultur im europäischen Fernsehen, 1998, S. 90 ff. 
den. Sie entwickeln die Deutsch-Französische Hochschule ${ }^{222}$ weiter und regen deutsche und französische Hochschulen an, sich an Netzwerken Europäischer Hochschulen zu beteiligen.

\section{Ausblick}

Europa befindet sich an einer Wegscheide. Der Brexit hat die reale Gefahr eines Auseinanderbrechens der EU aufgezeigt. Das Gewicht Europas in der globalisierten und digitalisierten Welt des 21. Jahrhunderts scheint im Sinken begriffen. Die erneuerte und vertiefte deutsch-französische Solidarität, die über den Vertrag von Aachen möglich ist, erweist sich vor diesem Hintergrund als wichtiges Symbol des Willens zur Selbstbehauptung. Dies ist gerade in einem Jahr der Wahlen zum Europäischen Parlament bedeutsam, in dem ein Anwachsen populistischer Kritik an der EU droht. Eine überwältigende Mehrheit der Deutschen und Franzosen ist auch weiterhin für eine vertiefte europäische Zusammenarbeit und gegen nationale Lösungsansätze bei wichtigen Zukunftsfragen. Diese bürgerschaftliche Bereitschaft für mehr Engagement in Richtung auf einen neuen Schwung für Europa hilft der Vertrag von Aachen aufzugreifen - nicht irgendwann, sondern jetzt. ${ }^{223}$

Der Vertrag von Aachen begründet zwar 30 Jahre nach dem 10-Punkte-Plan von Helmut Kobl als wichtiger Etappe zur deutschen Einheit noch keine konföderativen Strukturen zwischen Deutschland und Frankreich, wie sie nicht nur vom damaligen Bundeskanzler 1989 als deutsch-deutsche staatsrechtliche Struktur, sondern als deutsch-französische Integrationsperspektive bereits im Vorfeld des Élysée-Vertrags angedacht wurden. ${ }^{224}$ Der Vertrag von Aachen ist aber eine weiterer bedeutender Schritt auf dem Weg der beiden Nachbarn in der Mitte Europas zu einer besonderen vertraglich gebundenen Integrations-, Impuls- und Verantwortungsgemeinschaft.

Neben der Intensivierung der staatlichen Beziehungen kommt der im Vertrag angelegten Verdichtung des Netzwerkes kultureller, wirtschaftlicher, wissenschaftlicher und gesellschaftlicher Bindungen eine ggf. mit Blick auf das Integrationsziel sogar noch größere Bedeutung zu. Denn die deutsch-französische Zusammenarbeit lebt ebenso wie die europäische Integration - nicht nur von völkerrechtlichen Rechten und

222 Vgl. Abkommen vom 19. September 1997 zwischen der Regierung der Bundesrepublik Deutschland und der Regierung der Französischen Republik über die Gründung einer Deutsch-Französischen Hochschule, BGBl. 1999, II, S. 450; hierzu z.B. Gruber, Die deutsch-französische Zusammenarbeit auf völkerrechtlich institutionalisierter Ebene: Die Deutsch-Französische Hochschule, das Deutsch-Französische Jugendwerk und das Deutsch-Französische Forschungsinstitut Saint-Louis, in: Bezzenberger u.a. (Hrsg.), Die deutsch-französischen Rechtsbeziehungen, Europa und die Welt, Liber amicorum Otmar Seul, 2014, S. $179 \mathrm{ff}$.

223 Vgl. zu dieser Chance bürgerschaftlichen Engagements bereits Ukrow, Der Kern eines vereinten Europas. 10-Punkte-Plan für eine deutsch-französische Konföderation, EUROPA aktiv 2016/4, S. 3.

224 Zum Vorschlag von Präsident de Gaulle, eine Deutsch-Französische Union mit gemeinsamer Außen- und Verteidigungspolitik und einer einzigen Staatsangehörigkeit zu bilden, vgl. Fischer, Der diplomatische Prozess der Entstehung des deutsch-französischen Vertrages von 1963, Vierteljahreshefte für Zeitgeschichte 1993/41, S. 101, 105. 
Pflichten auf staatlicher Ebene; sie bedarf der steten Bestätigung innerer Legitimation durch Fortschritte für die einzelnen Bürger.

Ein Beispiel, das der aus Forbach stammende französische Abgeordnete Christophe Arend am Tag der Unterzeichnung des Vertrags von Aachen aufführte, zeigt solche praktischen Vorteile im Rahmen des Eurodistrikts SaarMoselle unmittelbar auf: „Ein Einwohner Forbachs, der einen Herzinfarkt hat, kann in Völklingen innerhalb von 15 Minuten behandelt werden. Wenn er nach Metz transportiert werden müsste, würde dies mindestens 45 Minuten dauern. Unsere Überlebensrate wurde in dieser Disziplin auf $93 \%$ erhöht. Und dies wird auf die Neurochirurgie, die Nuklearmedizin, die funktionelle Rehabilitation und die Nachsorge ausgedehnt werden“.225

Mit dem Vertrag von Aachen wird das Europa der verschiedenen Geschwindigkeiten um ein Modell erweitert, das nicht auf Stillstand und Bewahrung, sondern auf eine nachhaltige Dynamik für eine immer engere Union setzt. Bereits deshalb kommt dem Vertrag symbolische wie strategische Bedeutung zu. Er öffnet Perspektiven und Spielräume, die es nun in der Alltagsarbeit politisch wie ökonomisch, kulturell wie wissenschaftlich, hoheitlich wie zivilgesellschaftlich, anzusteuern und auszufüllen gilt.

\section{BIBLIOGRAPHIE}

ANDRAE, LISETTE, Reform in der Warteschleife: Ein deutscher Sitz im UN-Sicherbeitsrat?, Oldenbourg, 2002

VON ARNAULD, ANDREAS, „Unions(ergänzungs)völkerrecht“. Zur unions- und verfassungsrechtlichen Einbindung völkerrechtlicher Instrumente differenzierter Integration, in: Breuer, Marten u.a. (Hrsg.), Der Staat im Recht. Festschrift für Eckart Klein, Berlin, 2013, S. 509-526

APPEL, IVO, Staatliche Zukunfts- und Entwicklungsvorsorge, Tübingen, 2005

BAUMANN, ANSBERT, Begegnung der Völker? Der Élysée-Vertrag und die Bundesrepublik Deutschland, Frankfurt am Main, 2003

BÄUMLIN, RICHARD, Staat, Recht und Geschichte, Zürich, 1961

BECKER, ULRICH, Differenzierungen der Rechtseinheit durch „abgestufte Integration", Europarecht, 1998, Beiheft 1, S. 29 ff.

BENDER, TOBIAS, Die Verstärkte Zusammenarbeit nach Nizza. Anwendungsfelder und Bewertung im Spiegel historischer Präzedenzfälle der differenzierten Integration, Zeitschrift für ausländisches öffentliches Recht und Völkerrecht, 2001/61, S. 730-770

BENS, JONAS, Cyberwar und völkerrechtliches Selbstverteidigungsrecht, Bonner Rechtsjournal, 2011/2, S. 149-155

225 https://www.francebleu.fr/infos/international/le-traite-d-aix-la-chapelle-marque-un-ren ouveau-historique-des-relations-franco-allemandes-pour-le-1548082573 (05.03.2019). 
BEYERLIN, ULRICH, Pactum de contrabendo und pactum de negotiando im Völkerrecht?, Zeitschrift für ausländisches öffentliches Recht und Völkerrecht, 1976/36, S. 407-443

VON BOGDANDY, ARMIN; SCHILL, STEPHAN, Die Achtung der nationalen Identität unter dem reformierten Unionsvertrag, Zeitschrift für ausländisches öffentliches Recht und Völkerrecht, 2010/70, S. 701-734

BREDIMAS, ANTONIS, La Convention de l'Unesco sur la diversité culturelle et les règles de l'Organisation mondiale du commerce, Annuaire international des droits de l'Homme 2008/3, S. 271-285

BRÖHMER, JÜRGEN, Transparenz als Verfassungsprinzip, Tübingen, 2004

VON BUTTLAR, CHRISTIAN, Rechtsprobleme der verstärkten Zusammenarbeit nach dem Vertrag von Nizza, Zeitschrift für Europarechtliche Studien, 2001/4, S. 649-688

VON BUTTLAR, CHRISTIAN; KOTZUR, MARKUS; STEIN, TORSTEN, Völkerrecht, 14. Aufl., München, 2017

CALLIESS, CHRISTIAN; RUFFERT, MATTHIAS, (Hrsg.), EUV/AEUV, 5. Aufl., München, 2016

CLASSEN, CLAUS DIETER, Die Ableitung von Schutzplichten des Gesetzgebers aus Freibeitsrechten - ein Vergleich von deutschem und französischem Verfassungsrecht sowie der Europäischen Menschenrechtskonvention, Jahrbuch des öffentlichen Rechts, 1987/36, S. 29-48

CLAUSEN, CHRISTOPH, Das Verbältnis von Achtungs- und Schutzpflichten in Ausnabmesituationen, Berlin, 2018

COMBACAU, JEAN; SUR, SERGE, Droit international public, 12. Aufl., 2016

CONSTANTINESCO, VLAD, Les clauses de coopération renforcée, Revue trimestrielle de droit europeen, 1997/33, S. 751-767

CORTEN, OLIVER, The 'Unwilling or Unable' Test: Has it Been, and Could it be, Accepted?, Leiden Journal of International Law 2016/29, S. 777-799

DAMM, CAROLIN, Die Europäische Union im universellen Völkergewohnheitsrecht, Tübingen, 2016

DEFRANCE, CORINE (Hrsg.), PFEIL, ULRICH (Hrsg.), Der Élysée-Vertrag und die deutsch-französischen Beziehungen 1945-1963-2003, Berlin, 2005

DEFRANCE, CORINE; PFEIL, ULRICH (Hrsg.), La France, l'Allemagne et le traité de l'Élysée, 1963-2013, 2012

DEUTSCHER BUNDESTAG - WISSENSCHAFTLICHE DIENSTE, Staatliche Selbstverteidigung gegen Terroristen. Völkerrechtliche Bewertung der Terroranschläge von Paris vom 13. November 2015, WD 2 - 3000 - 203/15

DITTRICH, PAUL JASPER, Online Platforms and how to regulate them: An EU Overview, Bertelsmann Stiftung Policy Paper Nr. 2018/227 
DOEHRING, KARL, Völkerrecht, 1. Aufl., Heidelberg, 1999

DREIER, HORST, Grenzen demokratischer Freibeit im Verfassungsstaat, JZ 1994, S. $741-752$

DUPUY, PIERRE-MARIE; KERBRAT, YANN, Droit international public, 14. Aufl., 2018

EHLERMANN, CLAUS DIETER, Engere Zusammenarbeit nach dem Amsterdamer Vertrag: Ein neues Verfassungsprinzip?, Europarecht, 1997, S. 362-397

EHNTS, DIRK; ZEDDIES, LINO, Die Krise der VWL und die Vision einer Pluralen Ökonomik, Wirtschaftsdienst 2016/96, S. $769 \mathrm{ff}$.

EICHENHOFER, EBERHARD, Menschenrecht auf soziale Sicherbeit, Vierteljahresschrift für Sozialrecht, 2007/2, S. 87-101

FISCHER, PER, Der diplomatische Prozess der Entstehung des deutsch-französischen Vertrages von 1963, Vierteljahreshefte für Zeitgeschichte, 1993/41, S. $101 \mathrm{ff.}$

FRENZ, WALTER, Handbuch Europarecht. Band 6: Institutionen und Politiken, Heidelberg, 2011

FRIESEN, BIRGA, Das Abkommen von Cotonou unter besonderer Berücksichtigung des neuen Handelsregimes, Zeitschrift für europarechtliche Studien, 2009/3, S. 419-454

GEHNE, KATJA, Nachbaltige Entwicklung als Rechtsprinzip: Normativer Aussagegehalt, rechtstheoretische Einordnung, Funktionen im Recht, 1. Aufl., Tübingen, 2011

GEIGER, RUDOLF; KHAN, DANIEL-ERASMUS; KOTZUR, MARKUS; EUV/ AEUV, Kommentar, 6. Aufl., München, 2017

GÖTZ, VOLKMAR, Innere Sicherheit, in: Isensee, Josef; Kirchhof, Paul (Hrsg.), Handbuch des Staatsrechts, Bd. III - Das Handeln des Staates, 3. Aufl., Heidelberg, 2006, S. 1007-1035

GRABER, CHRISTOPH BEAT, The New UNESCO Convention on Cultural Diversity: A Counterbalance to the WTO?, Journal of International Economic Law, 2006/9, S. 553-574

GRABITZ, EBERHARD (Begr.); HILF, MEINHARD; NETTESHEIM, MARTIN (Hrsg.), Das Recht der Europäischen Union: EUV/AEUV, Kommentar, 65. Aufl., München, 2018

GROSSER, DIETER, Das Wagnis der Währungs-, Wirtschafts- und Sozialunion, München, 1998

GRUBER, JOACHIM, Die deutsch-französische Zusammenarbeit auf völkerrechtlich institutionalisierter Ebene: Die Deutsch-Französische Hochschule, das DeutschFranzösische Jugendwerk und das Deutsch-Französische Forschungsinstitut SaintLouis, in: Bezzenberger, Tilman u.a. (Hrsg.), Die deutsch-französischen Rechtsbeziehungen, Europa und die Welt, Liber amicorum Otmar Seul, BadenBaden, 2014, S. 179-194 
GUSY, CHRISTOPH, Gewäbrleistung von Freibeit und Sicherheit im Lichte unterschiedlicher Staats- und Verfassungsverständnisse, Veröffentlichungen der Vereinigung der Deutschen Staatsrechtslehrer, 2004/63, S. 151-188

HANANIA, LILIAN RICHIERI (Hrsg.), Cultural Diversity in International Law: The effectiveness of the UNESCO Convention on the Protection and Promotion of the Diversity of Culural Expressions, New York, 2014

HECTOR, PASCAL, Hybride Kriegsfübrung: Eine nene Herausforderung?, Zeitschrift für ausländisches öffentliches und Völkerrecht, 2016/76, S. 513-526

HEISE, ARNO, Pluralismus in den Wirtschaftswissenschaften - Klärungen eines umstrittenen Konzepts, Hamburg, 2016

HERDEGEN, MATTHIAS, Der Kampf um die Weltordnung, München, 2019

HERZOG, ROMAN, Staaten der Frübzeit: Ursprünge und Herrschaftsformen, München, 1988

HOFMANN, RAINER, Wieviel Flexibilität für welches Europa?- Gedanken zur zukünftigen Entwicklung der europäischen Integration, Europarecht, 1999, S. 713-735

HORN, KAREN, Europäische Währungseinheit oder Wettbewerb der Währungen?, in: Baur, Jürgen u.a. (Hrsg.), Recht und Wirtschaft der Europäischen Union, 1997

ISCHINGER, WOLFGANG, Welt in Gefabr: Deutschland und Europa in unsicheren Zeiten, Berlin, 2018

ISENSEE, JOSEF, Das Grundrecht auf Sicherheit: Zu den Schutzpflichten des freibeitlichen Verfassungsstaates, Berlin, 1983

JANSEN, THOMAS, Die Entstehung des deutsch-französischen Vertrages vom 22. Januar 1963, in: Blumenwitz, Dieter/Gotto, Klaus u.a. (Hrsg.), Konrad Adenauer und seine Zeit: Politik und Persönlichkeit des ersten Bundeskanzlers, Band 1, Stuttgart, 1976

KIRCHHOF, PAUL, Die rechtliche Struktur der Europäischen Union als Staatenverbund, in: von Bogdandy, Armin (Hrsg.), Europäisches Verfassungsrecht: Theoretische und dogmatische Grundzüge, Heidelberg, 2003, S. 1009-1043

KLEIN, ECKART, Der Élysée-Vertrag vom 22. Januar 1963, in: Bezzenberger, Tilman u.a. (Hrsg.), Die deutsch-französischen Rechtsbeziehungen, Europa und die Welt, in: Liber amicorum Otmar Seul, Baden-Baden, 2014, S. 248 ff.

KLEIN, ECKART, Unmittelbare Geltung, Anwendbarkeit und Wirkung von Europäischem Gemeinschaftsrecht, Saarbrücken, 1988

KULOW, ARNDT-CHRISTIAN, Inbalte und Funktionen der Präambel des EGVertrages, 1979 
LANGENFELD, CHRISTINE, Die dezentrale Kontrolle der Anwendung des Europäischen Gemeinschaftsrechts im innerstaatlichen Rechtsraum, in: Siedentopf, Heinrich (Hrsg.), Europäische Integration und nationalstaatliche Verwaltung Deutsche Vereinigung und institutionelle Weiterentwicklung der Europäischen Gemeinschaft, Stuttgart, 1991, S. 173-192

LANGENFELD, CHRISTINE, Die Gleichbehandlung von Mann und Frau im Europäischen Gemeinschaftsrecht, Baden-Baden, 1989

LAPPENKÜPER, ULRICH, Die deutsch-französischen Beziebungen 1949-1963. Von der „Erbfeindschaft“ zur „Entente élémentaire“, München, 2001

LAPPENKÜPER, ULRICH, Entente élémentaire. Die Geschichte des deutsch-französischen Freundschaftsvertrages vom 22. Januar 1963, Stuttgart, 2003

LEHMANN, MATTHIAS, Braucht Europa ein Handelsgesetzbuch?, Zeitschrift für das Gesamte Handelsrecht und Wirtschaftsrecht, 2017/181(1), S. 9-42

LEHMANN, MATTHIAS, Das Europäische Wirtschaftsgesetzbuch - Eine Projektskizze, Zeitschrift für das Privatrecht der Europäischen Union, 2017/14(6), S. $262-270$

MAGNUS, ULRICH, Die Gestalt eines Europäischen Handelsgesetzbuches, in: Basedow, Jürgen u.a. (Hrsg.), Festschrift für Ulrich Drobnig, Tübingen, 1998, S. 57-80

MARAUHN, THILO, North Atlantic Treaty Organization, in: Wolfrum (Hrsg.), The Max Planck Encyclopedia of Public International Law, 2012/7, S. $793 \mathrm{ff}$.

MARQUES, ANTONIO SILVEIRA MARQUES, Der Rechtsstaat der Risikovorsorge, Berlin, 2018

MARTENCZUK, BERND, Die differenzierte Integration nach dem Vertrag von Amsterdam, Zeitschrift für europarechtliche Studien, 1998/3, S. 447-474

MBENGUE, MAKANE MOISE, Preamble, in: WOLFRUM, RÜDIGER (Hrsg.), The Max Planck Encyclopedia of Public International Law, 2012/08, S. $397 \mathrm{ff}$.

MESSERSCHMIDT, KLAUS, Europäisches Umweltrecht, München, 2011

MÖLLING, CHRISTIAN, Die Zwei-Prozent-Illusion der Nato, SWP-Aktuell, 2014/54

MOORE, MARTIN; TAMBINI, DAMIAN (Hrsg.), Digital Dominance: The Power of Google, Amazon, Facebook, and Apple, New York, 2018

NAUMANN, KOLJA, Eine religiöse Referenz in einem Europäischen Verfassungsvertrag, Bonn, 2008

NICOLAYSEN, GERT, Rechtsfragen der Währungsunion, Berlin, 1993

NOLTE, GEORG, Bundeswehreinsätze in kollektiven Sicherheitssystemen, Zeitschrift für ausländisches öffentliches Recht und Völkerrecht, 1994/54, S. 652-685

NOLTE, GEORG, Das Verfassungsrecht vor den Herausforderungen der Globalisierung, VVDStRL 67 (2008), S. $129 \mathrm{ff}$. 
PERNICE, INGOLF, Zur Finalität Europas, Berlin, 2005, abrufbar unter: http://w ww.whi-berlin.de/documents/whi-paper0605.pdf (21.03.2019)

RATHKE, HANNES, Kollektiver Beistand in der EU gemäß Art. 42 Abs. 7 EUV und die Mitwirkungsrechte des Bundestages, 2015, abrufbar unter: https://www.bund estag.de/blob/396620/0a70a7885e83aca60333593f753ccbbf/kollektiver-beistand-i n-der-eu-data.pdf (05.03.2019)

RESS, GEORG, Staatszwecke im Verfassungsstaat - nach 40 Jabren Grundgesetz, Veröffentlichungen der Vereinigung der Deutschen Staatsrechtslehrer, 1990/48, S. 56-111

ROBBERS, GERHARD, Sicherheit als Menschenrecht: Aspekte der Geschichte, Begründung und Wirkung einer Grundrechtsfunktion, 1987

RÖBEN, VOLKER, Außenverfassungsrecht: Eine Untersuchung zur auswärtigen Gewalt des offenen Staates, Tübingen, 2007

RÖSLER, HANNES, Europäische Gerichtsbarkeit auf dem Gebiet des Zivilrechts: Strukturen, Entwicklungen und Reformperspektiven des Justiz- und Verfahrensrechts der Europäischen Union, Tübingen, 2012

SAUER, HEIKO, Die NATO und das Verfassungsrecht: neues Konzept - alte Fragen, Zeitschrift für ausländisches öffentliches Recht und Völkerrecht, 2002/62, S. 317-346

SCHAUER, MARTIN, Schengen - Maastricht-Amsterdam. Auf dem Weg zu einer flexiblen Union, Wien, 2000

SCHEFFLER, JAN, Das französische Verfassungsverständnis angesichts der Anforderungen des EG/EU-Rechts, ZaöRV 2007/67, S. 43-88

SCHILD, JOACHIM, Pariser Pragmatismus - Französische EU-Vertragsreformpolitik von Amsterdam bis Lissabon, in: Leiße, Olaf (Hrsg.), Die Europäische Union nach dem Vertrag von Lissabon, Wiesbaden, 2010, S. 23-41

SCHLIESKY, UTZ, Souveränität und Legitimität von Herrschaftsgewalt, Tübingen, 2004

SCHLÖGEL, MARTINA, Das Bundesverfassungsgericht im Politikfeld Innere Sicherbeit, Frankfurt, 2010

SCHULZE, SVEN-HENDRIK, Cyber- "War" - Testfall der Staatenverantwortlichkeit, Tübingen, 2015

SCHWARZE, JÜRGEN; BECKER, ULRICH; HATJE, ARMIN; SCHOO, JOHANN (Hrsg.), EU-Kommentar, 4. Aufl., München, 2019

SEYFRIED, PIA PHILIPPA, Ein europäischer Nachrichtendienst? Möglichkeiten und Grenzen nachrichtendienstlicher Kooperation auf EU-Ebene, Arbeitspapier Sicherheitspolitik, 2017/20

SHAW, MALCOLM, International Law, 8. Aufl., Cambridge, 2017

SIEGERT, MARCEL, Reform des UN-Sicherbeitsrats - Die Errungenschaft der Vergangenheit zukunftsfähig machen, Hamburg, 2015 
SIMMA, BRUNO; VERDROSS, ALBRECHT, Universelles Völkerrecht, 3. Aufl., Berlin, 1984

SKANTZ, MADELINE, The Unwilling or Unable Doctrine - The Right to Use Extraterritorial Self-Defense Against Non-State Actors, Stockholm, 2017

SOMERS, EDUARD, Belgium-Luxembourg Economic Union (BLEU), in: Wolfrum, Rüdiger (ed.), The Max Planck Encyclopedia of Public International Law, 2012/1, S. 869-873

STAHL, BERNHARD, Europäische Integration als Zivilisationsprozess, in: Dorner, Klaus u.a. (Hrsg.), Europäische Integrationsperspektiven: Ambivalenzen der Entwicklung und Lösungsansätze, 2013, S. 97-123

STARSKI, PAULINA, Right to Self-Defense, Attribution and the Non-State ActorBirth of the "Unable or Unwilling" Standard?-, Zeitschrift für ausländisches öffentliches Recht und Völkerrecht, 2015/75, S. 455-501

STOLL, PETER-TOBIAS, Sicherbeit als Aufgabe von Staat und Gesellschaft, Tübingen, 2003

STREINZ, RUDOLF (Hrsg.), EUV/AEUV, 3. Auflage, München, 2018

SUCKER, FRANZISKA, Der Schutz und die Förderung kultureller Vielfalt im Weltbandelsrecht, 2018

TAMMINGA, OLIVER, Hybride Kriegsfübrung. Zur Einordnung einer aktuellen Erscheinungsform des Krieges, SWP-Aktuell 27 (März 2015)

TELTSCHIK, HORST, Russisches Roulette, München, März 2019

THEISEN, HEINZ, Zukunftsvorsorge als Staatsaufgabe, Staatswissenschaften und Staatspraxis, 1995/6, S. 111-125

THIELE, JAN, Auslandseinsätze der Bundeswebr zur Bekämpfung des internationalen Terrorismus: Völker- und verfassungsrechtliche Aspekte, Frankfurt a. M., 2011

THOREL, JULIEN, Der Aachener Vertrag vom 22.01.2019. Nur ein symbolischer Akt oder auch politisch bedeutend?, cepAdhoc 22.01.2019, S. 2, abrufbar unter: https://www.cep.eu/fileadmin/user_upload/cep.eu/Studien/cepAdhoc_Aachener _Vertrag/cepAdhoc_Aachener_Vertrag.pdf (18.03.2019)

THYM, DANIEL, GASP und äußere Sicherbeit, in: von Arnauld, Andreas (Hrsg.), Europäische Außenbeziehungen, Enzyklopädie Europarecht, Bd. 10, Baden-Baden, 2014, S. 947-979

UKROW, JÖRG, Der Kern eines vereinten Europas. 10-Punkte-Plan für eine deutsch-französische Konföderation, EUROPA aktiv, 2016/4, S. 3

UKROW, JÖRG, Jenseits der Grenze - Rechtspopulismus in Polen und Ungarn, vorgänge Nr. 224, 2018/4, S. 57-75 
UKROW, JÖRG; ETTELDORF, CHRISTINA, „Fake News“ als Rechtsproblem, Riga, 2017

UKROW, JÖRG, Österreich und Spanien wollen Digitalstewer einführen, Zeitschrift für Datenschutz, 2019/02

UKROW, JÖRG, Richterliche Rechtsfortbildung durch den EuGH, Baden-Baden, 1995

UNRUH, PETER, Die Unionstrene: Anmerkungen zu einem Rechtsgrundsatz der Europäischen Union, Europarecht, 2002, Heft 1, S. 41-66

VOLLBERG, SUSANNE, Kultur im europäischen Fernsehen, Wiesbaden, 1998

VOON, TANIA, UNESCO and the WTO - A Clash of Cultures?, International an Comparative Law Quaterly, 2006/55, S. 635-651

VORMBAUM, MORITZ, Schutz der Rechtsgüter von EU-Staaten durch das deutsche Strafrecht, Münster, 2005

VRANES, ERICH, Lex Superior, Lex Specialis, Lex Posterior - Zur Rechtsnatur der "Konfliktlos̈ungsregeln", ZaöRV 2005/65, S. 391-405

WALLRAFF, ARNOLD, Kampf um den Konsens, Süddeutsche Zeitung v. 08.02.2019, S. 2

WALTER, CHRISTIAN, Regional Arrangements and the United Nations Charter, in: WOLFRUM, RÜDIGER (ed.), The Max Planck Encyclopedia of Public International Law, 2012/08, S. $746 \mathrm{f}$.

WOHLFAHRT, CHRISTIAN, Veränderungen des Lissabon-Vertrages im Hinblick auf die Doktrin der unmittelbaren Wirkung, Zeitschrift für ausländisches öffentliches Recht und Völkerrecht, 2010/70, S. 523-545

WOYKE, WICHARD, Deutsch-französische Beziehungen seit der Wiedervereinigung, 2. Aufl., Wiesbaden, 2004

ZEITZMANN, SEBASTIAN, Die Terrorakte von Paris: Anwendung des Art. 42 Abs. 7 EUV gerechtfertigt?, 22.03.2016, abrufbar unter: http://jean-monnet-saar.e $\mathrm{u} / ? \mathrm{p}=1043(05.03 .2019)$

ZUBOFF, SHOSHANA, Das Zeitalter des Überwachungskapitalismus, Frankfurt a. M., 2018 
